\title{
Environmental Geophysics of the Pilot Plant on the West Branch of Canal Creek, Aberdeen Proving Ground, Maryland
}

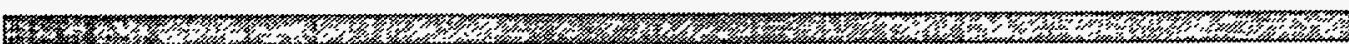

by L.D. McGinnis, S.F. Miller, C.R. Daudt, M.D. Thompson, H. Borden, M. Benson, and J. Wrobel*

Reclamation Engineering and Geosciences Section, Energy Systems Division,

Argonne National Laboratory, 9700 South Cass Avenue, Argonne, Illinois 60439

May 1994

Work sponsored by United States Department of Defense, United States Army, Aberdeen Proving Ground, Maryland

"Wrobel is affiliated with Directorate of Safety, Health, and Environment, Aberdeen Proving Ground, Maryland. 


\section{DISCLAIMER}

This report was prepared as an account of work sponsored by an agency of the United States Government. Neither the United States Government nor any agency thereof, nor any of their employees, make any warranty, express or implied, or assumes any legal liability or responsibility for the accuracy, completeness, or usefulness of any information, apparatus, product, or process disclosed, or represents that its use would not infringe privately owned rights. Reference herein to any specific commercial product, process, or service by trade name, trademark, manufacturer, or otherwise does not necessarily constitute or imply its endorsement, recommendation, or favoring by the United States Government or any agency thereof. The views and opinions of authors expressed herein do not necessarily state or reflect those of the United States Government or any agency thereof. 


\section{DISCLAIMER}

Portions of this document may be illegible in electronic image products. Images are produced from the best available original document. 


\section{Preface}

This report presents the final results and conclusions drawn from geophysical studies begun in November 1993, information vital to administrative and technical staff responsible for environmental planning and remediation at the Pilot Plant. Two technologies, not listed in the work plan, were added to the study to improve diagnostic interpretations, and two were removed because they were deemed unnecessarily redundant. The two technologies added are (1) bistatic ground-penetrating radar, which was used for interpreting site stratigraphy and detecting of paleochannels, and (2) EM61, which was used for detecting metallic objects buried close to metal buildings. The technologies deleted are seismic and resistivity sounding. Staff at Aberdeen Proving Ground, Directorate of Safety, Health, and Environment, and Argonne National Laboratory guided the work scope and its objectives. 


\section{Contents}

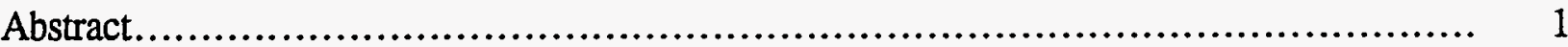

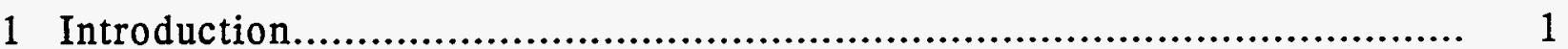

1.1 Site Background............................................................ 4

1.2 Physiographic Setting and Site Survey........................................ 4

1.3 Geology and Hydrogeology ................................................. 7

1.4 Instrumentation and Software ............................................. 14

2 Geophysical Surveys Outside the Security Fence................................. 17

2.1 Magnetic Surveys ......................................................... 17

2.1.1 Magnetic Gradiometry ............................................ 17

2.1.2 Total Field Magnetic Profiling............................................. 17

2.2 Electromagnetic Profiling with the EM31 .................................. 30

2.3 Ground-Penetrating-Radar Profiling ........................................ 44

3 Geophysical Surveys Inside the Security Fence.......................................... 56

3.1 Magnetic Surveys ........................................................ 56

3.1.1 Magnetic Gradiometry ............................................ 56

3.1.2 Total Field Magnetic Profiling......................................... 56

3.2 Electromagnetic Profiling with the EM31 and EM61.............................. 65

3.2.1 Conductivity Measurements with the EM31 .......................... 65

3.2.2 Millivolt Measurements with the Time Domain EM61 ................. 69

3.3 Ground-Penetrating-Radar Profiling ........................................ 79

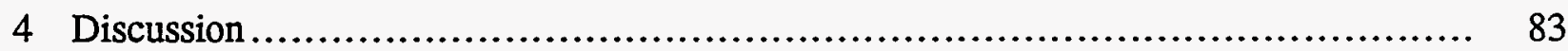

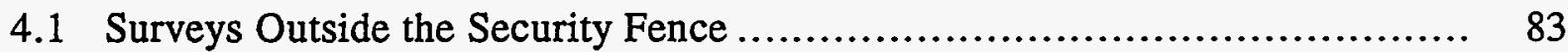

4.1.1 Hydrogeologic Framework ....................................... 83

4.1.2 Subsurface Utilities from Geophysical Measurements

Outside the Fence.................................................... 83

4.2 Subsurface Utilities from Geophysical Surveys Inside the Security Fence..... 85

5 Summary and Conclusions......................................................... 86

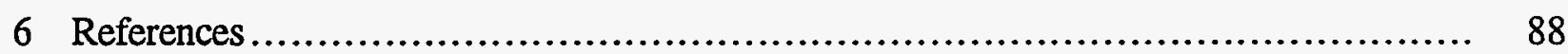

Appendix: Location of GPR Profiles.............................................. 91

Figures

1 Map Showing the Canal Creek Area and the Location

of the Pilot Plant on the West Branch of Canal Creek........................... 2

2 Site Map of the Pilot Plant and the Area Included in the Geophysical Surveys 


\section{Figures (Cont.)}

3 Underground Facilities around the Pilot Plant.......................................... 5

4 Underground Sewage Lines, Drain Pipes, Steam Conduits, and Sludge Lines Inside the Security Fence ....................................... 6

5 Generalized Hydrogeologic Section beneath the Canal Creek Area.................. 9

6 Gamma Logs from Borings Drilled by Using the Hollow-StemAuger Method .................................................................... 10

$7 \quad$ Magnetic Transects Outside the Security Fence .................................. 18

8 Regional Magnetic Field Outside the Security Fence .............................. 19

9 Magnetic Anomalies in the Northwest Corner of the Regional Map............... 21

10 Magnetic Anomalies Adjacent to the Northwest Corner of the

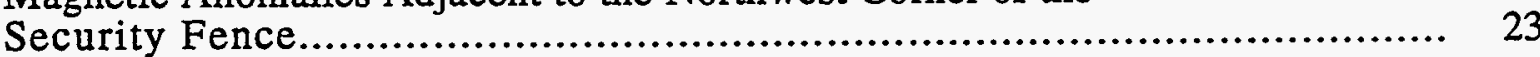

11 Magnetic Anomalies in the Northeast Quadrant of the Regional Survey ........... 25

12 Magnetic Anomalies East of the Security Fence................................ 27

13 Magnetic Anomalies Adjacent to the Southeast Fence Outside the Pilot Plant..... 29

14 Magnetic Anomalies between the Security Fence and Building E5654 ............ 31

15 Magnetic Anomalies in the Southwest Quadrant of the Regional Survey Outside the Security Fence ..................................... 33

16 EM31 Transects Outside the Security Fence............................................ 35

17 Regional EM31 Anomalies Outside the Security Fence .......................... 37

18 EM31 Contour Map in the Northwest Quadrant of the Regional Survey Area ........................................................... 39

19 EM31 Anomalies Outside the Northwest Corner of the Fence.................... 41

20 EM31 Anomalies Outside the Northeast Corner of the Fence..................... 43

21 EM31 Anomalies East of the Fence in the Area around Building E5611 ......... 45

22 EM31 Anomalies South of the Security Fence ................................. 47

23 EM31 Anomalies Southwest of the Security Fence and East of Building E5654........................................................... 49

24 EM31 Anomalies in the Southwest Quadrant of the Area Outside the Security Fence. 


\section{Figures (Cont.)}

25 Bistatic Ground-Penetrating-Radar Profile at Range Setting 150 Nanoseconds Crossing a Paleochannel at 450W from $000 \mathrm{~N}$ to $250 \mathrm{~N}$........ 52

26 Bistatic Ground-Penetrating-Radar Profile at Range Setting 150 Nanoseconds Crossing a Paleochannel at 400W from 000N to $250 \mathrm{~N}$........ 53

27 Bistatic Ground-Penetrating-Radar Profile at Range Setting 150 Nanoseconds Crossing a Paleochannel at 350W from 000N to 250N ........ 54

28 Bistatic Ground-Penetrating-Radar Profile at Range Setting 300 Nanoseconds Crossing a Paleochannel at $450 \mathrm{~W}$ from $50 \mathrm{~S}$ to $250 \mathrm{~N} \ldots \ldots \ldots . \quad 55$

29 Total Magnetic Field Inside the Security Fence...................................... 57

30 Total Magnetic Field Inside the Security Fence from $485 \mathrm{~N}$ to $605 \mathrm{~N}$............. 59

31 Total Magnetic Field Inside the Security Fence from 385N to 495N............. 61

32 Total Magnetic Field Inside the Security Fence from $215 \mathrm{~N}$ to $395 \mathrm{~N} . \ldots \ldots \ldots \ldots \ldots .63$

33 Total Magnetic Field Inside the Security Fence from 5S to 225N.................. 65

34 Regional EM31 Anomalies Inside the Security Fence ......................... 67

35 EM31 Anomalies Inside the Security Fence from $485 \mathrm{~N}$ to $600 \mathrm{~N}$................... 69

36 EM31 Anomalies Inside the Security Fence from $225 \mathrm{~N}$ to $495 \mathrm{~N} \ldots \ldots \ldots \ldots \ldots \ldots \ldots . . . . . . . .71$

37 EM31 Anomalies Inside the Security Fence from $5 \mathrm{~S}$ to $235 \mathrm{~N} \ldots \ldots \ldots \ldots \ldots \ldots \ldots . \ldots \ldots$

38 Regional EM61 Anomalies Inside the Security Fence .......................... 75

39 EM61 Anomalies Inside the Security Fence from 400N to 600N................... 77

40 EM61 Anomalies Inside the Security Fence from 200N to 400N.................. 79

41 EM61 Anomalies Inside the Security Fence from 0N to 200N.................... 81

42 Locations of GPR Anomalies Caused by Buried Utilities and Unidentified Objects Inside the Security Fence.................................... 82

\section{Tables}

1 Major Milestones for the Pilot-Plant Geophysics Study.............................. 7

2 Lithologic Logs for Well-Cluster Sites................................................ 11 


\section{Tables (Cont.)}

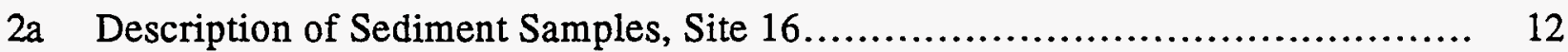

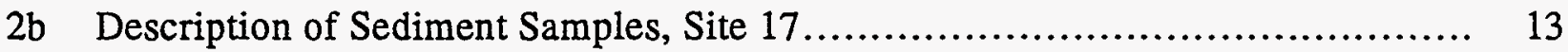

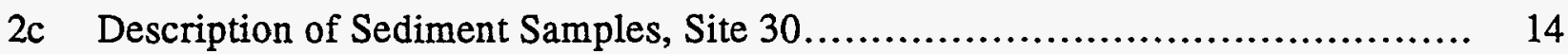

3 Status of Geophysical Anomalies at Buried Facilities Outside the Security Fence ..................................................... 84

4 Status of Geophysical Anomalies at Buried Facilities Inside the Security Fence................................................... 85

A.1 Ground-Penetrating-Radar Profiles: Outside the Pilot Plant ...................... 93

A.2 Ground-Penetrating-Radar Profiles: Inside the Pilot Plant ........................ 94 


\title{
Environmental Geophysics of the Pilot Plant on the West Branch of Canal Creek, Aberdeen Proving Ground, Maryland
}

\author{
by \\ L.D. McGinnis, S.F. Miller, C.R. Daudt, \\ M.D. Thompson, H. Borden, M. Benson, and J. Wrobel
}

\begin{abstract}
Plans to demolish and remediate the Pilot Plant complex in the Edgewood Area of Aberdeen Proving Ground have served to initiate a series of nonintrusive, environmental-geophysical studies. The studies are assisting in the location and identification of pipes, tanks, trenches, and liquid waste in the subsurface. Multiple databases have been integrated to provide support for detection of underground utilities and to determine the stratigraphy and lithology of the subsurface. The studies were conducted within the double security fence and exterior to the double fence, down gradient toward the west branch of Canal Creek. To determine if contaminants found in the creek were associated with the Pilot Plant, both the east and west banks were included in the study area. Magnetic, conductivity, inductive emf, and ground-penetrating-radar anomalies outline buried pipes, trenches, and various pieces of hardware associated with building activities. Ground-penetratingradar imagery also defines a paleovalley cut $30 \mathrm{ft}$ into Potomac Group sediments of Cretaceous age. The paleovalley crosses the site between Building E5654 and the Pilot Plant fence. The valley is environmentally significant because it may control the pathways of contaminants.
\end{abstract}

\section{Introduction}

Argonne National Laboratory is supporting the Environmental Management Division (EMD) at Aberdeen Proving Ground (APG), Maryland, as it completes a Remedial Investigation (RI) of the Pilot Plant facility in the Canal Creek area (Figure 1), pursuant to the Comprehensive Environmental Response, Compensation, and Liability Act (CERCLA). Under the terms of the project's work plan, Argonne conducted geophysical surveys that were concentrated in two areas (shown in Figure 2): (1) on the grounds inside the security fence and (2) outside the fence, within approximately $50 \mathrm{ft}$ of the fence on the north and east, south to Fleming Road and west to an aboveground steam line immediately east of and parallel to Hanlon Road.

Geophysical surveys were conducted in the areas shown in Figure 2 to assist a sampling and analysis team in locating potential contaminant sources and pathways, such as sewers, pipes, drainage tile, trenches, and natural paleochannels. 


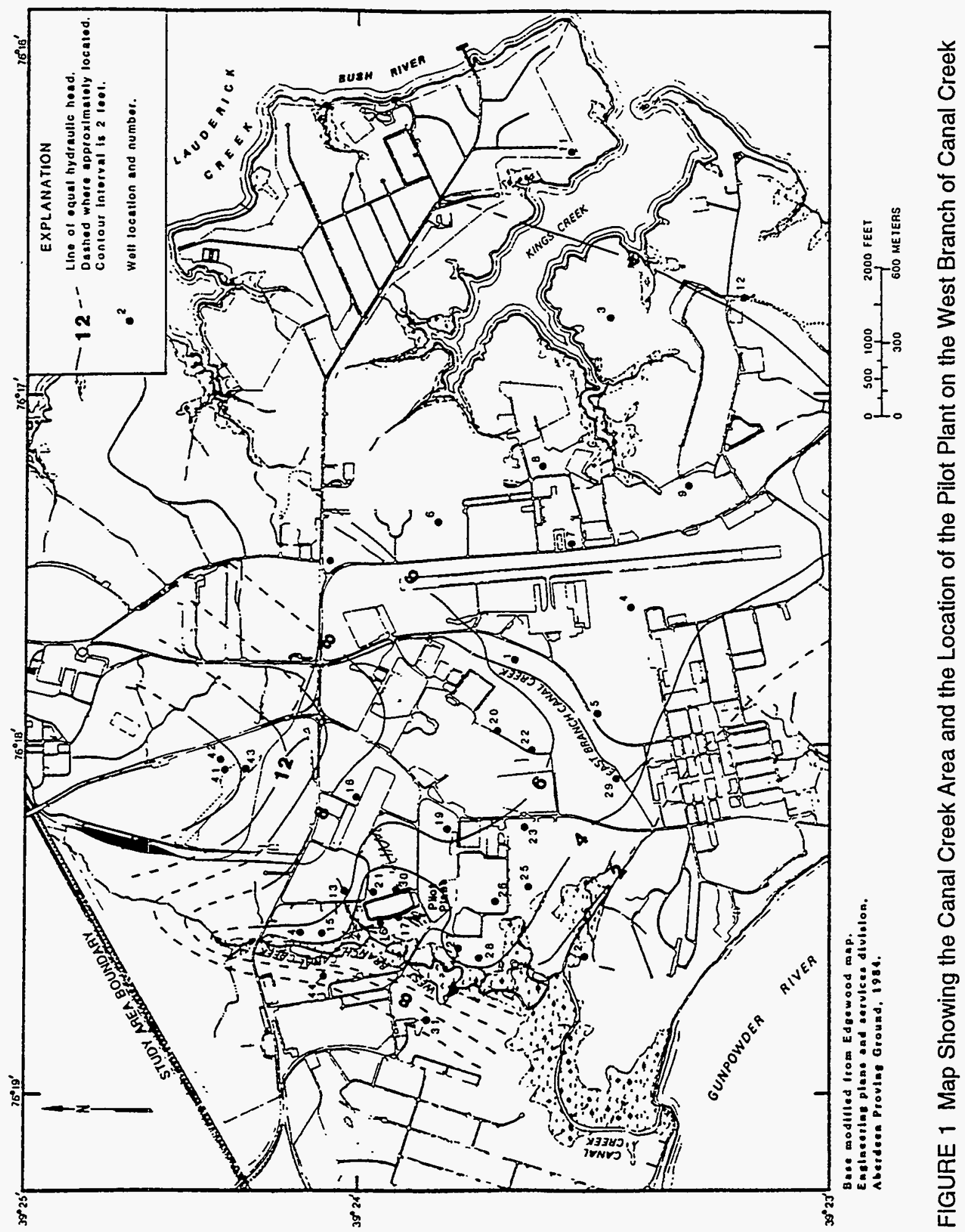




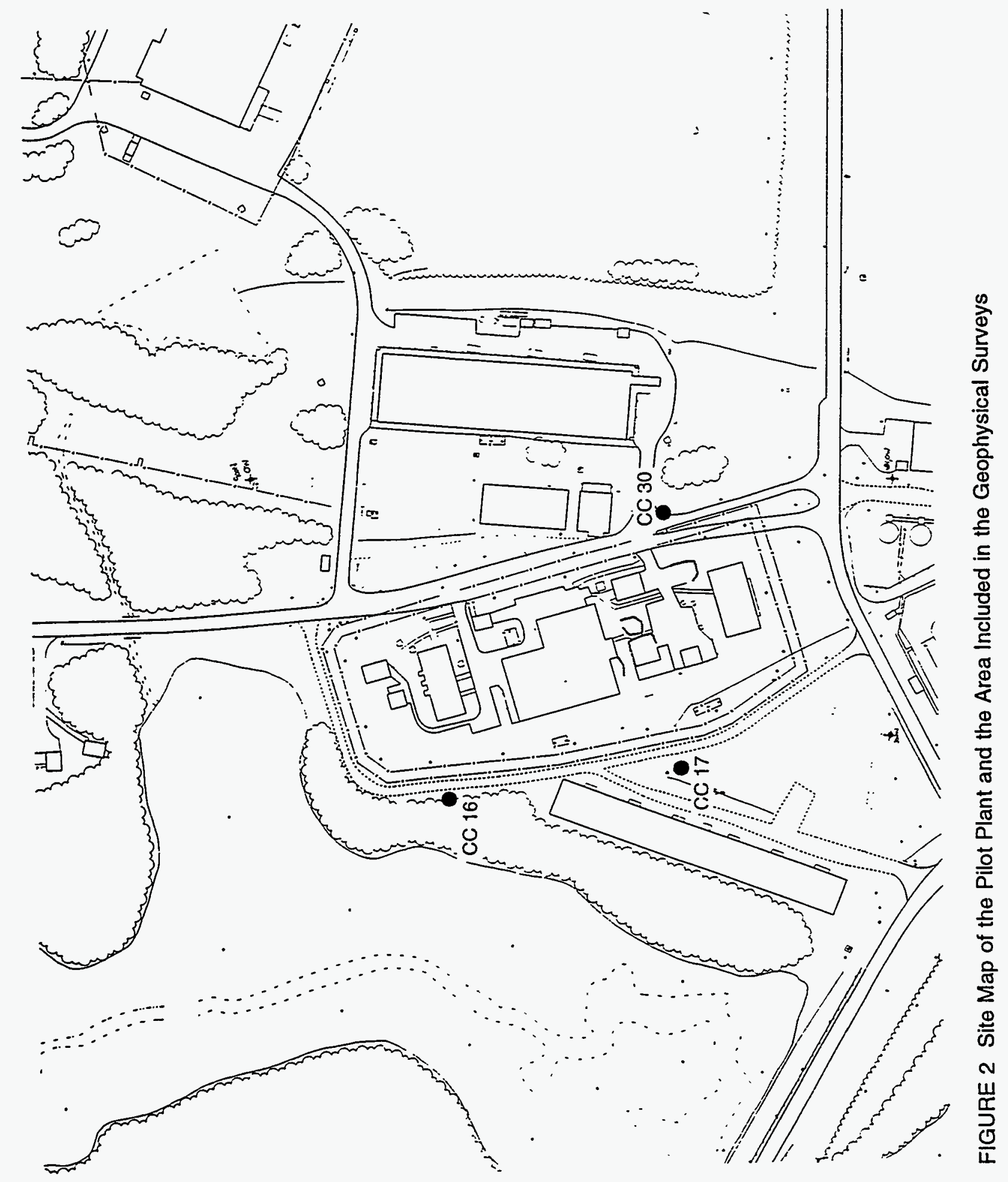


The specific objectives of the geophysical surveys were as follows:

1. Define storm, sanitary, and chemical sewer lines and drainage pipes connecting the Pilot Plant to wetlands and other facilities;

2. Identify possible underground tanks, drums, and miscellaneous materials beneath the Pilot Plant;

3. Define the horizontal distribution of possible contaminant plumes or buried debris; and

4. Characterize the hydrogeologic framework of sediments beneath the Pilot Plant.

Underground utilities in the Pilot Plant complex, inside and outside the security fence, are shown in Figure 3. A more detailed plot of the utilities that are inside the fence is shown in Figure 4. Major milestones and a chronology of the study are provided in Table 1.

\subsection{Site Background}

The Pilot Plant complex, which is centered around Building E5625 (and associated buildings), is located in the west branch of the Canal Creek drainage basin in the Edgewood Area of APG, which is in Harford County, Maryland (Figure 2). After the complex was constructed in 1942 (Nemeth et al. 1983), the site was used to manufacture CC2 Impregnite and incapacitating agents; it also served as a production facility for nerve agents. The facility was decommissioned in 1986 (EAI Corporation 1989).

\subsection{Physiographic Setting and Site Survey}

The Pilot Plant is located on the eastern margin of a small wetland bordering the west branch of Canal Creek. Canal Creek flows into the Gunpowder River, an estuarine basin, which, in turn, flows into Chesapeake Bay. Chesapeake Bay and its drainage system are located within the Atlantic Coastal Plain (physiographic province of Maryland). Elevations at the Pilot Plant average about $15 \mathrm{ft}$ above sea level and decrease to a few feet above sea level in the wetland.

The area surveyed (Figure 2) includes all of the Pilot Plant complex, inside and outside a security fence, except for the interiors of buildings. The area enclosed within the fence is approximately $600 \mathrm{ft}$ north-south and $300 \mathrm{ft}$ east-west; the long axis is oriented 15 degrees west of north. Dimensions of the area surveyed exterior to the fence are 1,150 ft east-west and $950 \mathrm{ft}$ north-south. To simplify data acquisition, the interior and exterior of the complex were surveyed relative to different coordinate systems. 


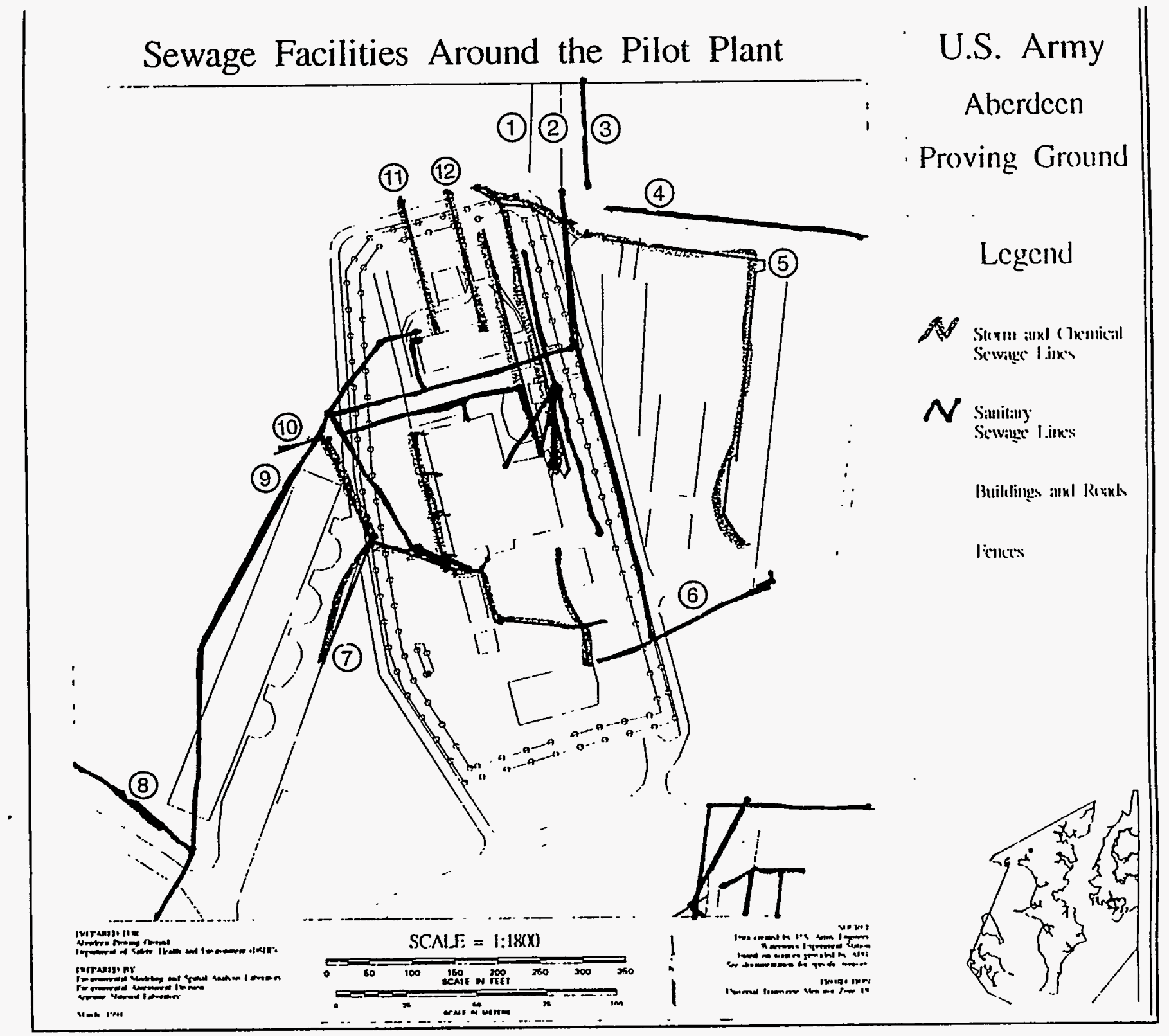

FIGURE 3 Underground Facilities around the Pilot Plant 


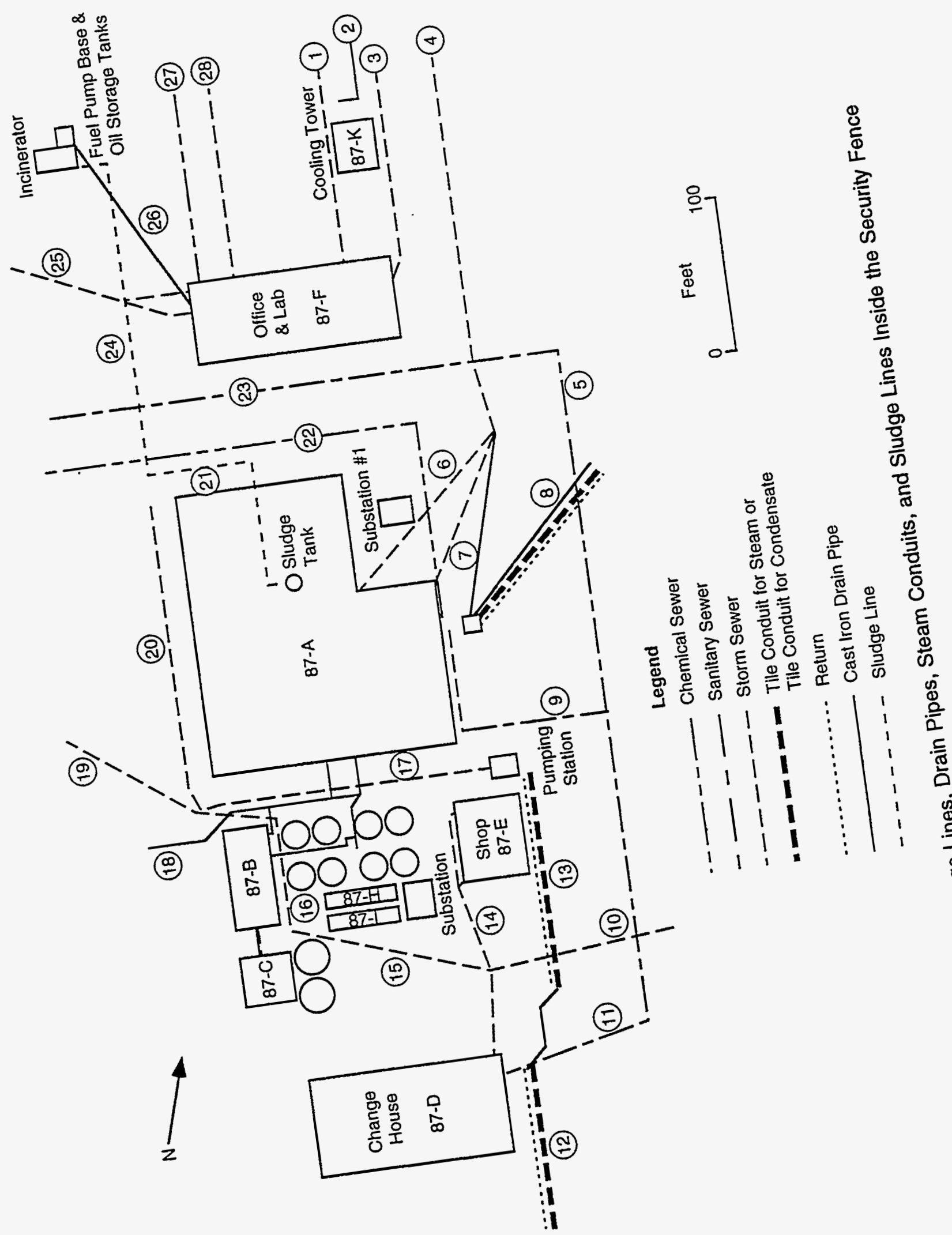

임 
TABLE 1 Major Milestones for the Pilot-Plant Geophysics Study

\begin{tabular}{lcc}
\multicolumn{1}{c}{ Milestone } & Date & Comment \\
\hline Submit Work Plan & $11 / 93$ & $\begin{array}{c}\text { Includes EM31, EM61, magnetics, } \\
\text { and ground-penetrating radar }\end{array}$ \\
Submit Health \& Safety Plan & $11 / 93$ & Final approval by APG 11/10/93 \\
Mobilize Field Team & $11 / 06-11 / 12 / 93$ & - \\
Transport Equipment & $11 / 13-11 / 14 / 93$ & - \\
Undertake Site Effort & $11 / 15 / 93-04 / 30 / 94$ & - \\
\hline
\end{tabular}

The exterior coordinates are tied to base APG bench marks, and the $00 \mathrm{E}, 00 \mathrm{~N}$ coordinate is located near the southeast corner of the survey area. Survey lines were run north-south and eastwest. The $00 \mathrm{~N}, 00 \mathrm{E}$ coordinate for the interior is located within the fence, in the southwest corner. The survey lines in the interior were run parallel to the walls of buildings. A 50-ft grid of wooden survey stakes was used as a guide for the geophysical surveys.

Orientations of geophysical transect lines were designed to cross storm, chemical, and sanitary sewer lines, as shown in Figures 3 and 4. To effectively use the maps in Figures 3 and 4 , readers should make transparencies of these figures and scale them to match geophysical survey maps shown in later sections.

\subsection{Geology and Hydrogeology}

The Pilot Plant complex is underlain by nonmarine, Talbot Formation sediments of Pleistocene age and Potomac Group sediments of Cretaceous age, resting on a Precambrian crystalline basement (Oliveros and Vroblesky 1989). The sediments were deposited on the Atlantic Coastal plain in the floodplains of rivers, lakes, and wetlands.

The crystalline basement, lying approximately $400 \mathrm{ft}$ beneath the Pilot Plant, consists of rocks similar to those found at the surface in the Piedmont Province, which is located northwest of the fall line (Oliveros and Vroblesky 1989). The fall line is approximately $10 \mathrm{mi}$ northwest of the Edgewood area of Aberdeen Proving Ground. The crystalline basement surface dips to the southeast at an angle of less than one degree (Bennett and Meyer 1952; Dingmen et al. 1956; Southwick and Owens 1969). East of the fall line, unconsolidated Atlantic Coastal Plain sediments overlie Piedmont basement rocks. 
Atlantic Coastal Plain sediments beneath the Edgewood area of APG were deposited during the Cretaceous Period and the Pleistocene Epoch (Oliveros and Vroblesky 1989). Most of the unconsolidated sediments are of the Potomac group of Cretaceous age. Although sediments of the Potomac group have been further subdivided into formations near Baltimore City, they have not been differentiated beneath APG (Oliveros and Vroblesky 1989).

Sediments that overlie the Potomac Group consist primarily of the Talbot Formation of Pleistocene age with minor amounts of Quaternary alluvium. The Talbot Formation is relatively thin and horizontally discontinuous in the western areas of Edgewood (Oliveros and Vroblesky 1989). Beneath the Edgewood area, the Talbot Formation is thickest where it occurs as fill in a paleochannel that is cut to a depth of at least $50 \mathrm{ft}$ into the Potomac Group sediments beneath the east branch of Canal Creek. The presence of a major Pleistocene channel cut $50 \mathrm{ft}$ into the Potomac Group sediments indicates that base level of erosion is equal to or less than that elevation.

A generalized hydrogeologic section beneath the Canal Creek area, taken from Lorah and Vroblesky (1989), is shown in Figure 5. They describe the section as follows:

Hydrogeologic units were defined partly on the basis of hydrologic characteristics of the units; therefore, the boundaries between the hydrogeologic units do not necessarily correspond with contacts between geologic units. The surficial aquifer sediments are primarily composed of the Talbot Formation and Potomac Group in some areas. The upper confining unit, the Canal Creek aquifer, the lower confining unit, and lower confined aquifer are composed of Potomac Group sediments.

The Pilot Plant is located in the western third of the Canal Creek area, near the feather-edge of the upper confining unit. Oliveros and Vroblesky (1989) state that hydrogeologic units above the lower confining unit "were difficult to separate because (1) the upper confining unit crops out within the study area, and (2) the upper confining unit is missing within a paleochannel and near the West Branch of Canal Creek." They also state that "the Canal Creek aquifer and the surficial aquifer are in direct hydraulic connection within the paleochannel and near the west branch of Canal Creek." Lorah and Clark (1992) have described groundwater contaminants in various aquifers in the Canal Creek area by using selected pumping scenarios.

Gamma logs recorded in three wells outside the Pilot Plant fence are shown on Figure 6; the locations of the wells are shown in Figure 2, and lithologies are described in Table 2. Descriptions of sediment samples taken from wells and geophysical studies indicate that nearsurface, flat-lying sands and clayey sands are underlain by dipping sands, which are capped by a dipping clay layer, as observed at Well CC17. The coarse sand lying at depths of 10-20 ft may be the top of the Canal Creek aquifer. 


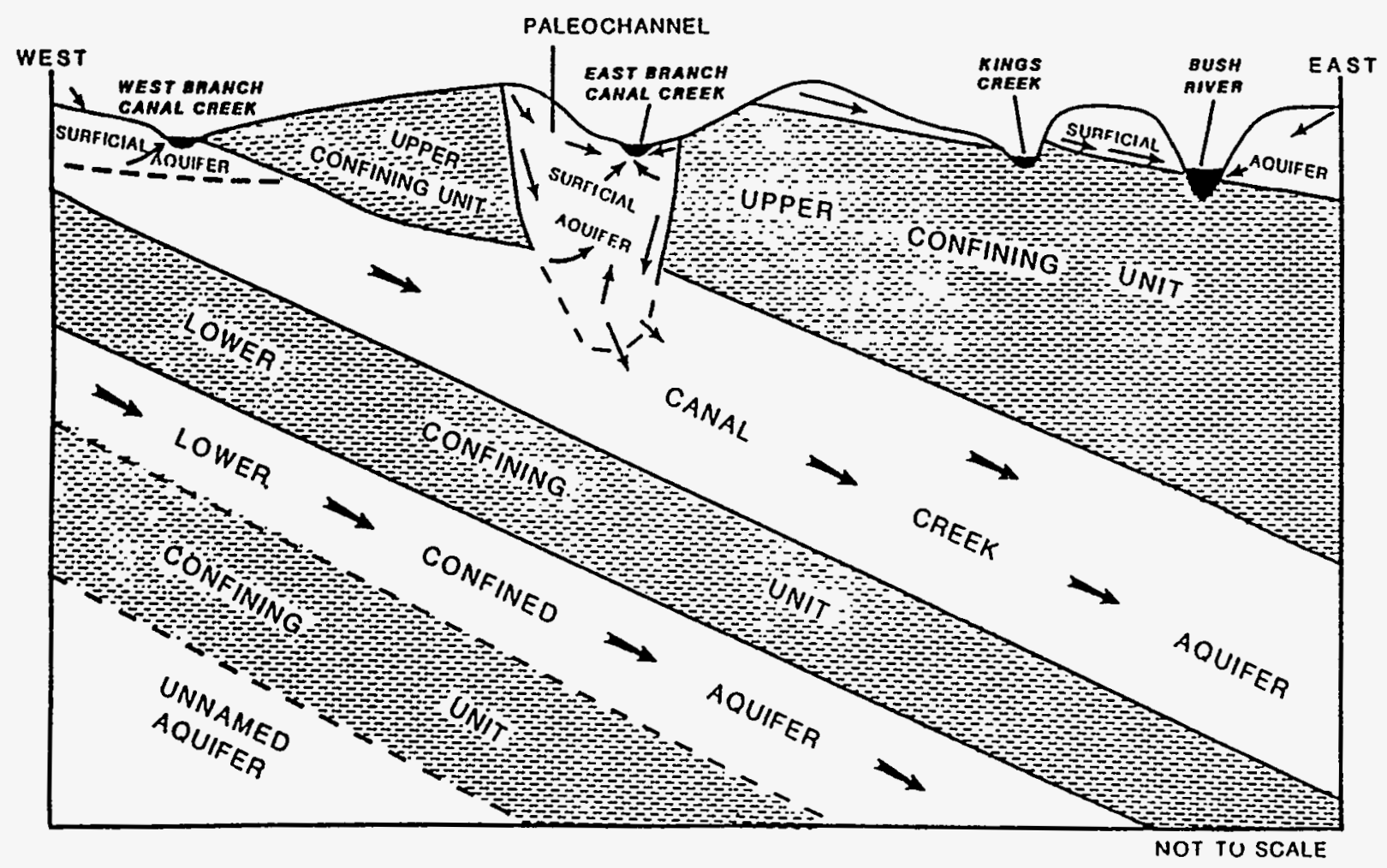

EXPLANATION

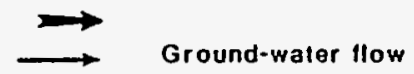

FIGURE 5 Generalized Hydrogeologic Section beneath the Canal Creek Area (Oliveros and Vroblesky 1989)

From observations at Beach Point (McGinnis et al. in press), and from studies elsewhere in the Canal Creek area (see references by L.D. McGinnis et al. 1992a,b; M.G. McGinnis et al. 1992a,b; Thompson et al. 1992a,b; Miller et al. 1992a,b), it is evident that a well-integrated tributary system of Pleistocene age was deeply incised into Potomac Group sediments as a result of successive episodes of sea level lowering of $300 \mathrm{ft}$ or more. The tributary system provides the framework for shallow groundwater flow and for potential recharge into Potomac Group aquifers. Mapping the configuration of this system is one of the objectives of geophysical studies at the Pilot Plant. The surface of the unconformity is discussed further in Section 3.3.

Although the primary reason for conducting geophysical surveys is to provide information about near-surface cultural features, the release of contaminants from these features directly affects groundwater quality in the framework of sediments below. 


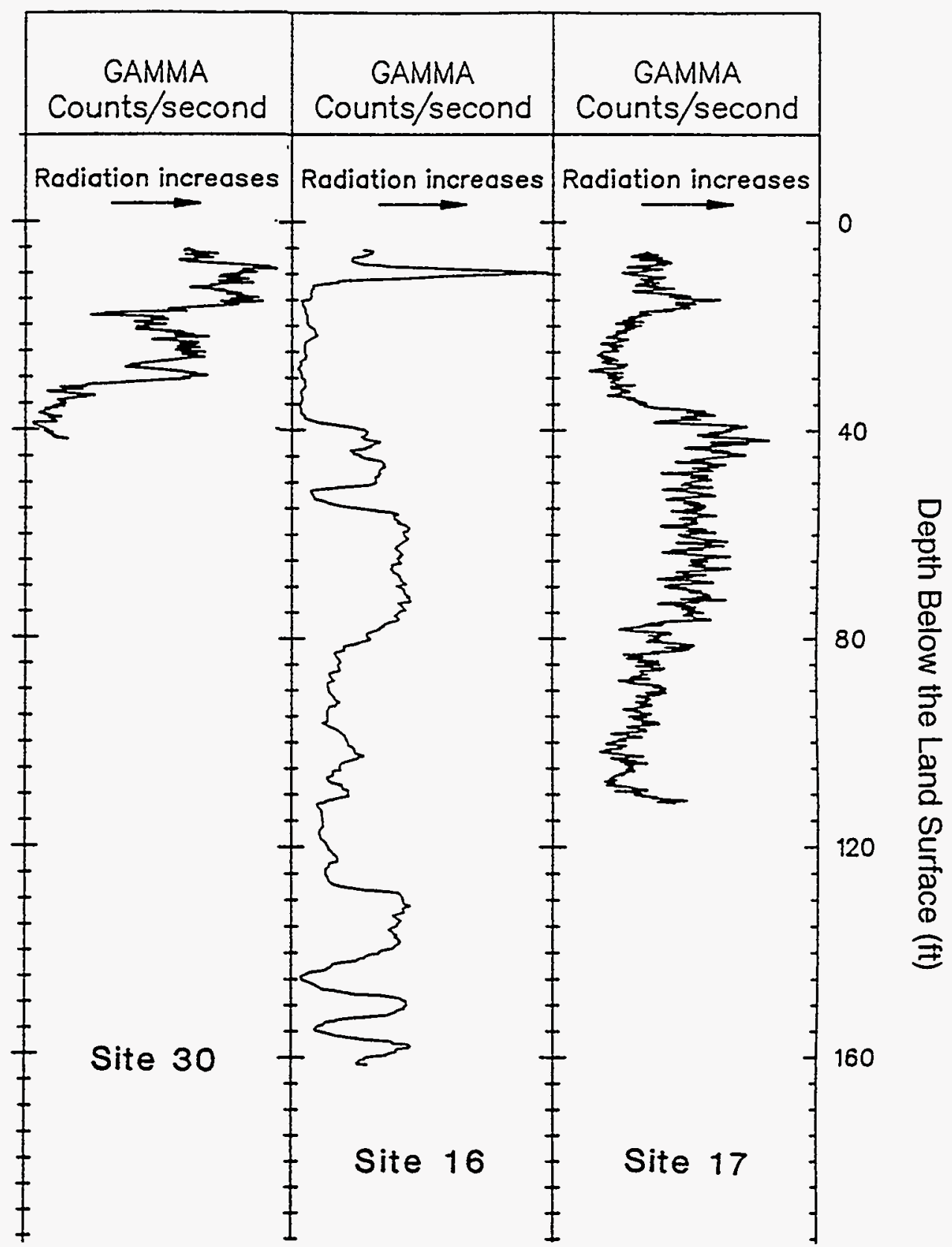

FIGURE 6 Gamma Logs from Borings Drilled by Using the Hollow-StemAuger Method (Oliveros and Gernhardt 1989) 
TABLE 2 Lithologic Logs for Well-Cluster Sites

(from Oliveros and

Gernhardt 1989)

Sand-Grade Scale

\begin{tabular}{cl} 
Grain Size $(\mu \mathrm{m})$ & Codea \\
\hline $1,410-2,000$ & $\mathrm{vcU}$ \\
$1,000-1,410$ & $\mathrm{vcL}$ \\
$710-1,000$ & $\mathrm{cU}$ \\
$500-710$ & $\mathrm{cL}$ \\
$350-500$ & $\mathrm{mU}$ \\
$250-350$ & $\mathrm{~mL}$ \\
$177-250$ & $\mathrm{fU}$ \\
$125-177$ & $\mathrm{fL}$ \\
$88-125$ & $\mathrm{vfU}$ \\
$62-88$ & $\mathrm{vfl}$
\end{tabular}

a In Tables 2a-2c, codes enclosed in brackets, at the selected horizons, refer to color designations as specified in the Munsell Soil Color Charts (1975). 
TABLE 2a Description of Sediment Samples, Site 16

\section{Description}

Depth

$(f t)$
Thickness

$(f t)$

Fill material, multicolored; mixture of clay, sand, and gravel

Clay and sand, interbedded; with thin layers of orange, micaceous sand [fL-fU] ${ }^{a}$ in light gray clay

Sand, orange [mL-mU]; interbedded; with gray-brown sandy clay containing gravel and iron concretions

Clay, sandy, gray and orange mottled, friable; with gravel

Sand and gravel, wet, multicolored; with well-sorted [mU] sand and consolidated sand lenses

Sand, clayey, white and orange mottled

Sand and gravel, silty, light brown to yellow, poorly sorted [mL-vcU]; with small (0.1-0.2-in.) gravel

Sand and gravel, pink, maroon and orange; with $\mathrm{CL}-\mathrm{CU}$ sand, yellow clay coatings on grains

Sand, clayey, multicolored, thinly laminated [fU]

Sand and clay, interbedded; with gray, fine [fU-mL] sand and dark gray, plastic, lighnitic, micaceous clay

Sand and clay, interbedded; with orange and pink fine clayey sand and pink-gray, lighnitic clay

Sand, multicolored, clean, well sorted [mU-cL]

No sample

Sand and clay, pink-gray, finely laminated; with fine [VFU] and friable, dense, lighnitic, micaceous clay

Sand, clayey, brown-gray, poorly sorted [fU-mL], micaceous

Sand, light brown, clean, well sorted [mL]

No sample

Sand, gray-brown, clean, well sorted [mL]; with thin layers of lighnitic, micaceous, sandy clay

No sample

Sand and clay, gray-brown, mixed in indistinct lenses

Sand, gray-brown, clean, well sorted [fU-mL]; with lenses of clay

Clay, dark gray, friable, hard, micaceous

Sand, clayey, gray [fU-mL], micaceous

$\begin{array}{rr}9.0 & 9.0 \\ 10.9 & 1.9\end{array}$

$14.0 \quad 3.1$

$17.8 \quad 3.8$

$23.8 \quad 6.0$

$24.0 \quad 0.2$

$38.0 \quad 14.0$

$\begin{array}{ll}40.7 & 2.7\end{array}$

$44.3 \quad 3.6$

$48.1 \quad 3.8$

$51.2 \quad 3.1$

$\begin{array}{ll}60.0 & 8.8\end{array}$

$75.0 \quad 15.0$

$81.0 \quad 6.0$

$84.5 \quad 3.5$

$91.0 \quad 6.5$

$100.0 \quad 9.0$

$105.3 \quad 5.3$

$120.1 \quad 14.8$

$124.8 \quad 4.7$

$136.5 \quad 11.7$

$146.8 \quad 10.3$

$147.3 \quad 0.5$

a Codes enclosed in brackets, at the selected horizons, refer to color designations as specified in the Munsell Soil Color Charts (1975). 
TABLE 2b Description of Sediment Samples, Site 17

Description

Depth Thickness

(ft)

(ft)

Soil, silty, brown

Sand, clayey, and silty, orange and gray mottled [VfL-fL]; ${ }^{a}$ with sand

5.0

5.0 becoming coarser at depth

Sand, multicolored, well sorted [mU]; with thin laminae of light gray clay

Clay, sandy, gray, maroon and orange mottled

$9.0 \quad 4.0$

Sand, clayey, white and multicolor banded; with well-sorted sand [mU], gravel becoming more abundant with depth

No sample

Sand and gravel, wet, clean, coarse

No sample

Sand and gravel, wet, clean, coarse

Clay, dark gray, plastic, micaceous; with gradational upper contact

Clay, brick-red and silver-gray mottled, friable, hard, micaceous; with red clay becoming dominant with depth

Sand, gray, medium to fine [fU-ml]; with dark gray clay lenses

12.9

3.9

Sand, dark gray, clean, well-sorted [mL-mU], wet

16.0

3.1

19.0

3.0

Sand, multicolored, clean, well-sorted [mU-cL]

$29.0 \quad 10.0$

34.0

5.0

35.8

1.8

39.0

3.2

40.6

1.6

41.0

0.4

Clay, dark gray

No samplo

Clay, dark gray, micaceous; with some small sand lenses

77.0

36.0

99.0

22.0

106.9

7.9

107.0

0.1

109.0

2.0

115.0

6.0

a Codes enclosed in brackets, at the selected horizons, refer to color designations as specified in the Munsell Soil Color Charts (1975). 
TABLE 2c Description of Sediment Samples, Site 30

\begin{tabular}{lrr}
\hline \multicolumn{1}{c}{ Description } & $\begin{array}{c}\text { Depth } \\
(\mathrm{ft})\end{array}$ & $\begin{array}{c}\text { Thickness } \\
\text { (ft) }\end{array}$ \\
\hline & & \\
\hline Soil & 5.1 & 0.1 \\
Fill material; containing rock fragments, sand and clay & 5.1 & 5.0 \\
Sand, clayey, pink brown and orange, [mL-mU]; a with purple modules & 5.8 & 0.7 \\
Clay, silty, gray-brown, hard, friable; with orange an pink mottling & 17.6 & 11.8 \\
Sand and clay, gray and orange mottled with layers of mixed sand and & 25.2 & 7.6 \\
$\quad$ clay & 26.2 & 1.0 \\
Clay, multicolored, marbled, plastic, micaceous & 31.7 & 5.5 \\
Silt, clayey, orange and maroon mottled laminated, micaceous & 41.0 & 9.3 \\
Sand, multicolored, wet [mU-vcU] & 42.5 & 1.5 \\
Sand, multicolored, wet [mL]; with thin layers of white clay & & \\
\hline
\end{tabular}

a Codes enclosed in brackets, at the selected horizons, refer to color designations as specified in the Munsell Soil Color Charts (1975).

\subsection{Instrumentation and Software}

Instruments used to acquire geophysical data at the Pilot Plant include the Schonstedt MAC-51-B, an EG\&G Geometrics cesium-vapor magnetometer, an EM-31 electrical conductivity meter, an EM-61 metal detector, and an SIR-3 ground-penetrating radar (GPR) with monostatic and bistatic antennae. Processing software included with the instruments (such as the DAT31 and DAT61) provided routines for reducing electromagnetic data. A version of these programs was also used to process magnetic data. Contouring programs include Surfer (Golden), Minc (U.S. Geological Survey), and COLMX (Argonne). The Radan-1 package was used to process GPR imaging data.

To avoid ferrous objects, the Schonstedt MAC-51B magnetic gradiometer and cable locator was used to scan survey areas before marker stakes were emplaced. The Schonstedt is a dualmode instrument designed for detecting shallow buried iron and steel objects and tracing underground cables and pipes. The system consists of a transmitter and a dual-function receiver, which is designed to detect anomalous magnetic gradients.

Magnetic data were acquired with an EG\&G Geometrics, G-822L cesium-vapor magnetometer. The magnetometer is a continuously recording, total-field, microprocessor-based instrument capable of resolving anomalies to one nanotesla. For a proper understanding of magnetic field maps acquired with this instrument, the characteristics of magnetic fields and the instrument-specific recording properties of the magnetometer require some explanation. 
When the EG\&G instrument is used to survey areas dominated by near-surface magnetic sources, two factors can result in the loss of information: (1) the sampling interval is too large (under-sampling), and entire sequences of paired peaks and troughs are therefore not measured (skipped over), and (2) the magnetometer is not physically able to tune itself in a "high" gradient area to obtain a reliable reading; as a result, the magnetometer outputs a "no-data" value.

To minimize the loss of information from the first factor, the distance between profiles and the sampling interval should be spaced along a profile at the depth of interest and expected wavelength for the given survey site. The magnetometer and the surveying technique used at APG yield approximately 3-5 samples per foot along a profile, which easily allows anomalies at wavelengths as small as $1.0 \mathrm{ft}$ to be detected. Tie-line profiles are normally recorded in orthogonal directions to reduce the sampling bias perpendicular to profile trends.

The second factor is a hardware limitation, and its effect on the final contoured magnetic-anomaly maps is far more deleterious. In this case, the magnetometer begins to "see" a magnetic peak or trough but quickly becomes out of "tune" and outputs "no-data" values for the corresponding profile positions. At some later time, referred to by Argonne staff as a "tuning-lag," the magnetometer has retuned and begins to output valid data. A data gap generally produces a single polarity anomaly, either negative or positive, that has a greater wavelength than the true anomaly.

One must carefully scrutinize the contoured magnetic anomaly map to correctly identify artifacts produced from either under sampling or instrument limitations. This task primarily involves conducting a detailed comparison of observed magnetic anomalies and surface features. By incorporating field notes that define locations of metal debris, building and utility maps, and other geophysical data (such as GPR and EM anomaly maps) into the interpretation phase, magnetic features on the final contoured map are less likely to be misidentified. The above discussion demonstrates why profiles and tie lines should be run in sets of orthogonal directions.

Because of their dipolar field, magnetic anomalies exhibit a characteristic shape - a positive magnetic peak and at least one negative magnetic trough. If iron-rich waste is buried in the northern hemisphere and becomes magnetized in the earth's field, a large positive anomaly will occur over a symmetrically shaped body, with a weak negative offset to the north. The horizontal distance between the paired peak and trough is proportional to the size, shape, and depth at which the source is buried, whereas the amplitude of the anomaly is inversely proportional to the depth of burial. Metallic debris at, or just below, the ground surface produces strong, closely spaced magnetic peaks and troughs that are separated by high-gradient areas.

As may be inferred from the above discussion, the sign of magnetic anomalies must be viewed with extreme caution, because in a region of high gradients, the magnetometer becomes untuned and provides zero readings. Contouring software has been designed to bridge the zero gap with mean values taken from the last readable data along the profile. Thus, because of the bipolarity of magnetic anomalies (and the variability of gradients), an isolated anomaly or a lineament could change from a positive to a negative feature along the trend. For the purposes 
reported here, the magnitude of the anomaly is unimportant, but it is important to identify the feature as a lineament or as a "single" source.

Electrical conductivity measurements were made with the Geonics EM31, an electromagnetic instrument that provides mean values of conductivity, in millisiemens/meter $(\mathrm{ms} / \mathrm{m})$, of soils ranging from 0 to approximately $20 \mathrm{ft}$ in depth. Apparent conductivity measured by the EM31 is an average conductivity over the depth range.

Potential field data were obtained with an EM61, a time-domain inductive instrument that focuses an electrical surge into the ground and measures the response of metallic objects to induced fields. The EM61 consists of a portable, coincident time-domain transmitter and receiver, which defines locations of buried metallic targets. The Pilot Plant complex was the first APG site at which the EM61 was used. On the market for approximately two years, the EM61 has been tested and compared with other metal-detection devices, including magnetometers. It provides the best overall resolution of ferrous and nonferrous objects, with freedom from aboveground cultural interference, to maximum depths of about $10 \mathrm{ft}$.

Ground-penetrating-radar (GPR) surveying was accomplished by using a Geophysical Survey Systems, Inc. (GSSI), model SIR-3 with a model 38 video display unit that was connected by a $300-\mathrm{ft}$ cable to a variable-frequency transceiver. The SIR-3 was also used with a bistatic antenna system, which provided subsurface imaging data to depths of $30 \mathrm{ft}$. Data were recorded on a digital audio tape through the model 38 system, which was downloaded to a personal computer. The control unit/video display was located in the transport vehicle. An IBMcompatible processing computer was set up in a field office so that radar profiles could be downloaded, data-tape quality checked, and preliminary data processing performed on the profiles. Radan III computer software written by GSSI was used for processing the GPR data. 


\section{Geophysical Surveys Outside the Security Fence}

\subsection{Magnetic Surveys}

Magnetic surveys were conducted outside the fence by using magnetic gradiometry and total field magnetic intensity.

\subsubsection{Magnetic Gradiometry}

The Schonstedt gradiometer was used to avoid shallow magnetic debris during emplacement of survey stakes. The instrument does not record data or provide a quantifiable reading; it simply emits a tone that represents differences in the magnetic field as measured by two sensors in the wand end of the instrument. The area was swept with the wand, and anomalous locations were marked with spray paint. The gradiometer sweep was also used to indicate areas in which more quantitative geophysical equipment was needed for more detailed coverage.

\subsubsection{Total Field Magnetic Profiling}

The configuration of the magnetic field outside the Pilot Plant fence is based on transects shown in Figure 7. These transects were used to acquire the regional data contoured in Figure 8. Data were acquired at a rate of 10 readings/s (at a walking pace), resulting in less than one-foot spacing along traverses spaced five feet apart. Errors introduced into the magnetic data due to uncorrected diurnal variations, errors in location, or inadequate speed in responding to a changing signal are small compared to the varying amplitudes of anomalies; therefore, anomalies displayed in Figure 8 are qualitatively significant. Changes in instrument position or attitude relative to the ground surface introduce some error. Moving around surface obstacles, changes in walking pace, or failure to trigger fiducial markers at the proper location will also produce some positioning error. Fiducial marks were placed on the data at 50-ft intervals and at the beginnings and ends of survey lines. Errors were kept to a minimum by carefully controlling acquisition and processing procedures.

The regional magnetic anomaly map exterior to the fence (Figure 8) contains prominent features, some of which are associated with underground utilities and fill material, while others are unexplained. Blown-up sections of the regional map are shown in Figures 9-13; the paragraphs that follow describe anomalies in the figures, beginning in the northwest corner of the survey area and moving clockwise around the Pilot Plant exterior. 


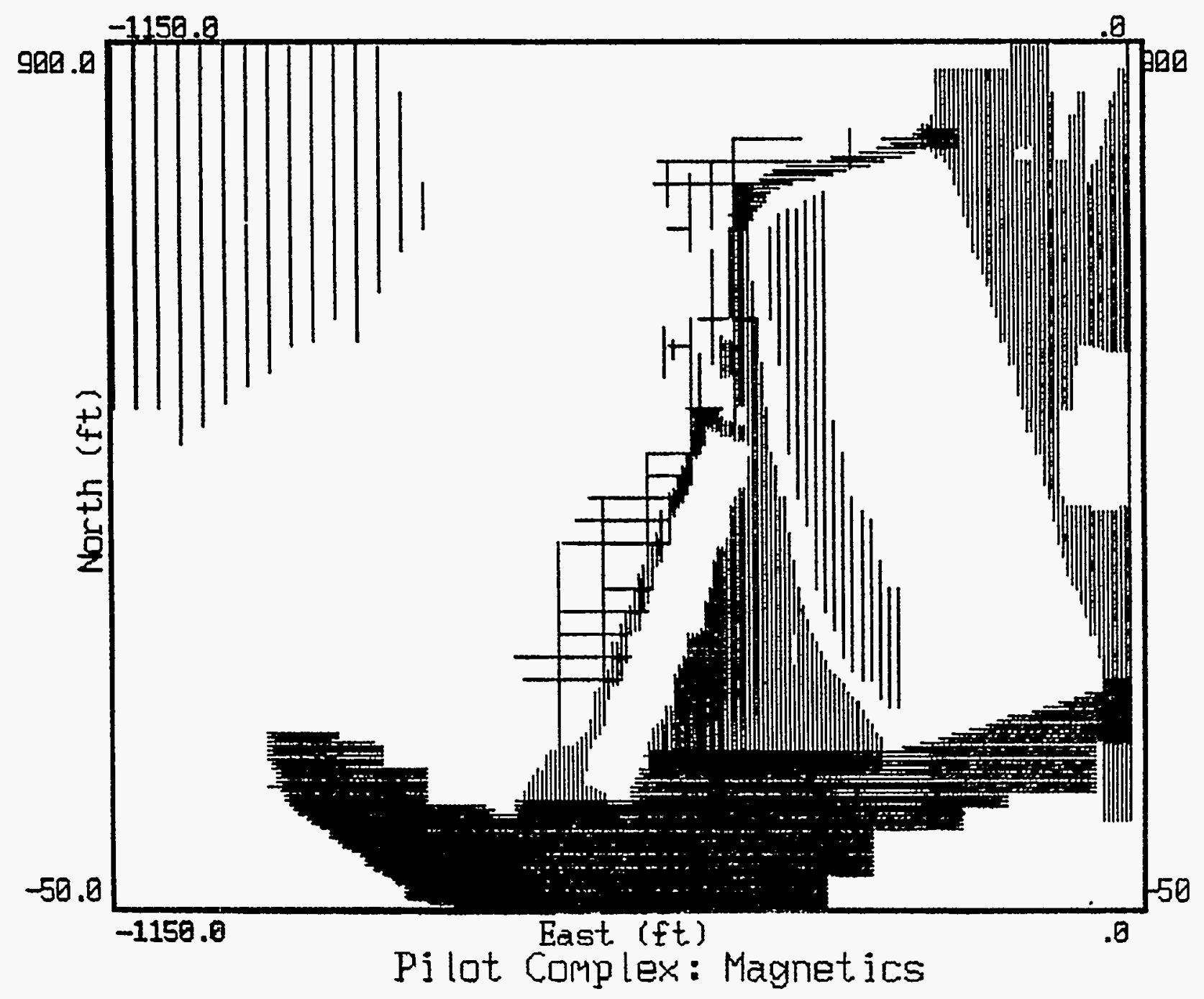

FIGURE 7 Magnetic Transects Outside the Security Fence

1. In the northwest quadrant (Figure 9), three low-intensity, positive lineaments converge to a point at $878 \mathrm{~W}, 655 \mathrm{~N}$. The lineaments consist of high-intensity, small, circular anomalies that are observed on at least nine separate profiles. The features are maintained even where amplitude is not unusually large. The area contains known surface debris; therefore, all of the anomalies are probably associated with fill material pushed into a former basin occupied by the West Branch of Canal Creek.

2. In the north-central area (Figure 10), just north and northwest of the Pilot Plant fence and east of the wetland, several small anomalies radiate out from the fence. Survey lines were restricted in this area because the fence and wetland 


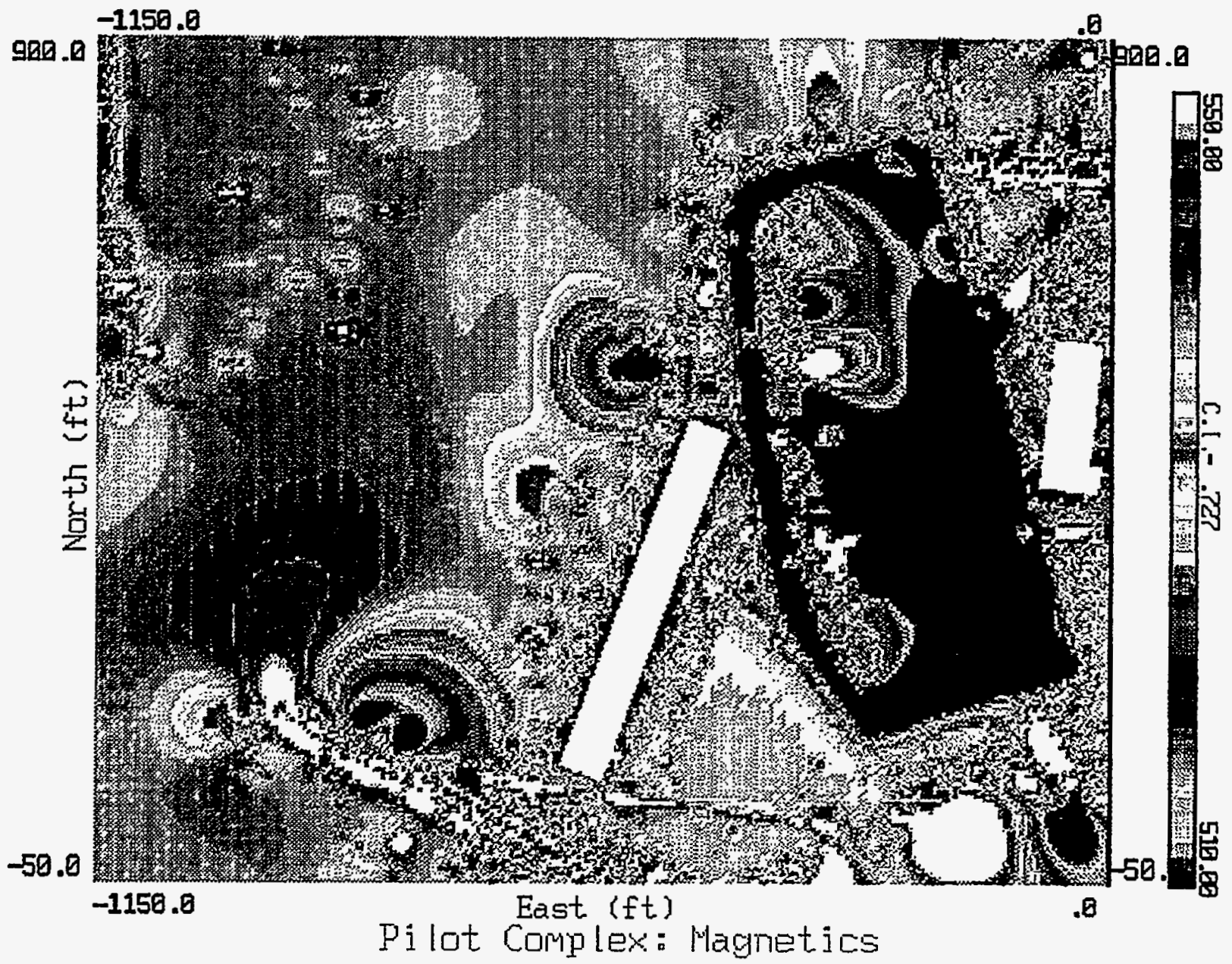

FIGURE 8 Regional Magnetic Field Outside the Security Fence

were nearby. All of the anomalies are defined by one-line profiles; therefore, undue significance should not be placed on them. It should be noted, however, that anomalies radiating out toward the fence from the interior do intersect the fence in this area. The anomaly located at coordinates $477 \mathrm{~W}, 712 \mathrm{~N}$ is suspected to be real and due to a buried pipe.

3. The northeast quadrant (Figure 11) contains three major lineaments: one trending east-west from the northeast corner of the complex, a second oriented due north and angled slightly to the east from the fence, and a third trending N45E from its intersection with the second lineament. Although segments of the lineaments appear as minima, they do so because high gradients have converted magnitudes. The lineament trending due north is produced by a sanitary sewer line. The east-west trend is associated with multiple lineaments that include storm and sewer lines. The source of the lineament trending northwest-southwest is probably due to an overhead steam pipe. 


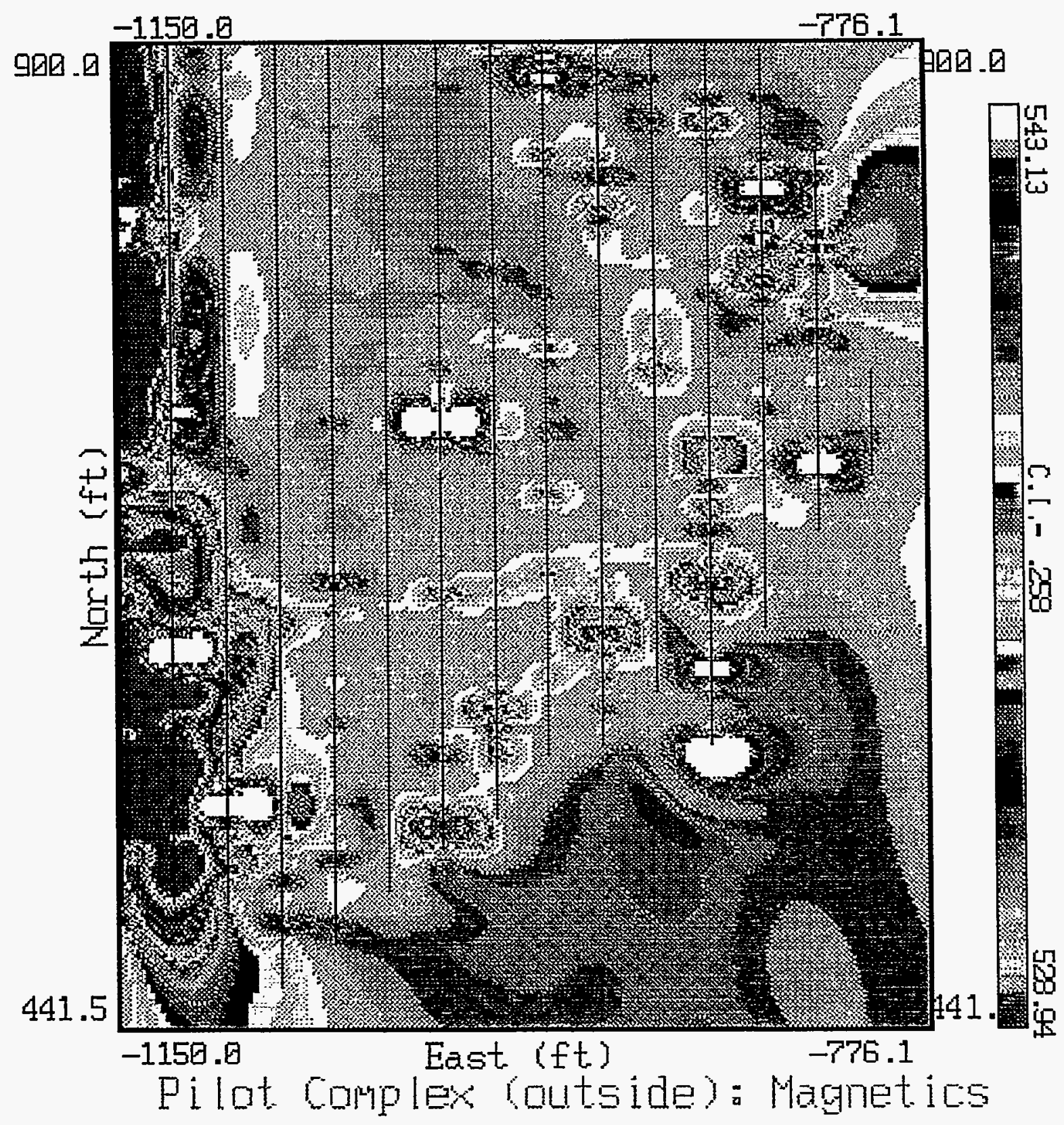

FIGURE 9 Magnetic Anomalies in the Northwest Corner of the Regional Map 


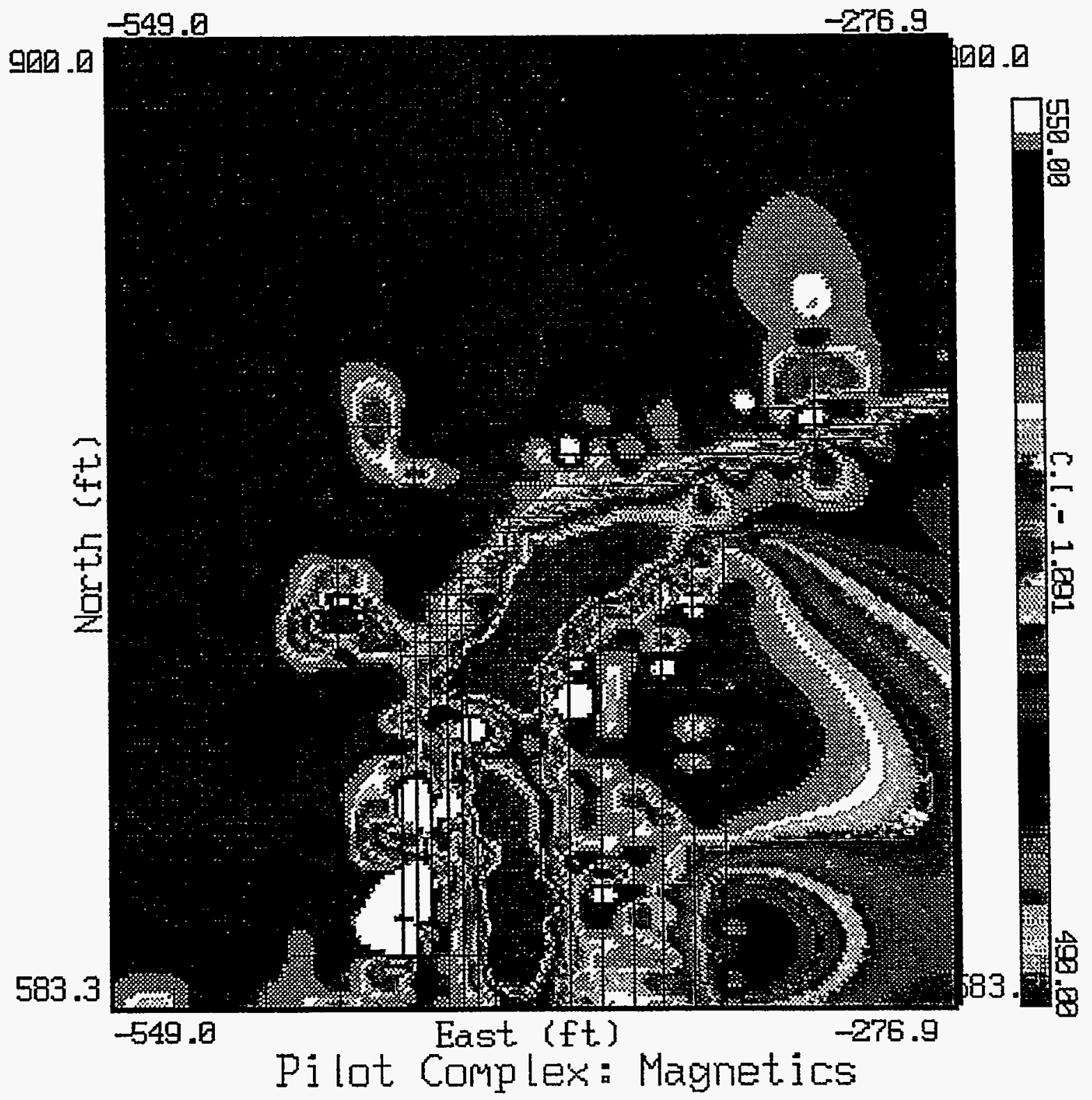

FIGURE 10 Magnetic Anomalies Adjacent to the Northwest Corner of the Security Fence. (A magnetic lineament extends from the fence interior, under the fence, and beyond the perimeter road outside the security fence.) 


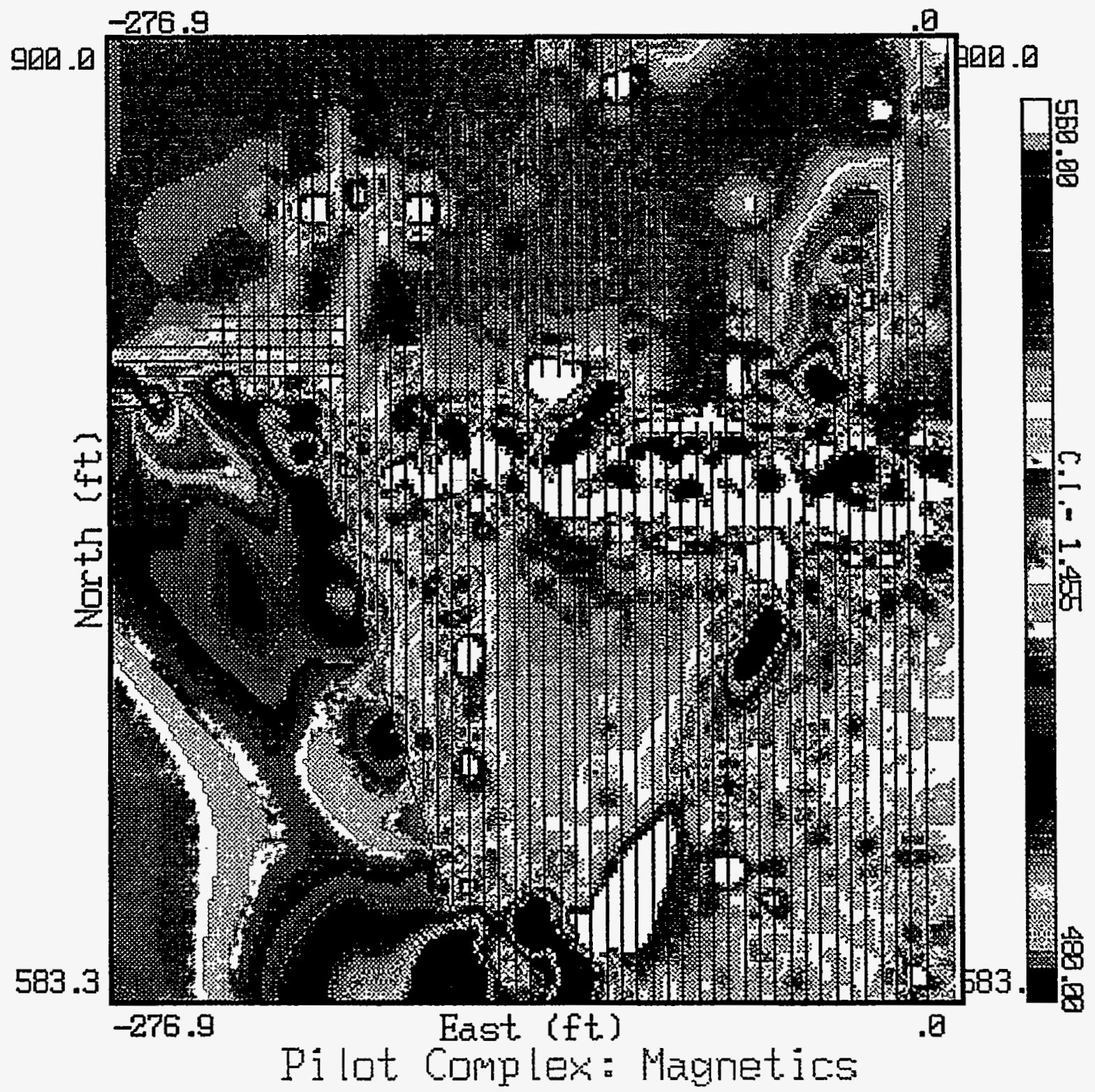

FIGURE 11 Magnetic Anomalies in the Northeast Quadrant of the Regional Survey 


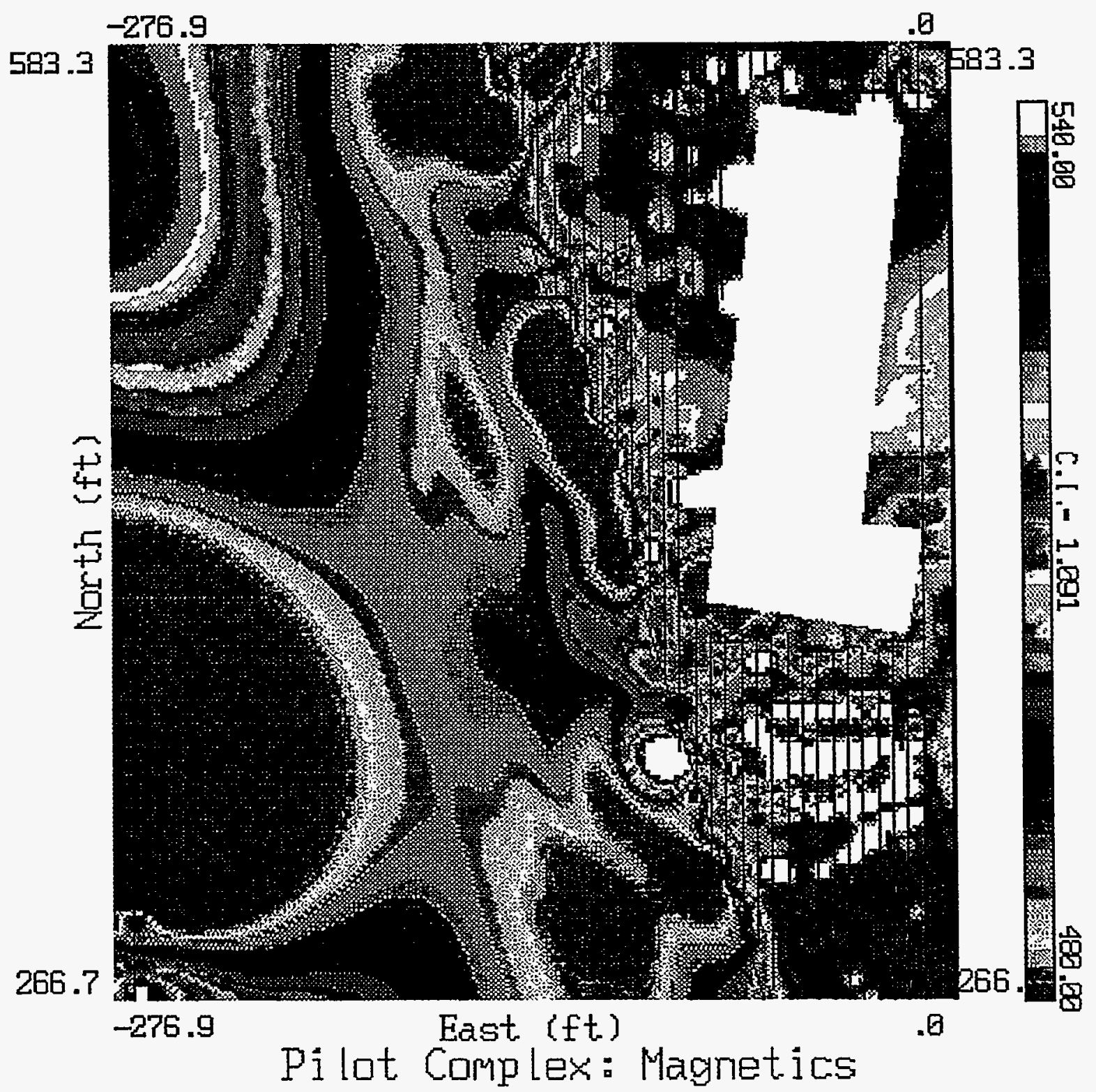

FIGURE 12 Magnetic Anomalies East of the Security Fence 


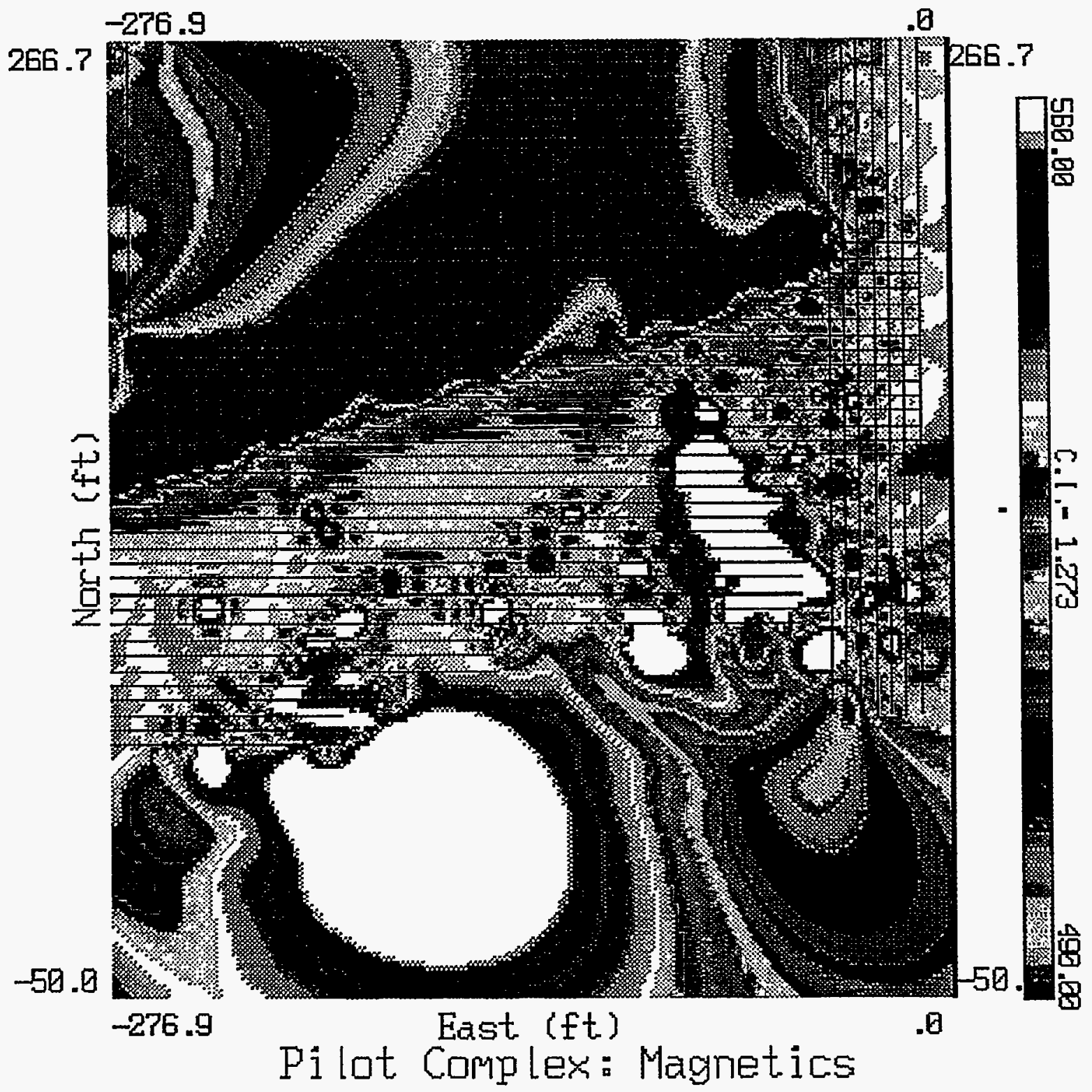

FIGURE 13 Magnetic Anomalies Adjacent to the Southeast Fence Outside the Pilot Plant 
4. East of the fence, from approximately $185 \mathrm{~N}$ to $600 \mathrm{~N}$ (Figure 12), unidentified erratics in road fill cause many small anomalies; however, a sanitary sewer line also causes the broad, east-west trend centered at $44 \mathrm{~W}, 347 \mathrm{~N}$. A small lineament diverging southwest from the larger anomaly may be associated with an underground pipe.

5. In the southeast quadrant (Figure 13), a buried steam line causes a prominent anomaly; however, the area is littered with unexplained features, some of which are lineaments, while others are single-source anomalies. Lineaments may represent iron pipes, whereas the more localized features remain unidentified. A lineament located approximately $190 \mathrm{ft}$ southwest from the southeast corner of the fence suggests that a buried line extends into the Pilot Plant complex.

6. Southwest of the fence (Figure 14), immediately east of Building E5654, a chemical sewer line produces a lineament that trends southwest parallel to an access roadway. The sewer line extends into the Pilot Plant complex. An additional lineament trending east-west across the southern lawn is associated with a newly constructed buried utility line; the sections of the line and manhole covers are still visible from the surface.

7. A prominent lineament trending west-northwest in the southwestern corner of the survey area (Figure 15) is associated with Fleming Road and a bridge. A buried sewer line probably parallels the road. An east-west lineament converging with the road on the north is the western extension of the east-west sewer line identified in item 6 . A large circular anomaly in the south-central area of the map is unexplained.

\subsection{Electromagnetic Profiling with the EM31}

Electrical conductivity was measured outside the fence at the Pilot Plant complex with the EM31. Conductivity and resistivity can be used interchangeably to define hydrogeologic framework, cultural changes in natural systems, and water chemistry. The chemistry of interstitial water plays the dominant role in earth resistivity; for this reason, electrical methods are particularly suited for tracking contaminants. Profile locations used to collect electromagnetic data are shown in Figure 16. Transects were spaced five feet apart along north-south and east-west headings. Data were acquired by using a digital data logger at a 0.5 -s sampling rate, resulting in a mean station spacing of $1.5 \mathrm{ft}$. A contour map of regional electromagnetic data is shown in Figure 17.

Conductivities, ranging from 10 to several hundred $\mathrm{ms} / \mathrm{m}$, are caused by the juxtaposition of natural and anthropogenic anomalies. The configuration of the electromagnetic surface shown in Figure 17 is dominated by prominent lineaments produced by roads, steam lines, and sewers. 


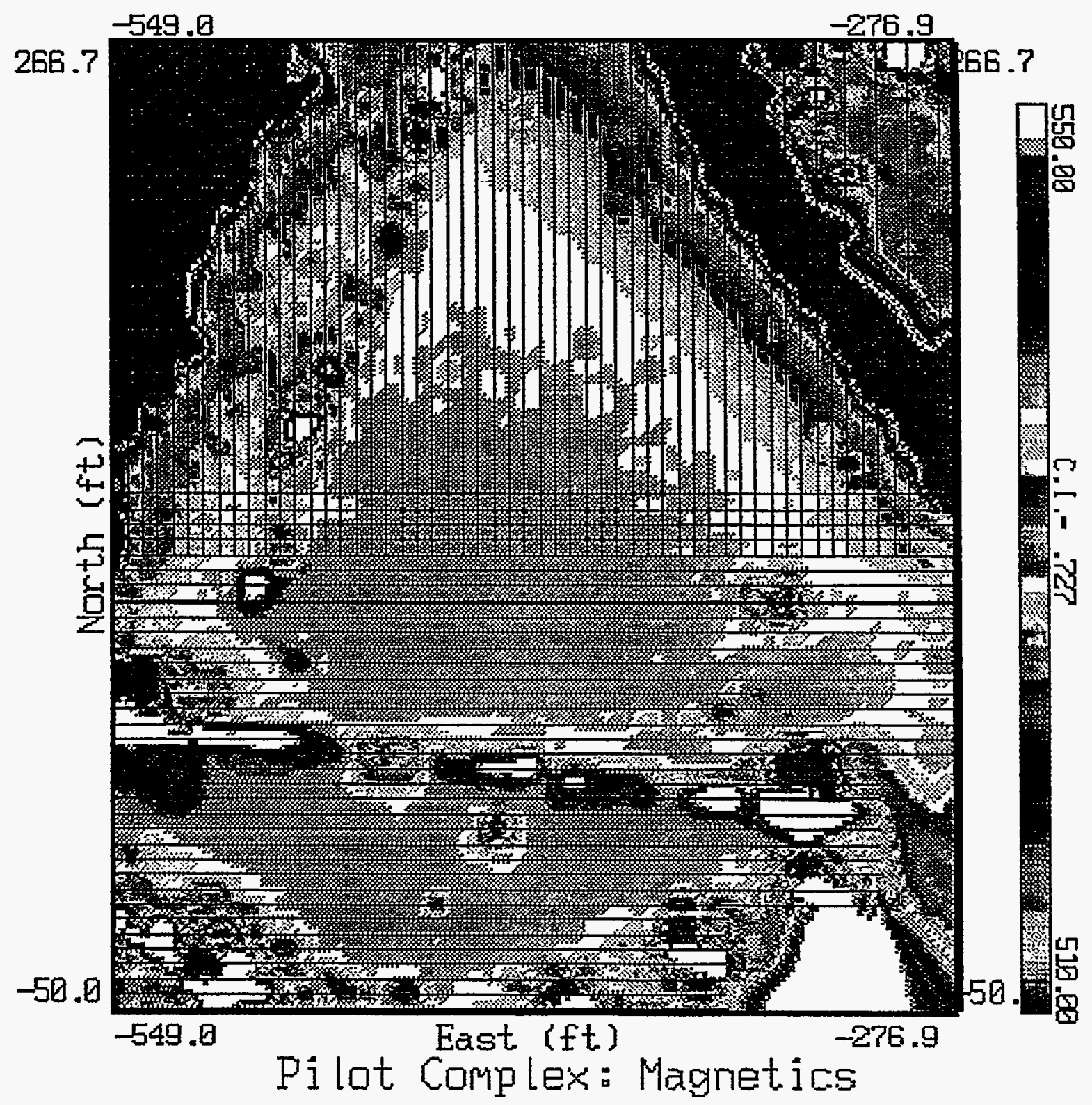

FIGURE 14 Magnetic Anomalies between the Security Fence and Building E5654 


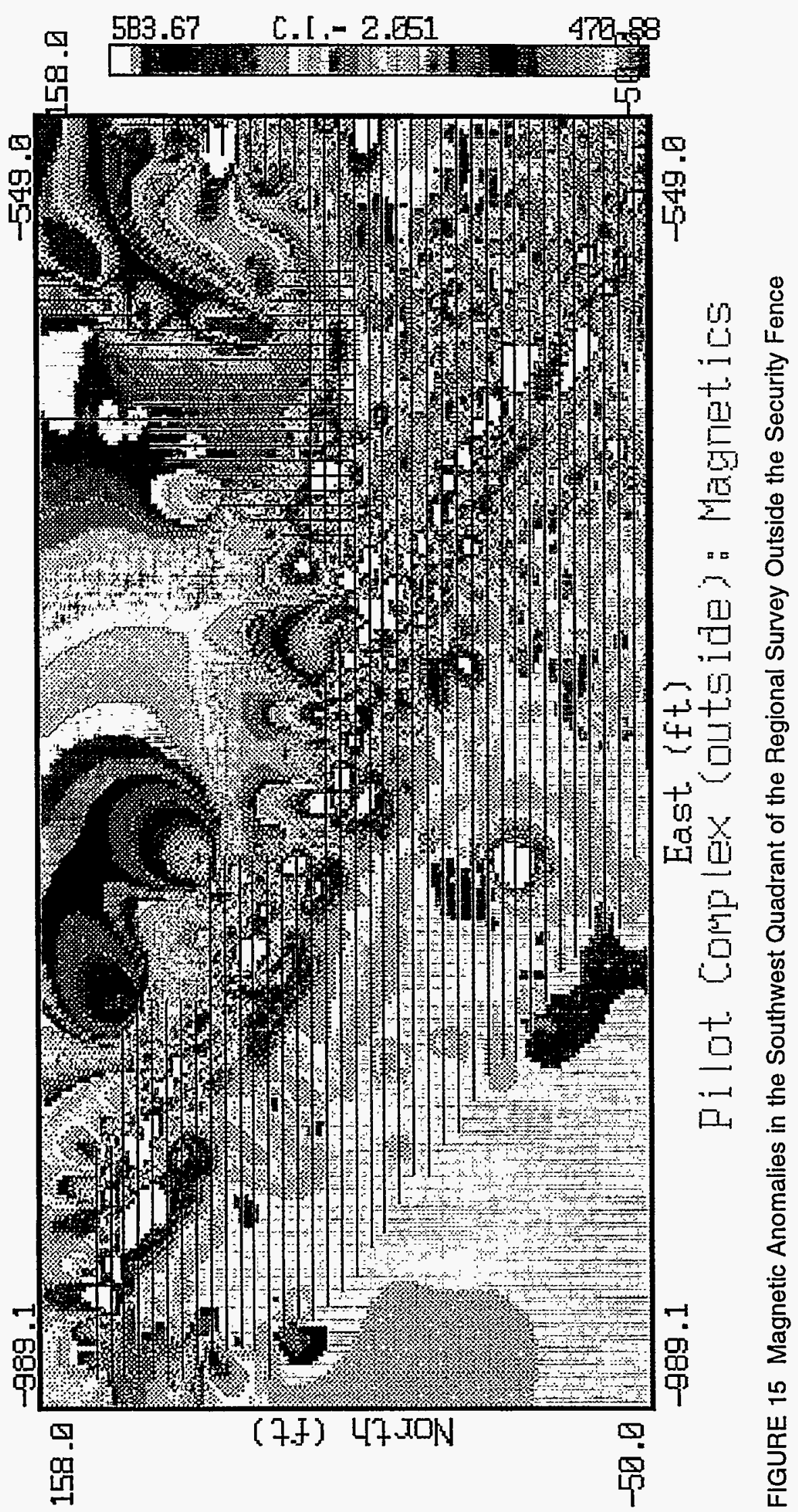




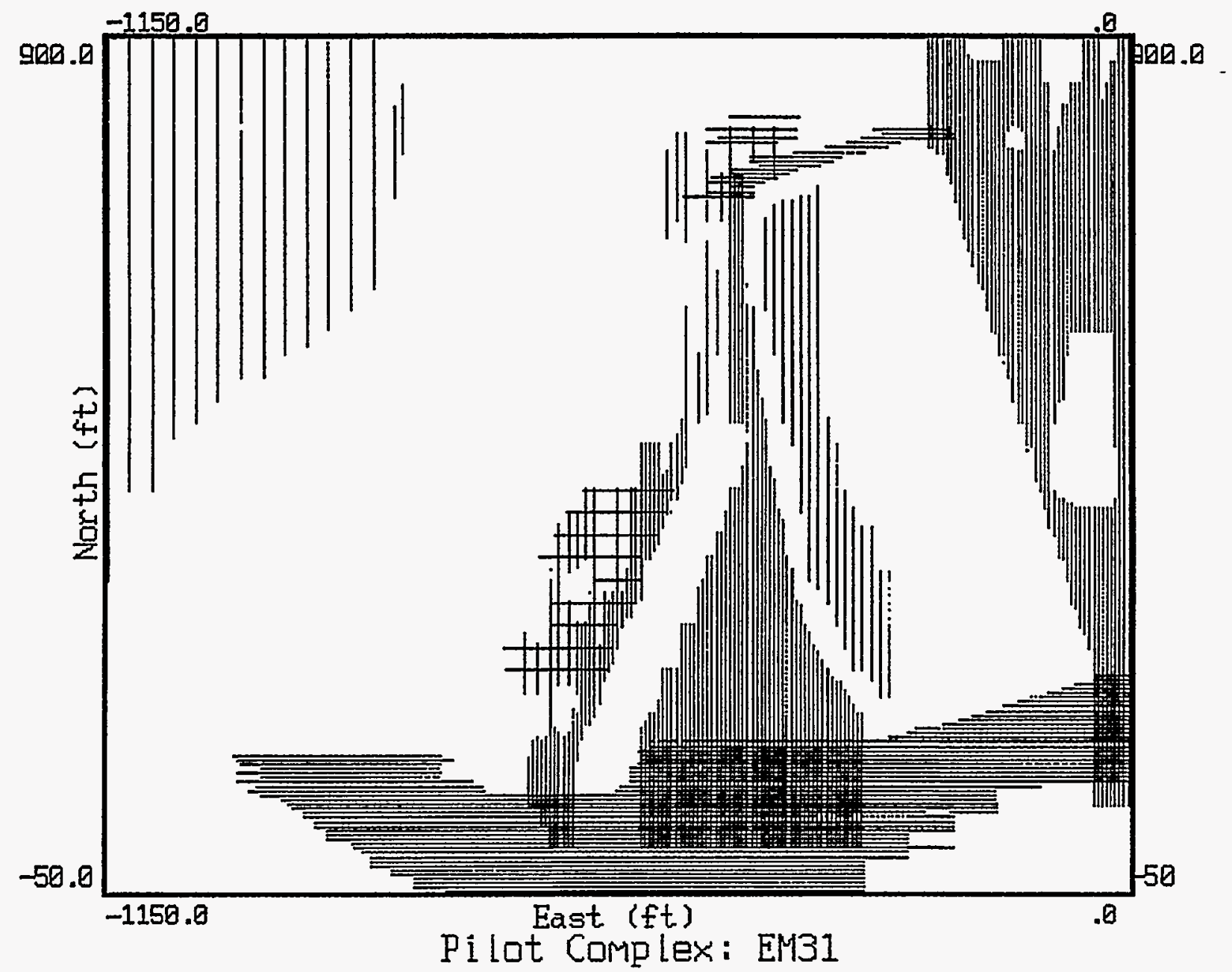

FIGURE 16 EM31 Transects Outside the Security Fence

A comparison of the EM31 regional map with the location maps of underground sewer lines and pipes illustrates a strong one-to-one correlation. In addition, many of the anomalies shown in Figure 17 are broad bands of higher conductivities caused by road-bed material. The regional map of the exterior area is quite free of small point sources. Features on the conductivity map, beginning in the northwest corner and moving clockwise, are described in the following paragraphs.

1. The western edge of the northwest corner is dominated by high-amplitude anomalies caused by an overhead steam pipe just east of Hanlon Road (Figure 18). Two small circular anomalies are located $240 \mathrm{ft}$ east of the northwest corner of the survey area, the centers of which are located at $850 \mathrm{~W}-791 \mathrm{~N}$ and $850 \mathrm{~W}-831 \mathrm{~N}$. The source of these anomalies is unknown, although they are probably caused by surface debris. Background conductivities are generally low in the northwest corner, which has very little relief. Background conductivities increase along the southern edge of the 


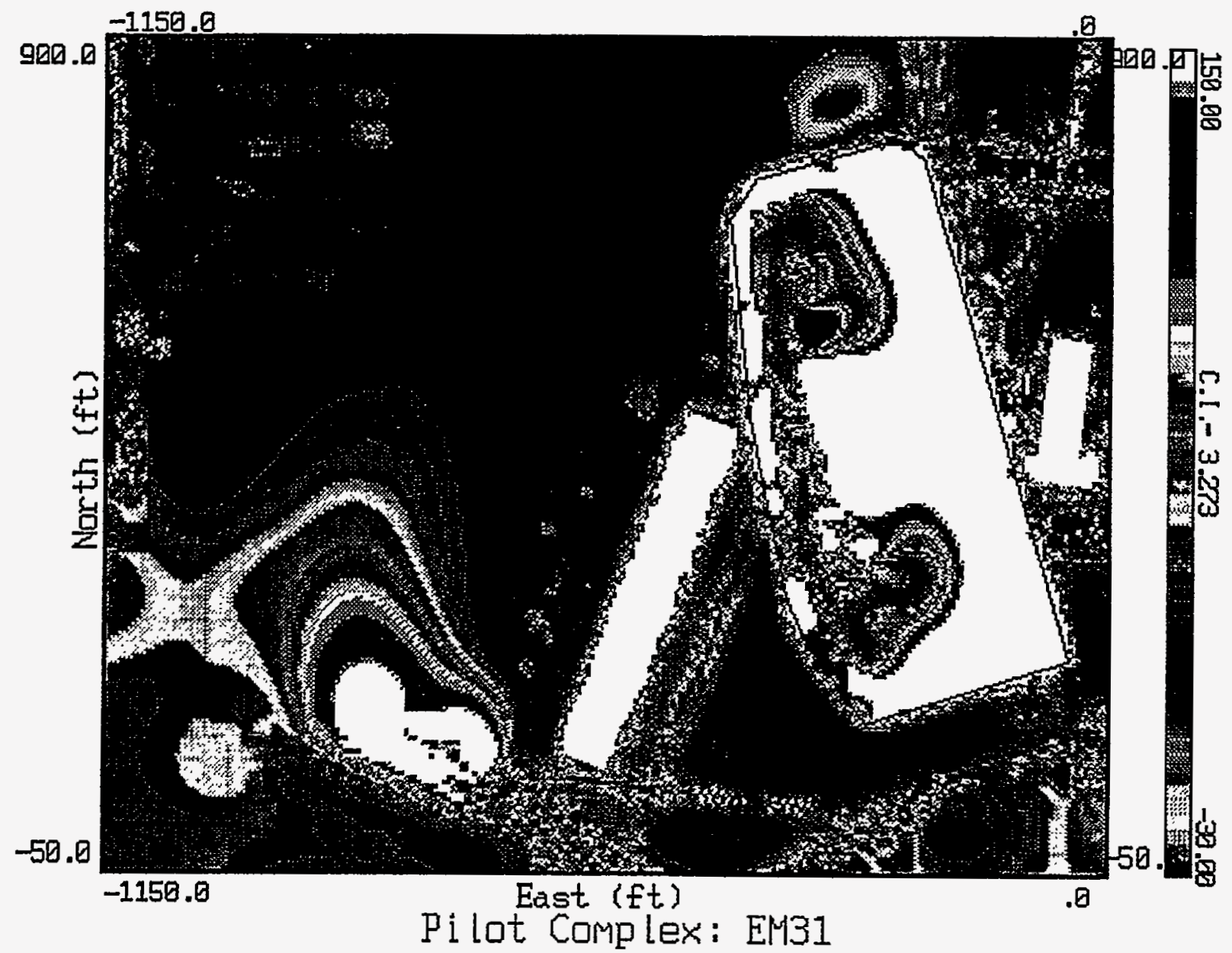

FIGURE 17 Regional EM31 Anomalies Outside the Security Fence

northwest corner as a result of a drop in elevation and an increase in soil saturation as the area approaches the wetland. No lineaments are present that would suggest sewer lines cross the area (as suggested by the regional magnetic anomalies shown in Figures 8 and 9).

2. The north-central area (Figure 19) contains one anomaly trending to the northwest that may represent a drainage pipe (as suggested in the discussion on regional magnetics). An electromagnetic protrusion extends to the northwest from the northwest corner - it may be an extension of an anomaly observed inside the fence. The lack of survey lines more than $70 \mathrm{ft}$ west of the northwest corner limits interpretations.

3. The northeast corner of the area outside the fence contains at least four conductivity lineaments (Figure 20) associated with storm, chemical, and sanitary sewer lines. The lineaments, also shown on the magnetic map in 


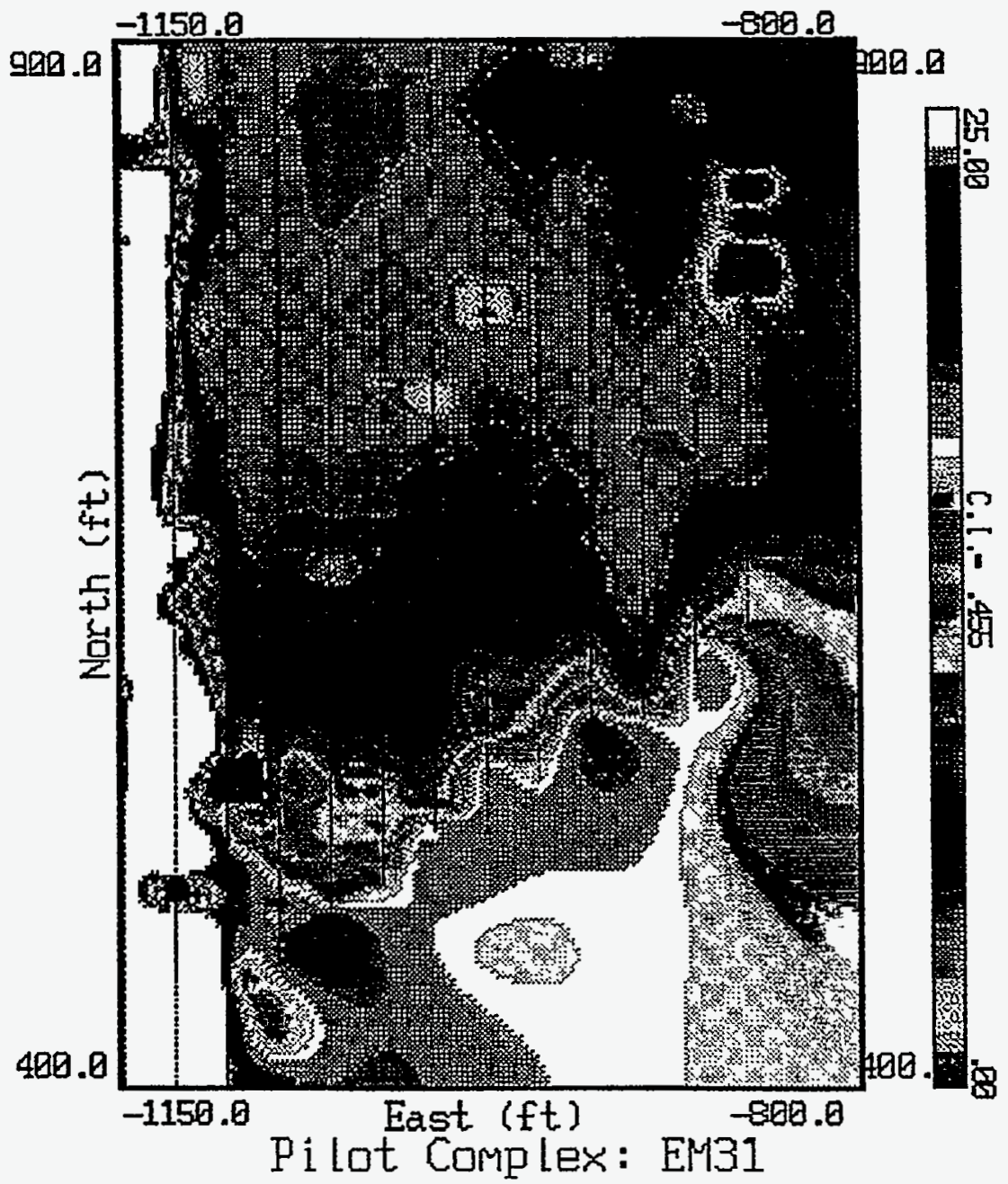

FIGURE 18 EM31 Contour Map in the Northwest Quadrant of the Regional Survey Area

Figure 11, are also partially caused by surface materials (such as road fill). The east-west road projecting to the east from the northeast corner of the fence has a subparallel anomaly south of the main-road anomaly. This feature is unexplained, but it could be caused by a buried pipe. The high-amplitude positive anomaly crossing the road and exiting the map in the far northeast corner is produced by an overhead steam line. A positive anomaly projecting north from the road, near its intersection with the fence, is probably caused by various sewer lines.

4. East of the fence, the steam-line anomaly is observed trending northward from the fence at $123 \mathrm{~W}, 590 \mathrm{~N}$ (Figure 21). A road anomaly south of Building E5609 projects into the fence. A small positive lineament, centered at $94 \mathrm{~W}, 496 \mathrm{~N}$, is associated with Building E5611. 


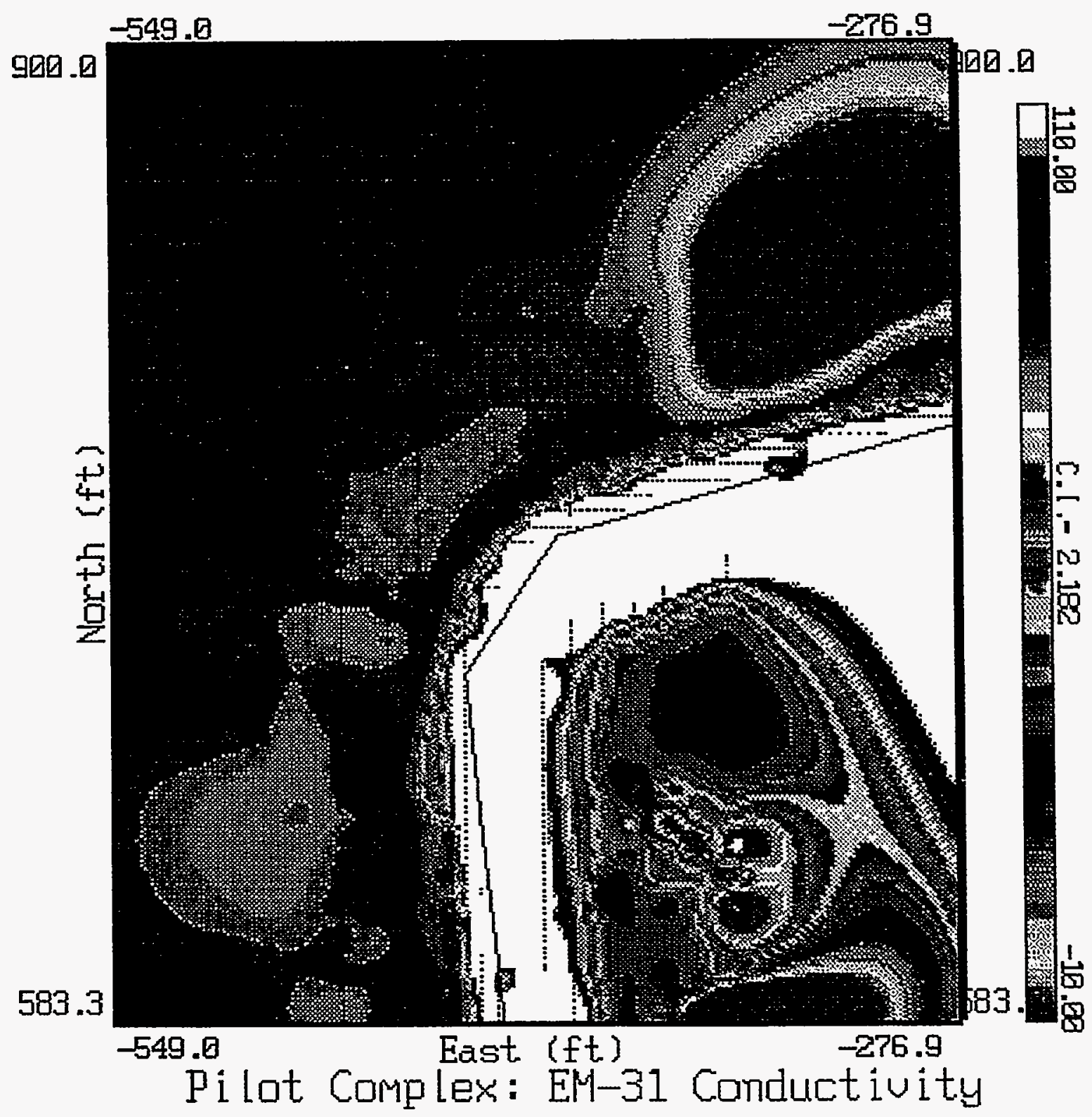

FIGURE 19 EM31 Anomalies Outside the Northwest Corner of the Fence 


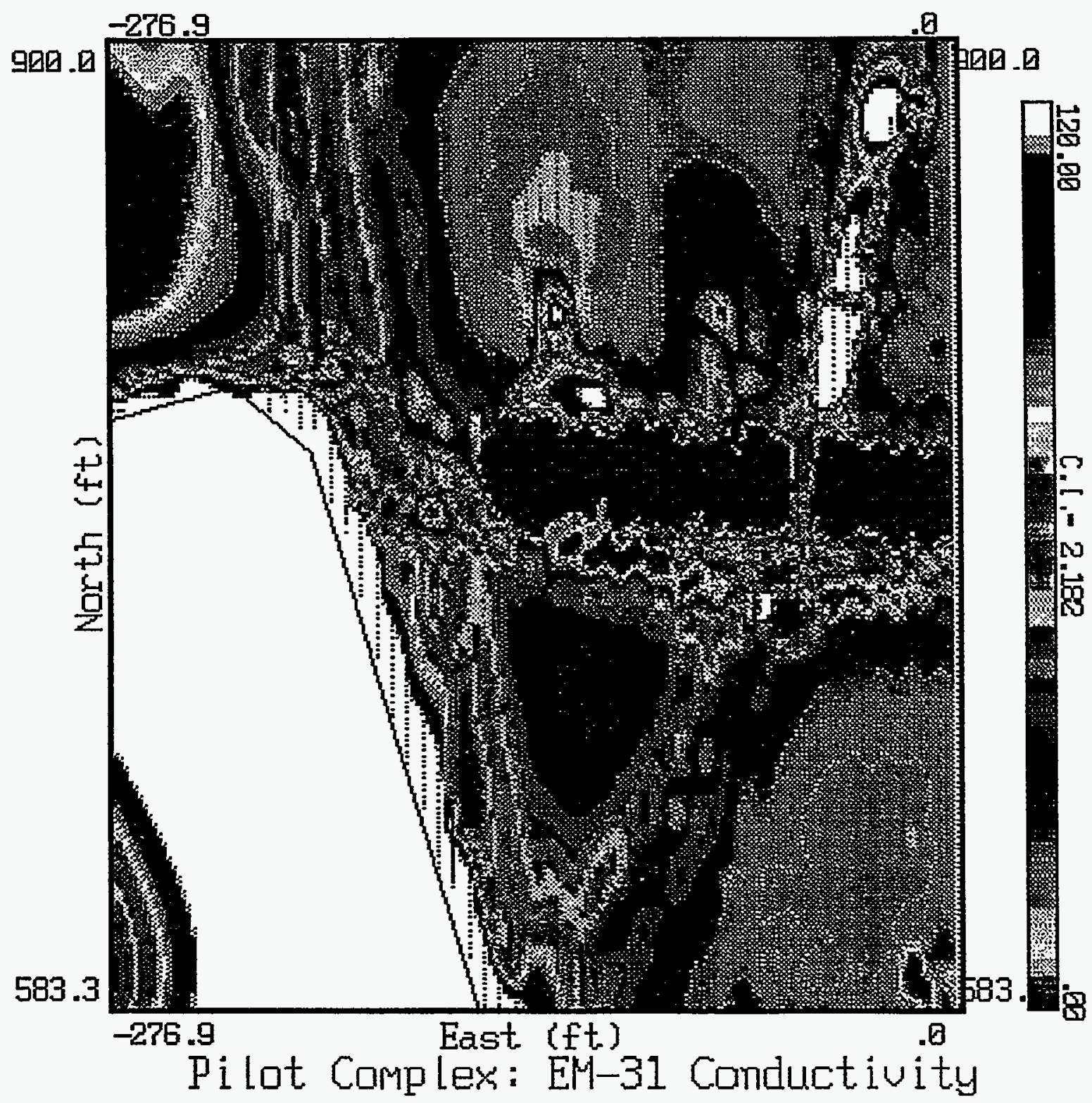

FIGURE 20 EM31 Anomalies Outside the Northeast Corner of the Fence 
5. All features south of the Pilot Plant fence (Figure 22) are produced by steam lines and by present or former roads (or by culverts under the road).

6. Southwest of the fence, between the fence, Fleming Road, and Building E5654, several prominent lineaments are associated with roads and underground pipes (Figure 23). The lineament crossing the road at $305 \mathrm{~W}$, $21 \mathrm{~N}$ is caused by a buried sewer line.

7. In the southwest corner (Figure 24) between Building E5654 and the wetland, the major lineament is Fleming Road and the bridge. A sewer line intersects the road at approximately $746 \mathrm{~W}, 68 \mathrm{~N}$. Several small, unexplained anomalies are observed in the approaches to the wetland on the west.

\subsection{Ground-Penetrating-Radar Profiling}

Ground-penetrating-radar profiling was carried out in midwinter of 1993-94, when the ground surface was coated with several inches of ice. The high-dielectric-constant, smooth-ice surface yielded some of the best radar penetration and resolution obtained during the Argonne geophysical program at APG. Before the production lines for the survey were run at the Pilot Plant, replicate runs were made over the same line to determine which of the two transceivers, the $100-$ or $300-\mathrm{MHz}$ antenna, provided the best results. The transceiver providing the best penetration and resolution for the study of stratigraphic characteristics was the $300-\mathrm{MHz}$ antenna. The $300-\mathrm{MHz}$ antenna has a VR of $1.5 \mathrm{ft}$ (VR is the minimum thickness of thin layer that is resolvable). Regional surveys were run in both the monostatic and bistatic mode by using the $300-\mathrm{MHz}$ antenna.

The maximum depth of penetration in the monostatic mode at the Pilot Plant ranged from 10 to $15 \mathrm{ft}$ below the ground surface, although penetration in some areas was less than $5 \mathrm{ft}$. For the regional survey, a range setting of $150 \mathrm{~ns}$ was used at a scan rate of $32 \mathrm{scans} / \mathrm{s}$. The transceiver was pulled by hand at approximately $2 \mathrm{ft} / \mathrm{s}$. Maximum depth of penetration in the bistatic mode was greater than $30 \mathrm{ft}$.

The area surrounding the Pilot Plant, in the west branch of Canal Creek, was a former wetland, which was underlain by a tributary system draining into the west branch. Before the Pilot Plant was constructed, fill material was used to raise the ground surface to well above the water table. The combination of fill and depositional bedding planes below the fill in the natural sediments results in strong, horizontal reflectors in the near surface.

In the area between the security fence and Building 5654, the near-surface reflectors are underlain by reflectors dipping into a paleochannel oriented west to east. Several transects across the paleochannel (see Figures 25-28) indicate that it is over $250 \mathrm{ft}$ wide and approximately $30 \mathrm{ft}$ 


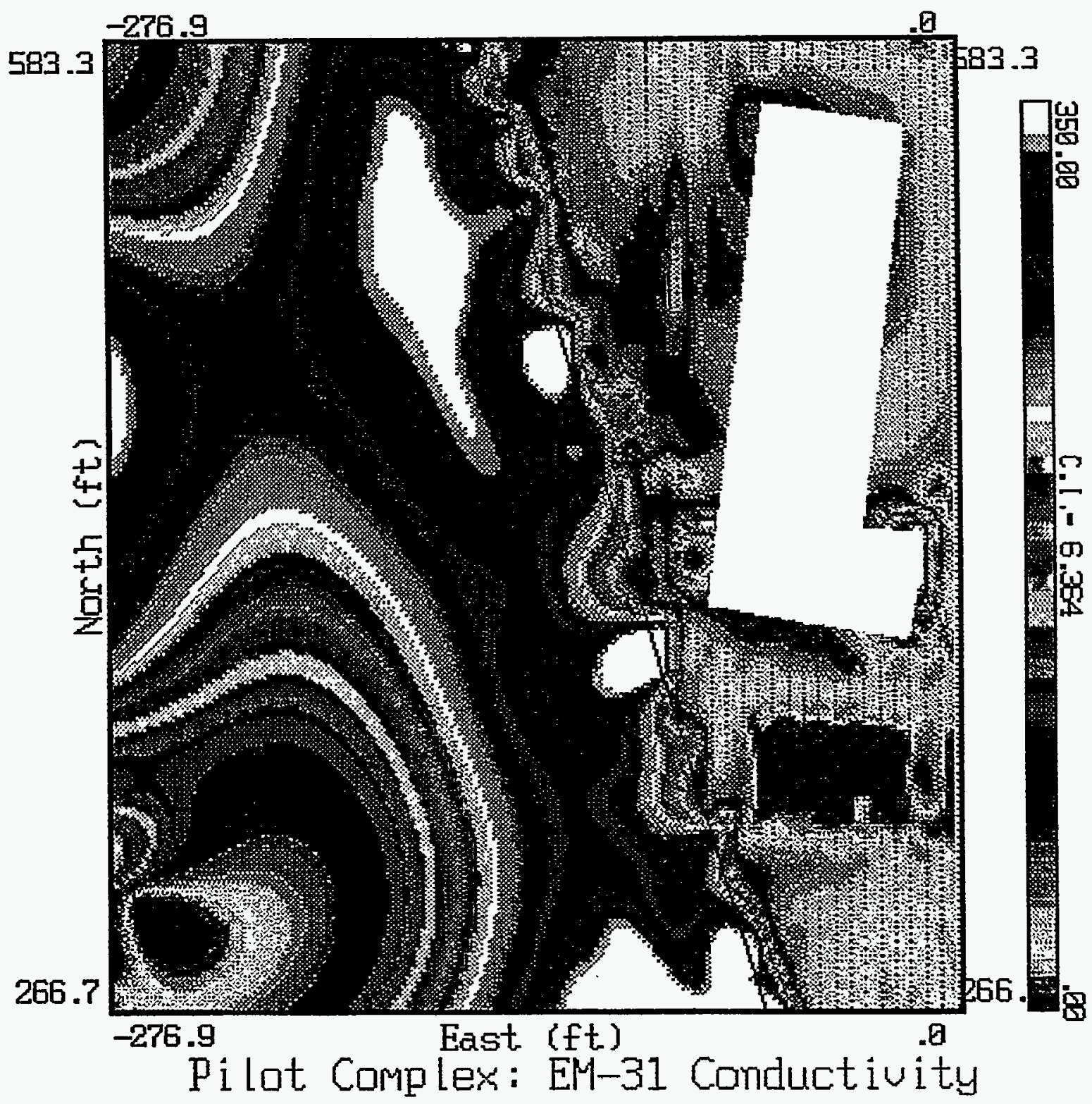

FIGURE 21 EM31 Anomalies East of the Fence in the Area around Building E5611 


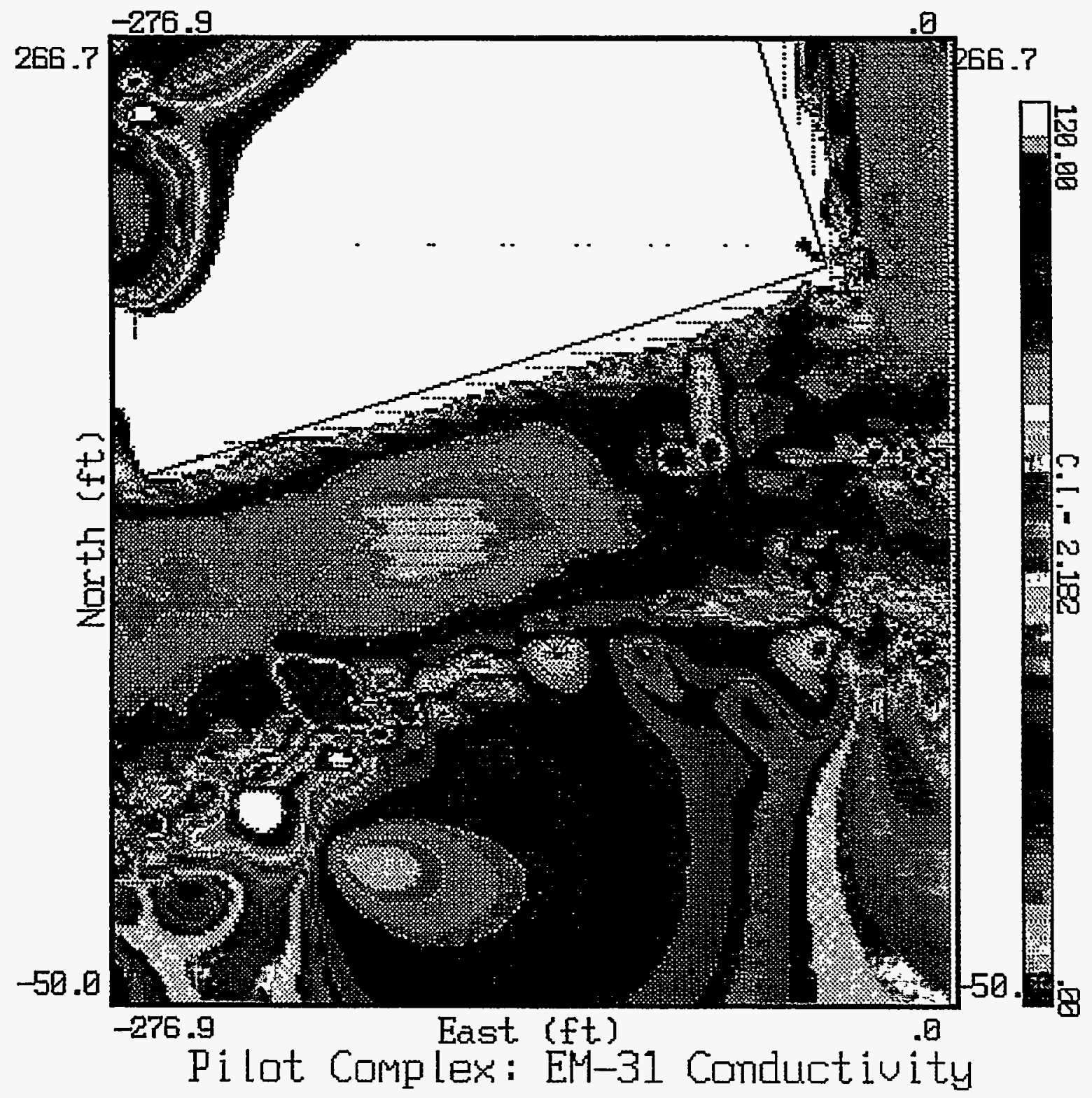

FIGURE 22 EM31 Anomalies South of the Security Fence 


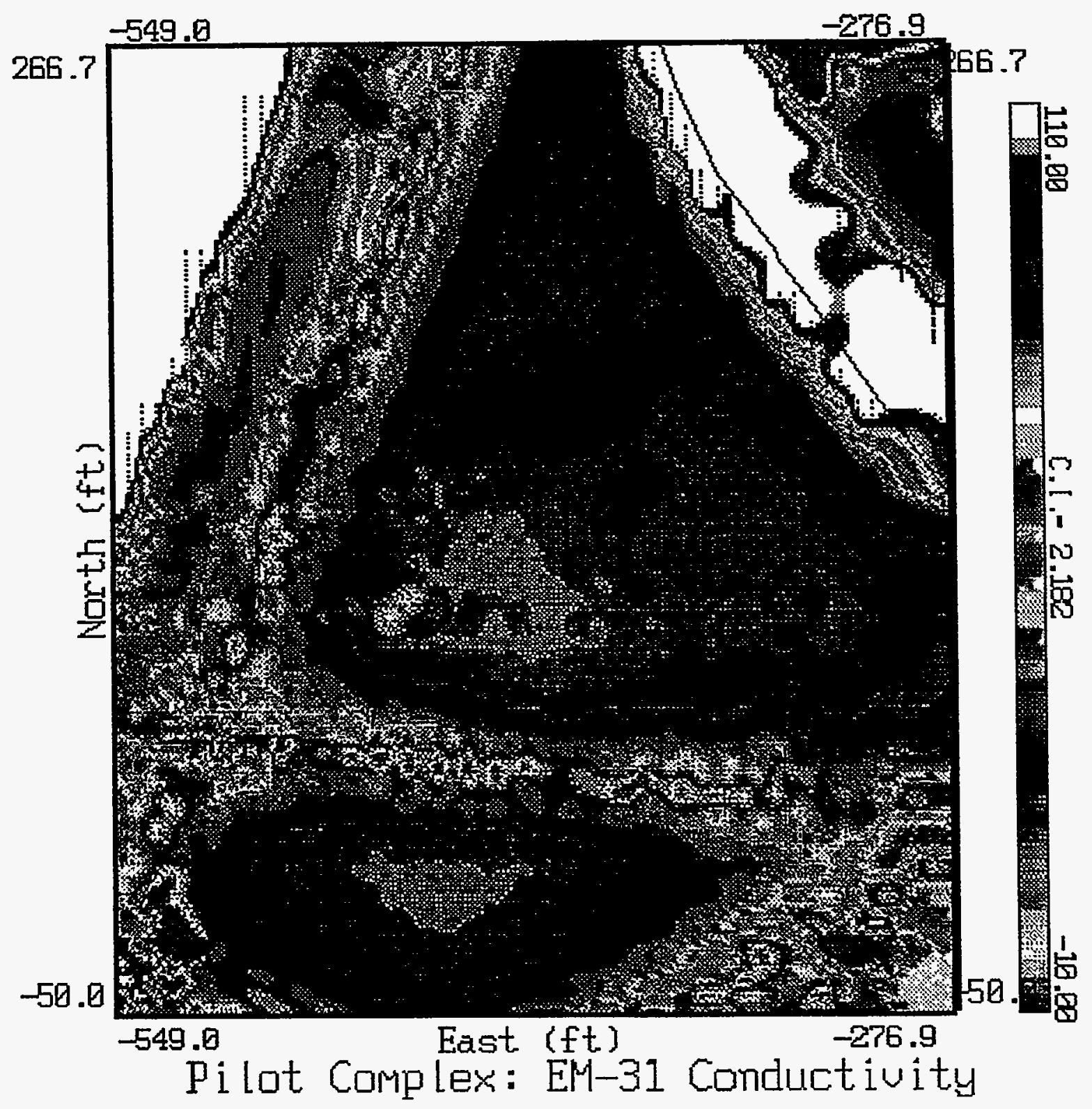

FIGURE 23 EM31 Anomalies Southwest of the Security Fence and East of Building E5654 


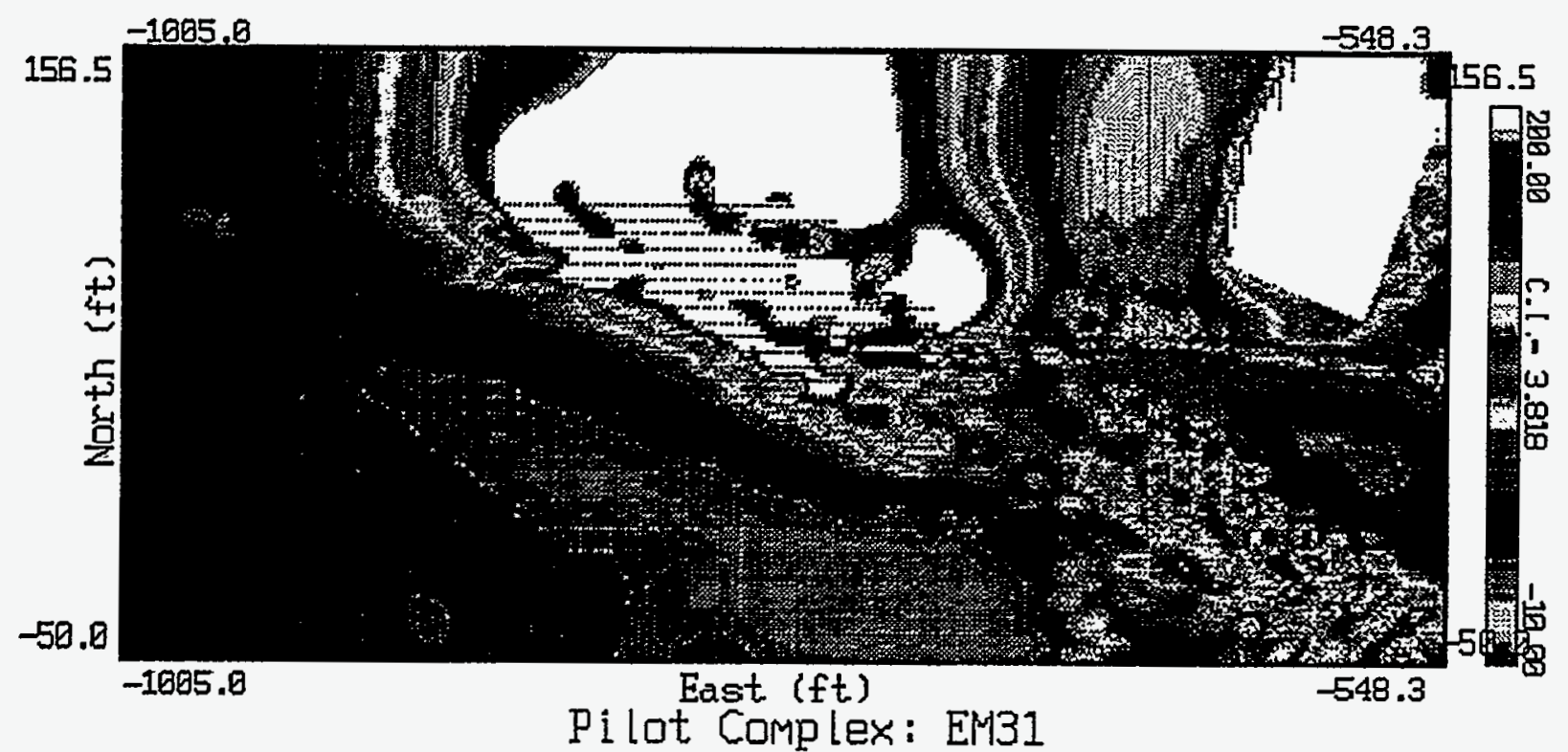

FIGURE 24 EM31 Anomalies in the Southwest Quadrant of the Area Outside the Security Fence

deep. The paleochannel intersects the Pilot Plant area along the southwest security fence and underlies the southern third of the Pilot Plant complex. Although the survey lines did not extend beyond 50S, relief on the erosional surface underlying the valley is probably as great or greater to the south as it is in the area surveyed. The reflector on the south (Figure 28) rises to approximately $10 \mathrm{ft}$ below ground surface when it again dips to the south. Because of the relationship of the valley to the west branch, the buried valley discovered in this study is probably a former tributary to a paleochannel underlying the west branch of Canal Creek. Also, the unconformity separating Potomac Group Cretaceous sediments from the Talbot Formation of Pleistocene age is probably the surface upon which the valley system is constructed. 


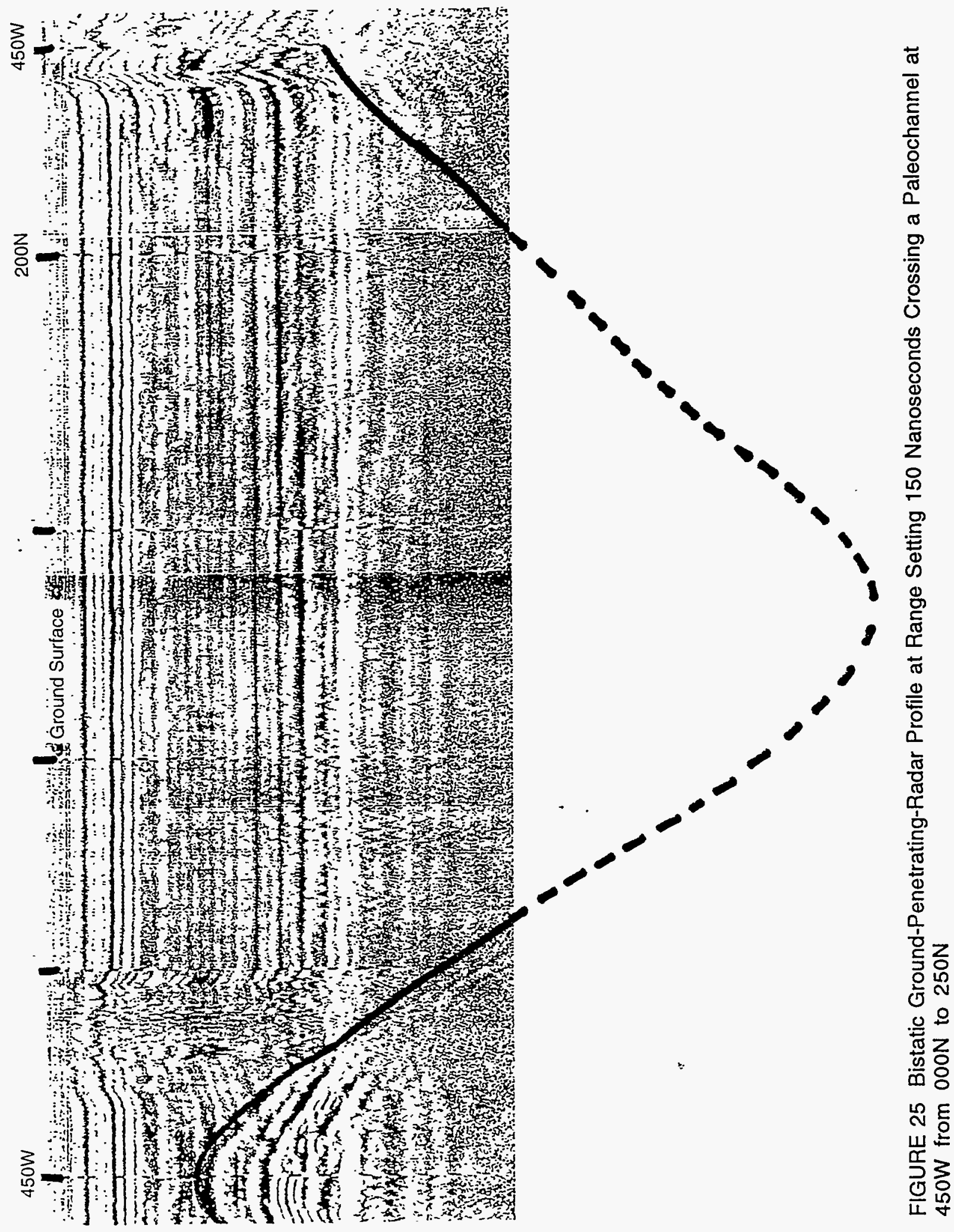




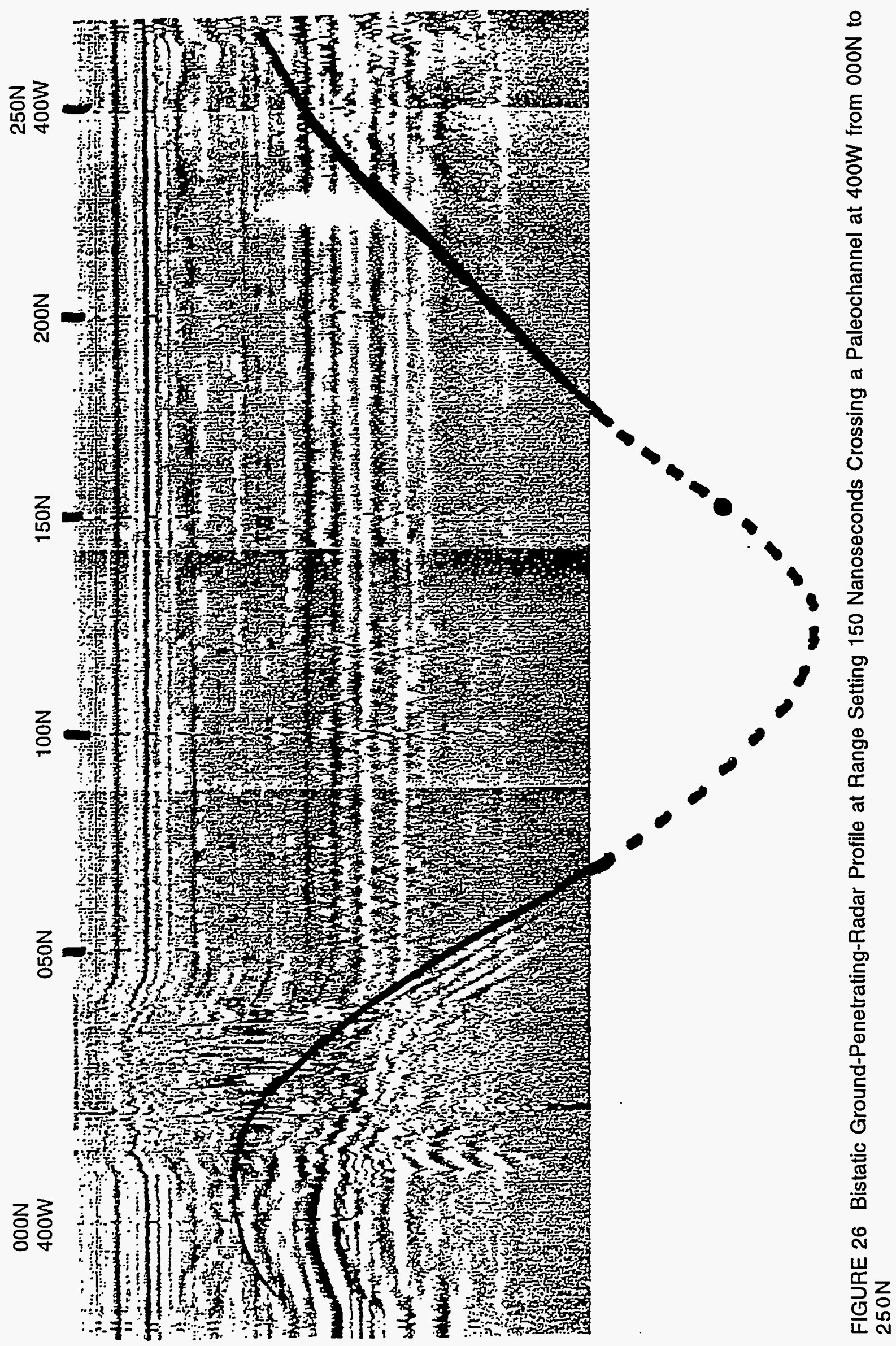




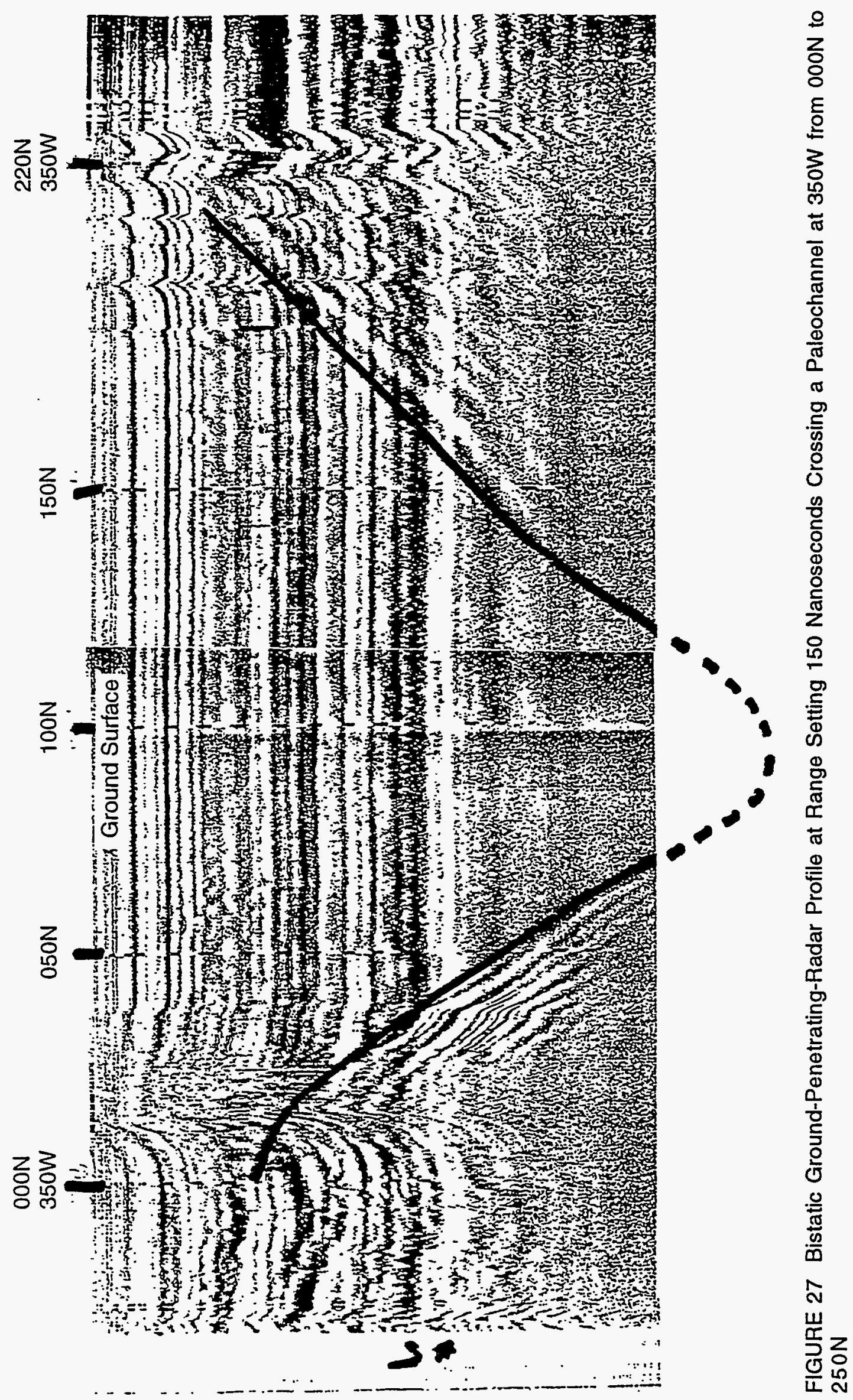


$-50 N$ $450 \mathrm{~W}$

OON

$50 \mathrm{~N}$

$100 \mathrm{~N}$

$150 \mathrm{~N}$

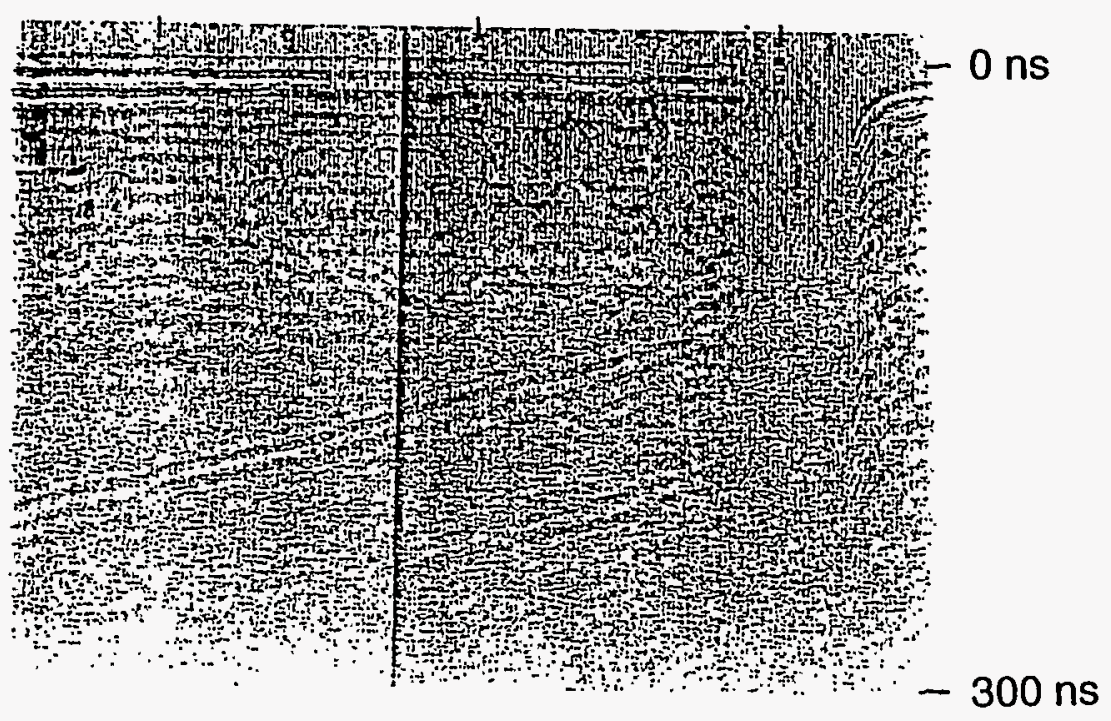

FIGURE 28 Bistatic Ground-Penetrating-Radar Profile at Range Setting 300 Nanoseconds Crossing a Paleochannel at 450W" from $50 \mathrm{~S}$ to $250 \mathrm{~N}$ 


\section{Geophysical Surveys Inside the Security Fence}

The Pilot Plant Complex inside the fence, measuring $600 \times 330 \mathrm{ft}$, contains approximately 10 metal buildings. All instruments used outside the fence, as well as the Geonics EM61, were used in surveys inside the fence. Because all of the instruments are sensitive to surface and subsurface metal conductors, eliminating interference caused by surficial features is difficult. Because defining buried metals in close proximity to aboveground metal structures is important, it was decided to employ a device, recently put on the market, that is relatively insensitive to interference from objects on the earth's plane. The Geonics EM61 metal detector transmits focused inductive fields downward from a coil lying in the plane of the earth's surface, and it receives signals returned via a coaxial coil from metal objects vertically below the plane of the coils.

\subsection{Magnetic Surveys}

Magnetic surveys were conducted by using two instruments - one was used to avoid metal objects when stakes were driven into the ground, and a second was used to measure the total magnetic field.

\subsubsection{Magnetic Gradiometry}

The field team used the Schonstedt magnetic gradiometer to avoid driving survey stakes into shallow magnetic debris. The area was swept with the wand, and anomalous locations were marked with spray paint. The gradiometer sweep was also used to identify areas that required detailed coverage with the more quantitative geophysical equipment.

\subsubsection{Total Field Magnetic Profiling}

The area inside the Pilot Plant fence was surveyed along profiles separated at five-foot intervals. Lines were read parallel to exterior building walls and to the east fence. In the discussions that follow, the north-south direction is assumed to lie along the east fence, and the $O E, O N$ coordinate is assumed to be in the southwest corner of the fenced-in interior. Anomalies proceed from the northern end of the complex to the south. Magnetic anomalies peripheral to buildings are shown in Figure 29. Buildings are outlined in white, as are high-intensity positive anomalies. In the following paragraphs, anomalies are discussed by area because of the large number of anomaly sources inside the fence.

1. Figure $30-$ Magnetics from $485 \mathrm{~N}$ to $605 \mathrm{~N}$. North-south lineaments are observed $10-20 \mathrm{ft}$ inside the fence, on the east and west. A second, more subtle, parallel lineament is 


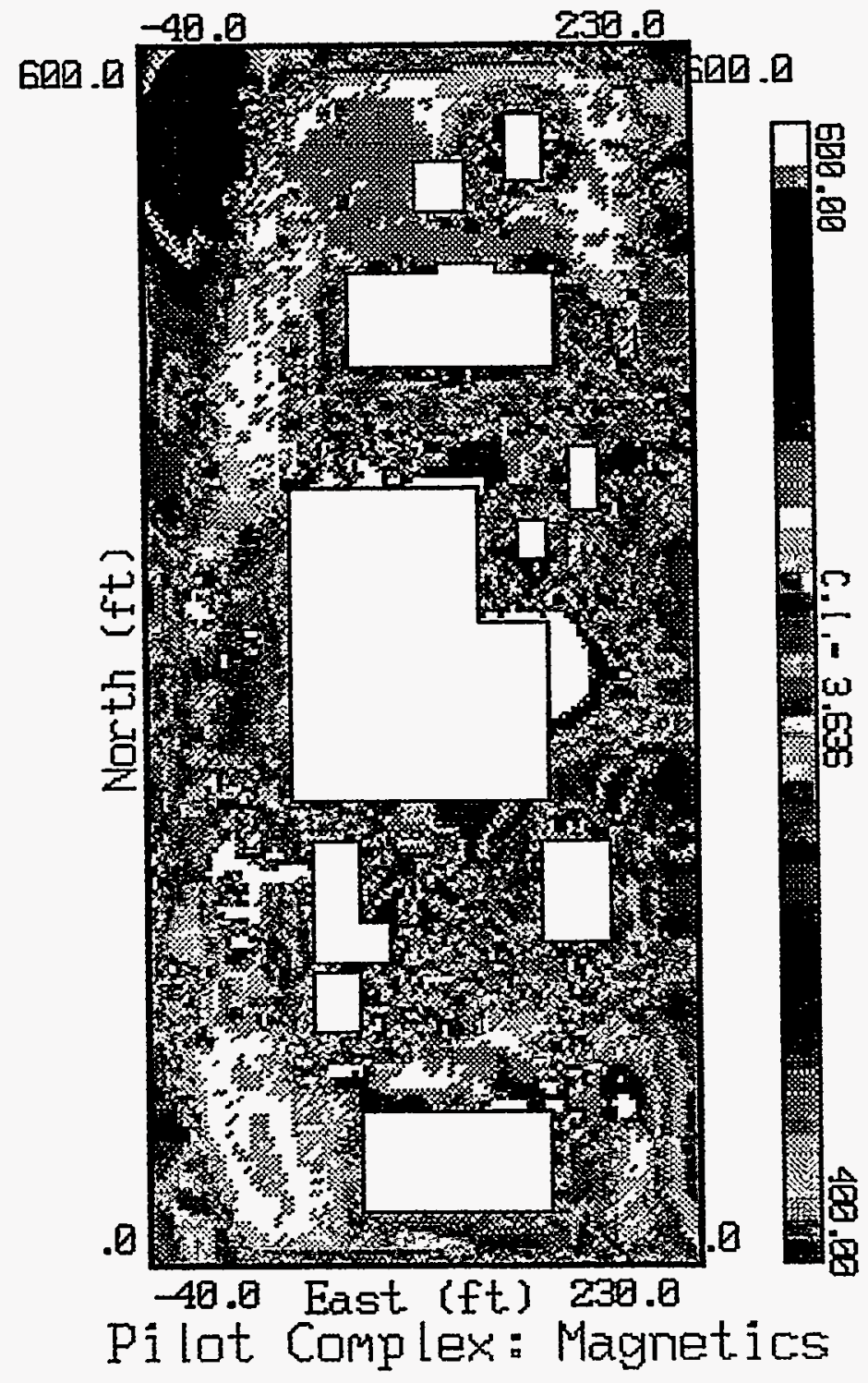

FIGURE 29 Total Magnetic Field Inside the Security Fence 


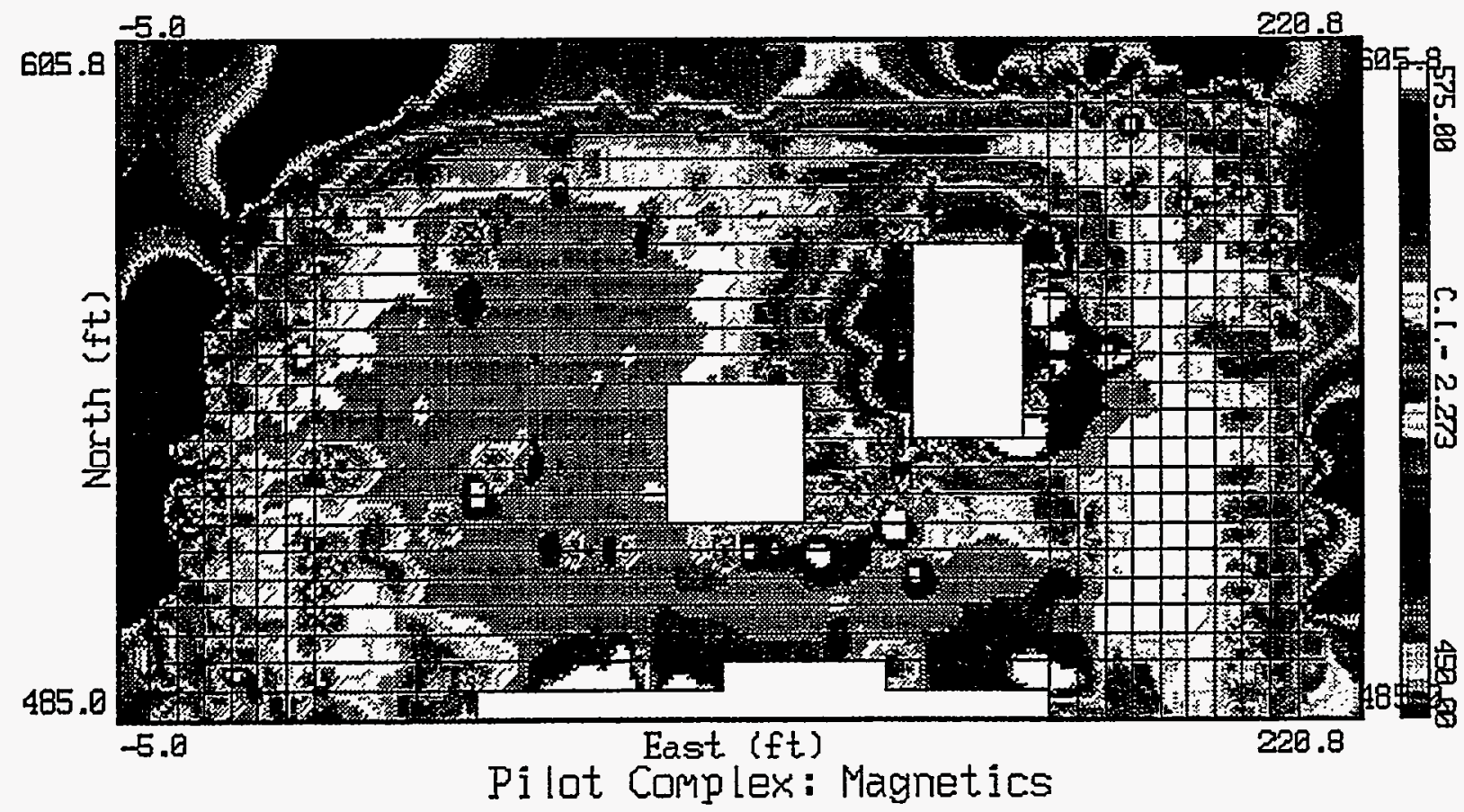

FIGURE 30 Total Magnetic Field Inside the Security Fence from $485 \mathrm{~N}$ to $605 \mathrm{~N}$

observed $15 \mathrm{ft}$ to the west of the western trend, suggesting that it may be associated with the double lines shown in the northwest corner. An east-west lineament is present at $515 \mathrm{~N}$, which is shown in the central part of Figure 30.

An anomaly seen only on two lines, consisting of a positive-minimum pair, is located at $59 \mathrm{E}, 525 \mathrm{~N}$. Three circular anomalies, consisting of two small positives and a negative, are centered around 54E, 567N and are unexplained. An anomalous zone centered around 173E, $547 \mathrm{~N}$ may be caused by Building E5633, although a tightly constrained, circular positive anomaly cannot be explained in terms of a source in the building. Small anomalies within $10 \mathrm{ft}$ of the fence probably have their sources in the fence or in gravel fill near the fence. The anomalies in the northeast corner are associated with fill from a former road.

2. Figure $31-$ Magnetics from $395 N$ to $495 N$. Two lineaments extending south about 20-30 ft east of the western fence extend into this section of the Pilot Plant from the lineaments shown in Figure 30. These lineaments correspond with the features shown in Figure 4; however, a complex magnetic zone in the southwestern quarter of this figure obscures good definition of these lineaments. The trends continue south to the southern limits of Figure 31 . The anomalies along this trend are unusual because they consist of noncontinuous, isolated, circular bulls eyes, separated by quiet magnetic zones. The sources may be characteristic of a long pipe. 


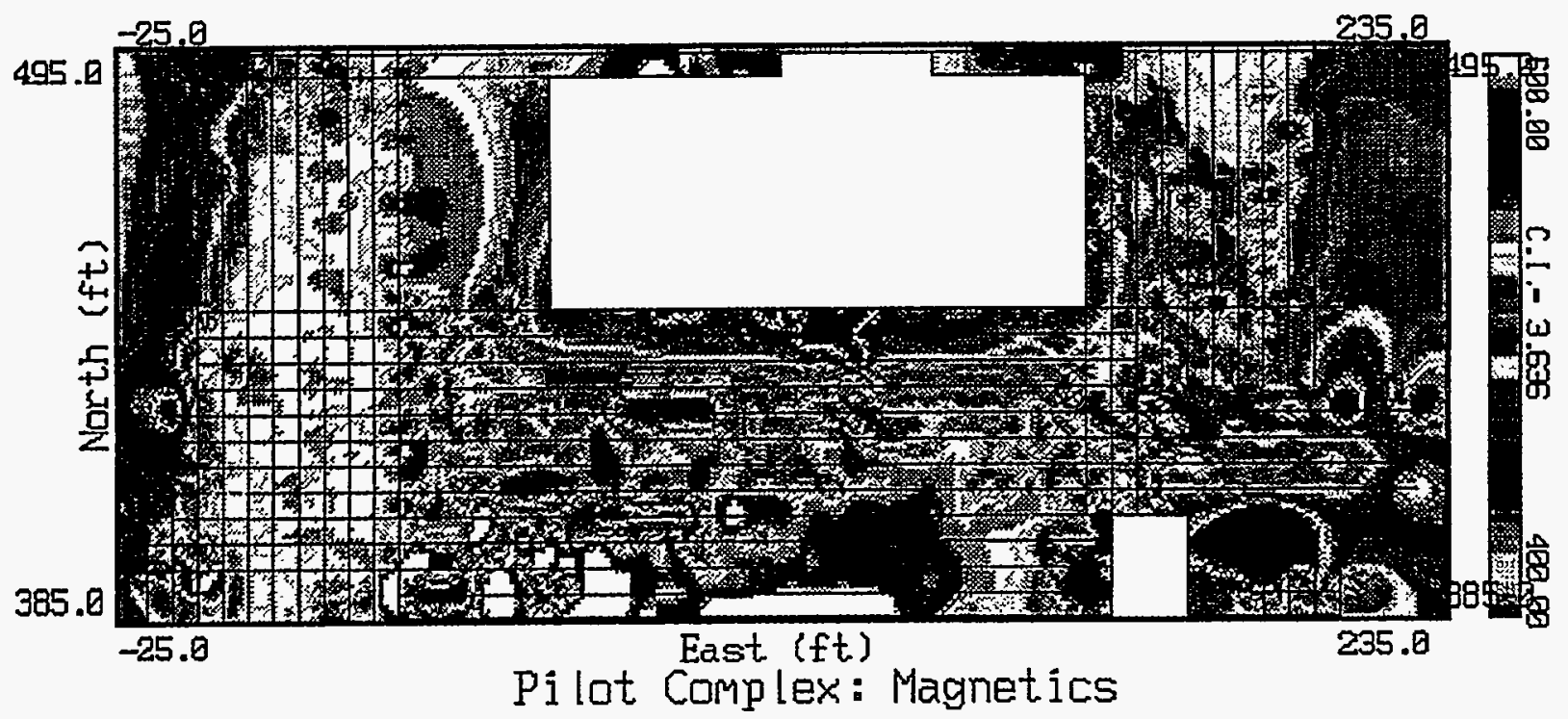

FIGURE 31 Total Magnetic Field Inside the Security Fence from $385 \mathrm{~N}$ to $495 \mathrm{~N}$

The open area north of Building E5625 was surveyed with east-west lines spaced five feet apart. A parking area covered with a concrete slab, measuring $30 \times 20 \mathrm{ft}$ and centered at $398 \mathrm{~N}$, $123 \mathrm{E}$, is covered by a reinforced concrete slab and is anomalous. Magnetic lineaments are observed immediately west of the slab, which may indicate the presence of underground metal piping. An anomaly trending east-west between $410 \mathrm{~N}$ and $415 \mathrm{~N}$, west of the parking area, appears to connect with the north-south linear trend described in item 1, above. An unidentified anomaly beginning at $394 \mathrm{~N}, 70 \mathrm{E}$ trends northwest and appears to connect with these features. Isolated single-line anomalies are located east of Building E5625. Sources of other isolated anomalies east of the slab are not associated with known underground lines.

3. Figure 32 - Magnetics from $215 N$ to $395 N$. This area is occupied primarily by Building E5625. The area between the building and the western fence was surveyed along northsouth profiles spaced five feet apart. Five isolated positive anomalies are too large to be associated with fill. The more prominent anomalies include one centered at $325 \mathrm{~N}, 19 \mathrm{~W}$, which can be seen on three lines and is associated with a large, paired, negative anomaly. A second anomaly at $309 \mathrm{~N}, 12 \mathrm{E}$ is observed on two lines. A third anomaly at $240 \mathrm{~N}, 10 \mathrm{~W}$ is observed on only one line. A fourth anomaly at $235 \mathrm{~N}, 3 \mathrm{E}$ is seen on two lines.

Positive anomalies observed in the space northeast of the building are associated with pipes and sewer lines, but they are difficult to differentiate.

4. Figure $33-$ Magnetics from $-5 N$ to $225 N$. Because many of the lines are close to buildings, a large number of the anomalies shown in this area are due to interference. The major anomaly in this area is a large, three-limbed, positive anomaly, centered at $194 \mathrm{~N}, 10 \mathrm{E}$. The 


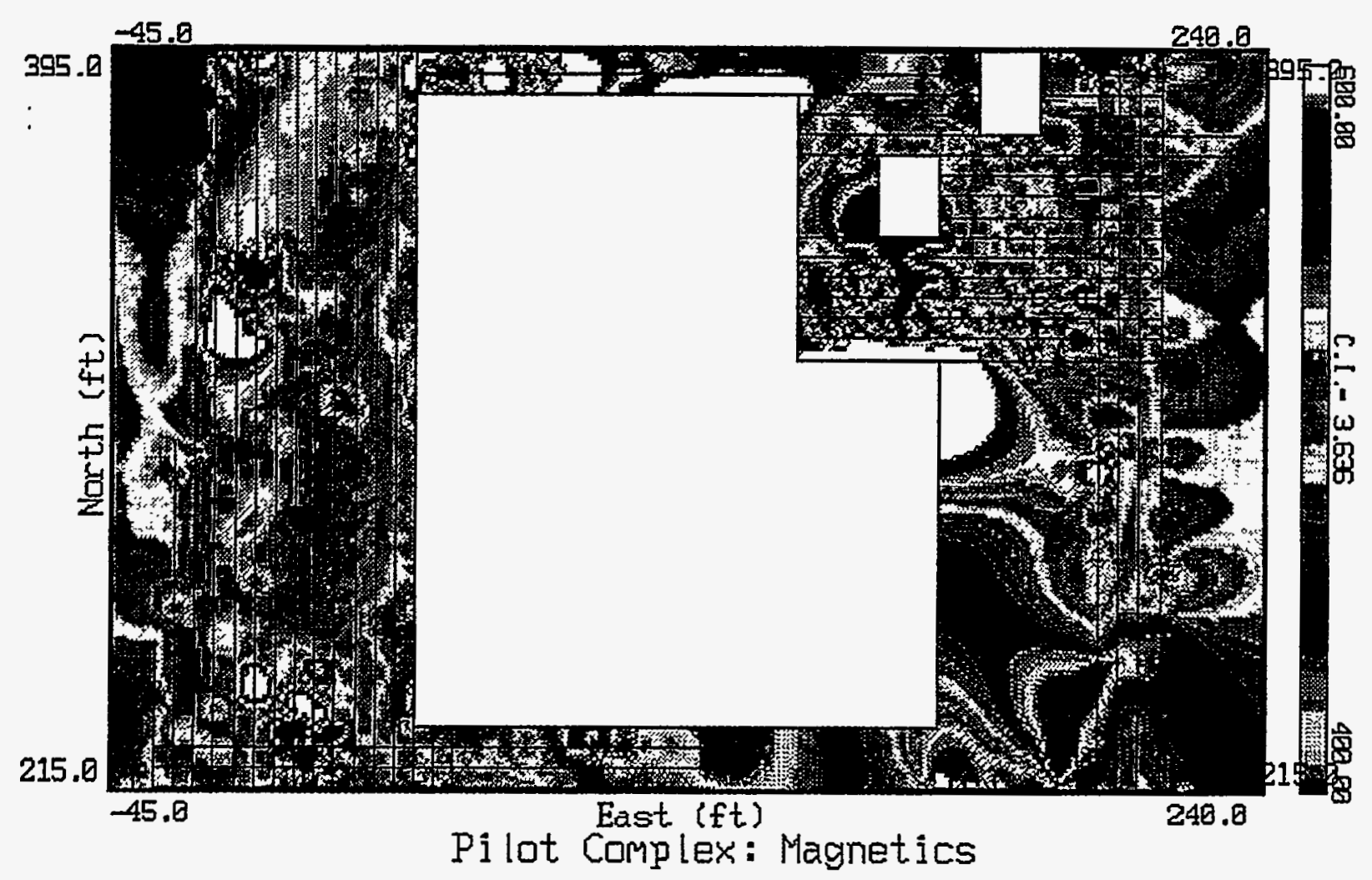

FIGURE 32 Total Magnetic Field Inside the Security Fence from $215 \mathrm{~N}$ to $395 \mathrm{~N}$

anomaly trends westward from Building E5618 and may be associated with that building's former functions.

The area west of Building E5617 is filled with small positive anomalies that may be related to fill material. Between Buildings E5618 and E5621, an intricate pattern of small anomalies is unexplained. The anomalies are also obvious on the map in Figure 29 and should be of concern during remediation. Some of the anomalies occur along lineaments, which may suggest the presence of buried pipes (see Figure 4).

The southeast quadrant of area 4 bears many of the same characteristics as described in item 2, above. The eastern margin of the interior is a former road bed, which may explain many of the anomalies. In fact, zones of small positive anomalies, particularly where they occur as lineaments $20-30 \mathrm{ft}$ wide, probably represent former road beds.

The southwestern quadrant of this area contains a broad, magnetic, positive anomaly, which may indicate road-bed material. 


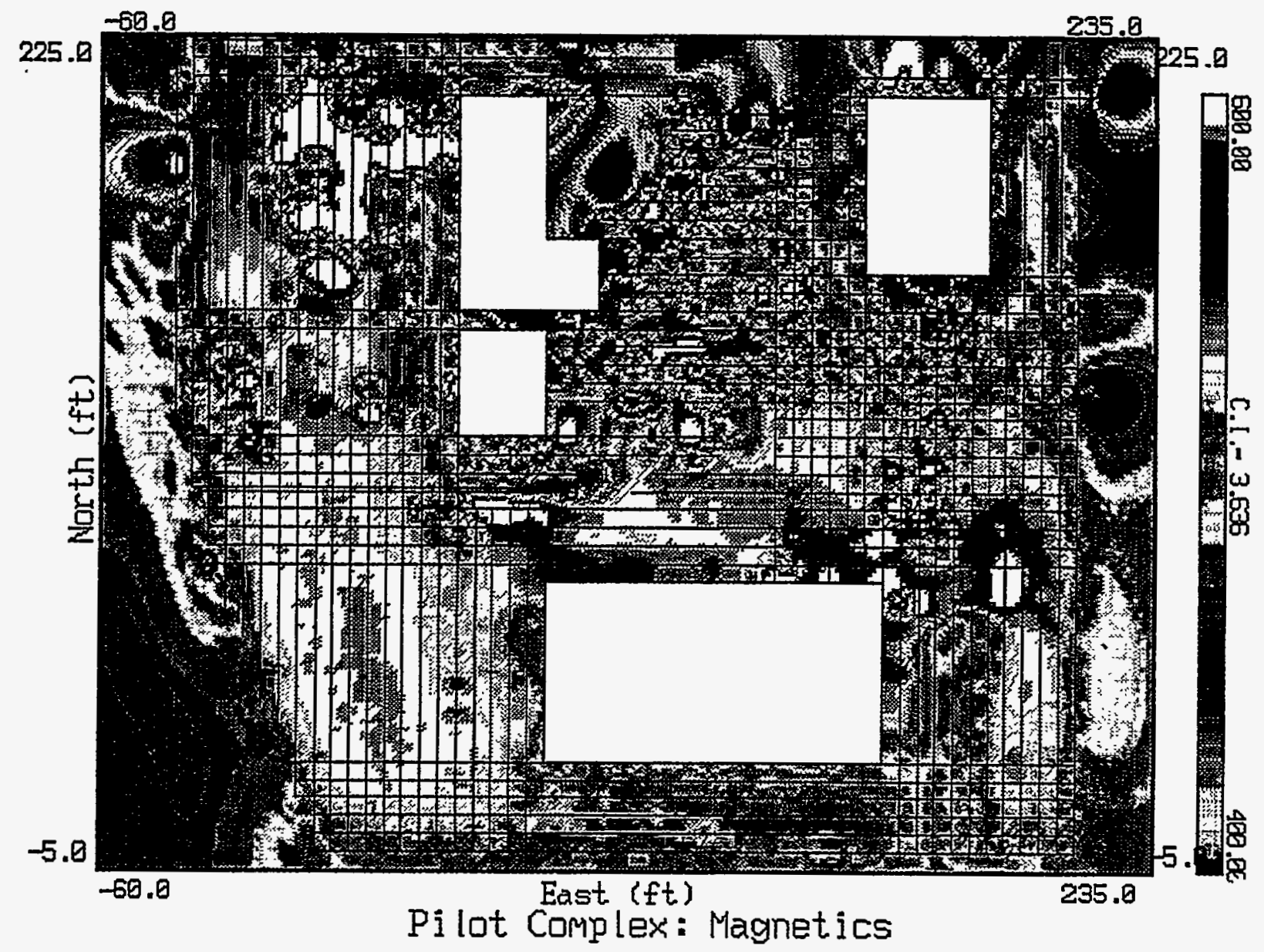

FIGURE 33 Total Magnetic Field Inside the Security Fence from $5 S$ to $225 \mathrm{~N}$

\subsection{Electromagnetic Profiling with the EM31 and EM61}

Electrical properties of the earth were measured inside the fence with two electromagnetic instruments, including the EM31 (with output read in conductivity) and the EM61 (with output in millivolts [mV]).

\subsubsection{Conductivity Measurements with the EM31}

Electromagnetic data were collected along east-west and north-south profiles spaced five feet apart. The regional map of the interior (Figure 34) indicates several prominent anomalies not shown on the magnetic maps. Line locations are shown on the three detailed maps in Figures 35-37. Data were acquired on a digital data logger at a 0.5 -s sampling rate, resulting in a mean station spacing of $1.5 \mathrm{ft}$. Because EM 31 is extremely sensitive to aboveground interference, most of the anomalies observed in the interior of the fence are caused by the fence and buildings. 


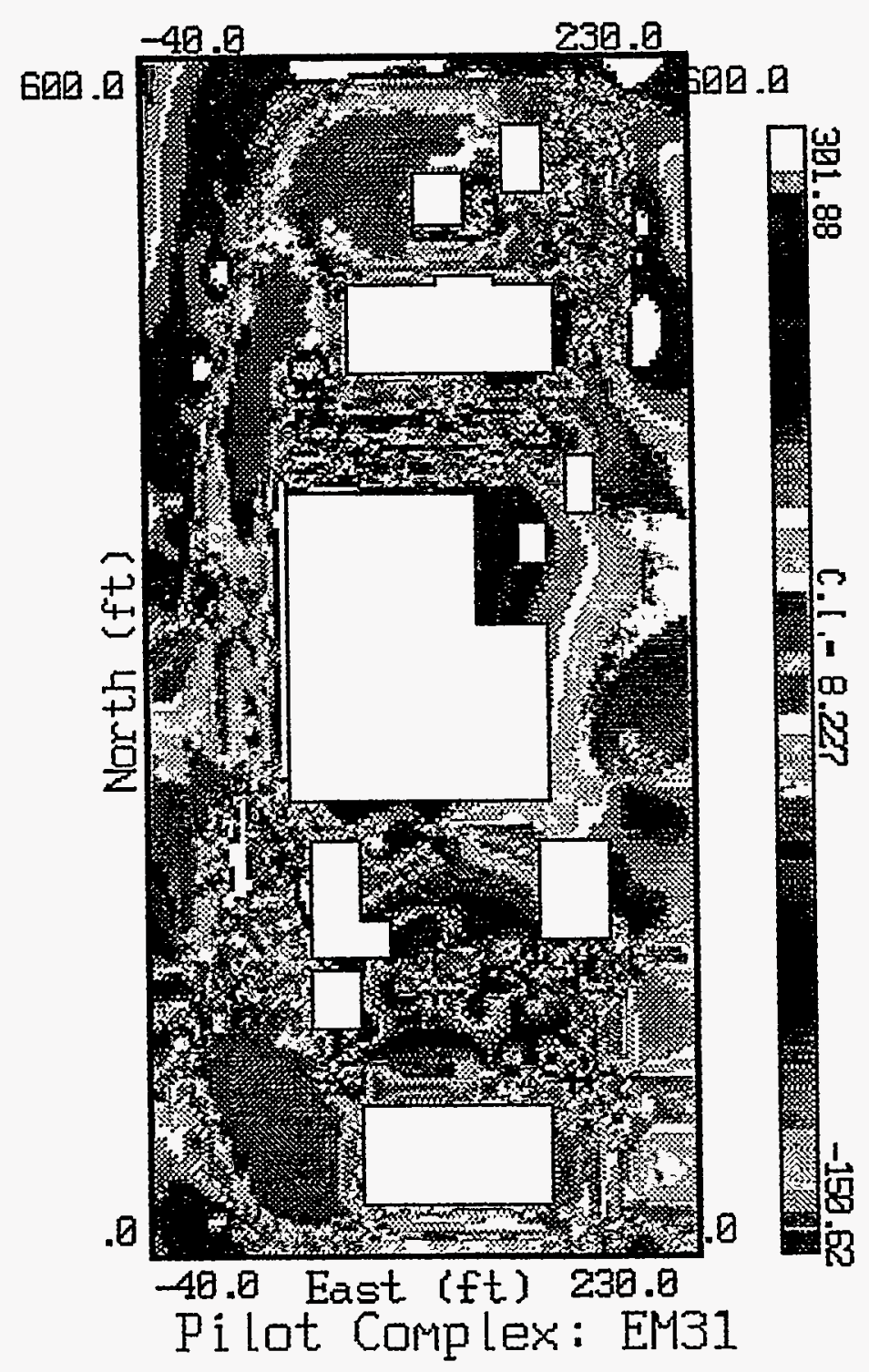

FIGURE 34 Regional EM31 Anomalies Inside the Security Fence

1. Figure $35-$ Conductivity from $485 \mathrm{~N}$ to $600 \mathrm{~N}$. One anomaly is observed in the western half of this area, centered at $504 \mathrm{~N}, 47 \mathrm{E}$. This anomaly is a well-defined lineament trending to the northwest and is associated with an equivalent anomaly observed on the magnetic map. The anomalies are probably caused by a cast-iron drain pipe (shown in Figure 4).

The eastern half of this area is full of EM31 anomalies that are caused by as many as four sewer lines, road-bed fill, and aboveground material.

2. Figure 36 - Conductivity from $225 \mathrm{~N}$ to $495 \mathrm{~N}$. Little useful information about this area could be obtained with the EM31 because of fence and building interference, although the area 


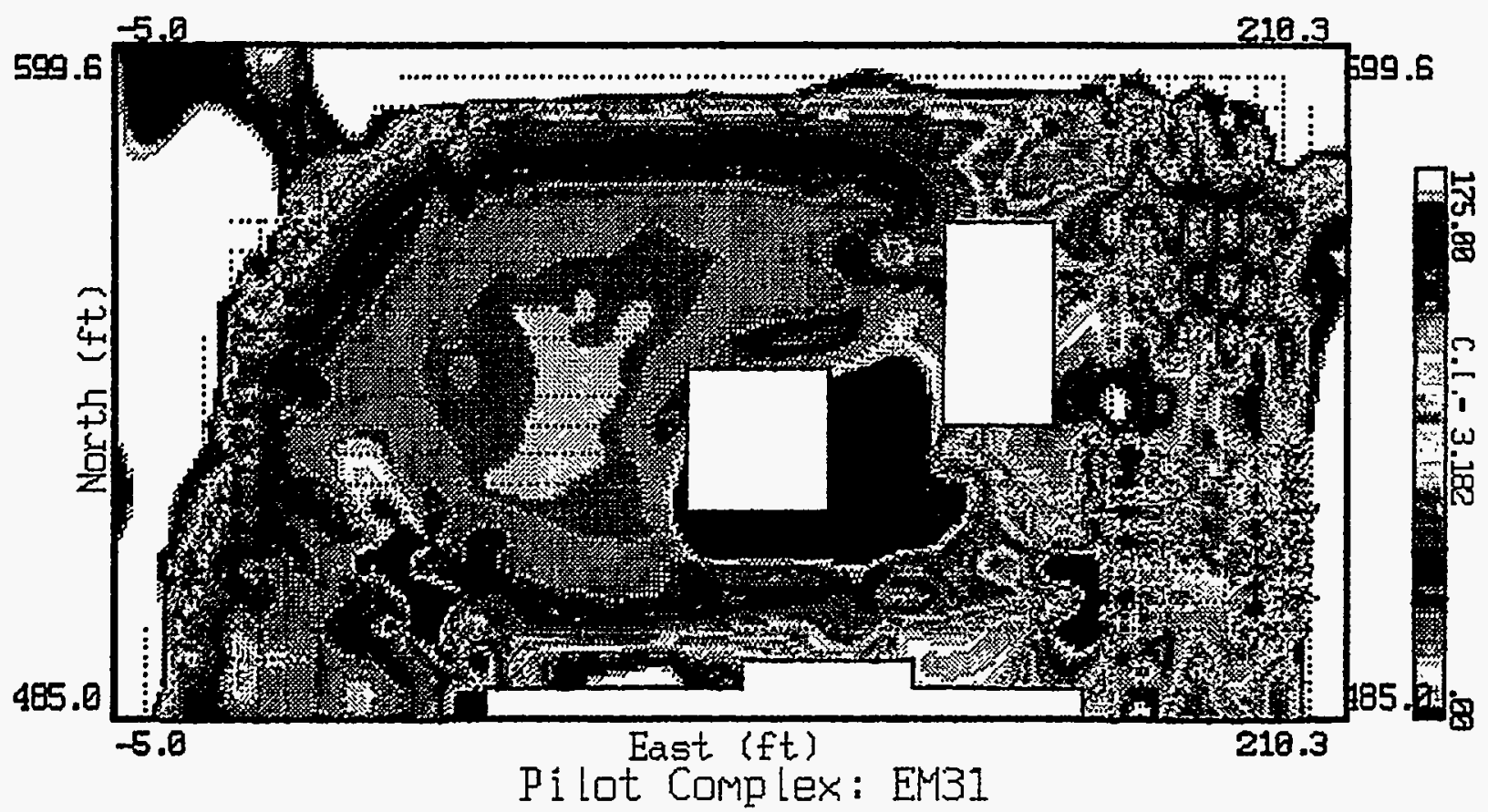

FIGURE 35 EM31 Anomalies Inside the Security Fence from $485 \mathrm{~N}$ to $600 \mathrm{~N}$

does contain two recognizable anomalies. One is observed along three north-south lines and is centered at $336 \mathrm{~N}, 14 \mathrm{~W}$. The anomaly has no surface feature, although it is only about $10 \mathrm{ft}$ from the fence. A smaller, also unexplained, feature is located at $237 \mathrm{~N}, 4 \mathrm{E}$.

3. Figure 37 - Conductivity from $-5 N$ to $235 N$. An anomaly complex centered at $196 \mathrm{~N}$, $23 \mathrm{E}$ is associated with similar anomalies observed by means of the magnetic and EM61 surveys. The EM31 anomaly contains both positive and negative features. A stream conduit caused a positive lineament in the southeast corner of the figure.

\subsubsection{Millivolt Measurements with the Time Domain EM61}

Data acquired by means of the EM61 metal detector (Figure 38), and detailed maps shown in Figures 39-41, show a dramatic improvement in discriminating buried metals adjacent to the buildings in the Pilot Plant complex. Survey lines shown in Figures 39-41 were acquired with north-south lines on the west and east, with east-west lines on the north and south ends of the interior, and, where possible, between buildings.

1. Figure 39 - Millivolt Measurements from $400 \mathrm{~N}$ to $600 \mathrm{~N}$. The map of EM61 data shown in Figure 39 displays many of the same features evidenced in the magnetic and EM31 illustrations, although more subtle lineaments are immediately obvious, and the obvious lineaments 


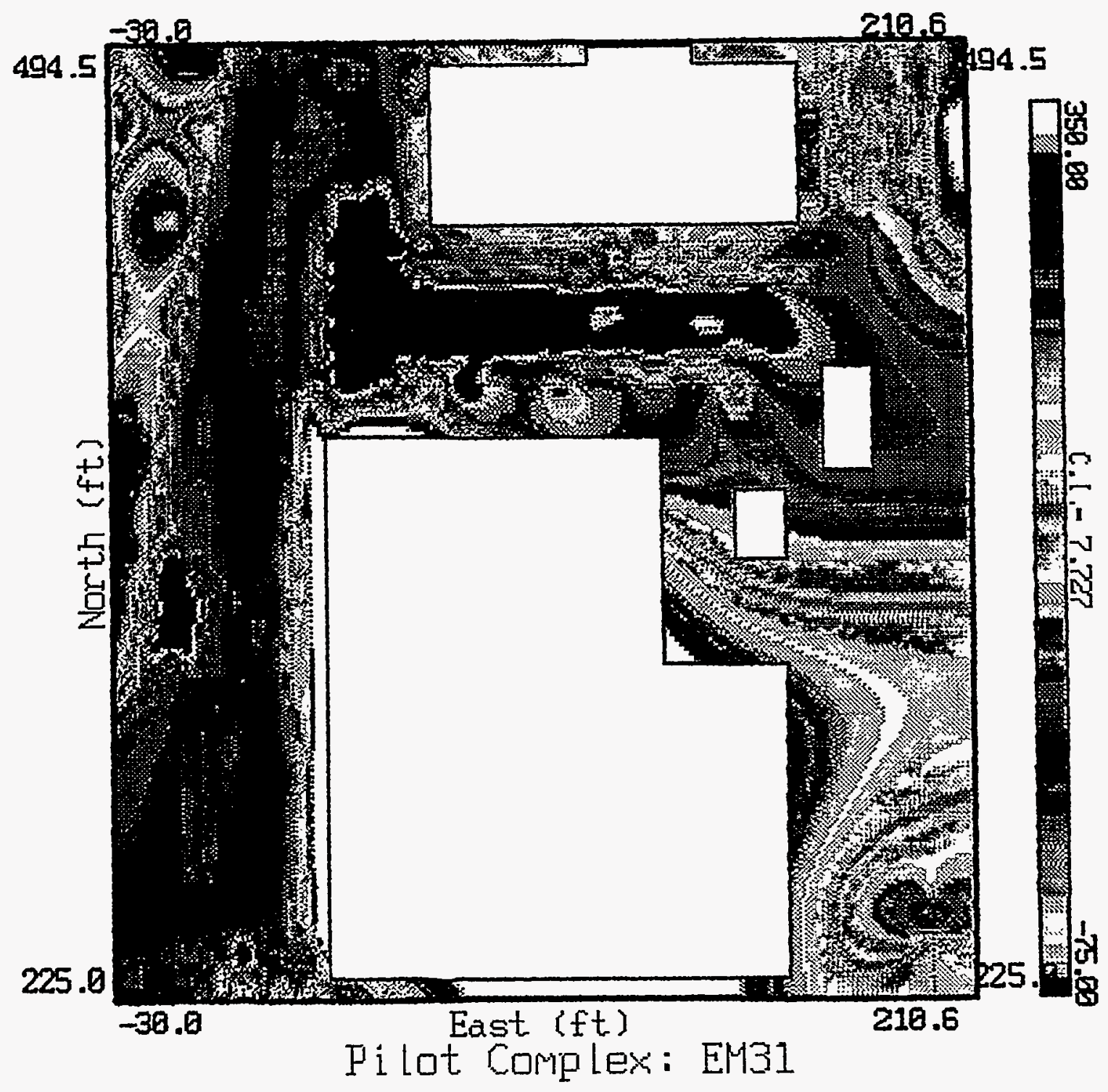

FIGURE 36 EM31 Anomalies Inside the Security Fence from $225 \mathrm{~N}$ to $495 \mathrm{~N}$

are more prominent. The rectangular sewer and pipeline network is clearly marked, up to within several feet of building walls. One lineament is, however, less well marked, and that is the northwest lineament extending from the northwest corner of Building E5625 to the former incinerator. A buried metal pipe caused this anomaly. Surface debris caused large circular anomaly centered at $490 \mathrm{~N}, 14 \mathrm{E}$. The source of a small circular anomaly at $524 \mathrm{~N}$, 60 east is unknown.

An east-west lineament between $575 \mathrm{~N}$ and $580 \mathrm{~N}$ is caused by a buried pipe. The lineament connects with the north-south lineament in the northwest corner at coordinates $570 \mathrm{~N}, 16 \mathrm{E}$. Although this anomaly is partially obscured north of building E5633, it appears to continue to the east, where it crosses a north-south lineament. 


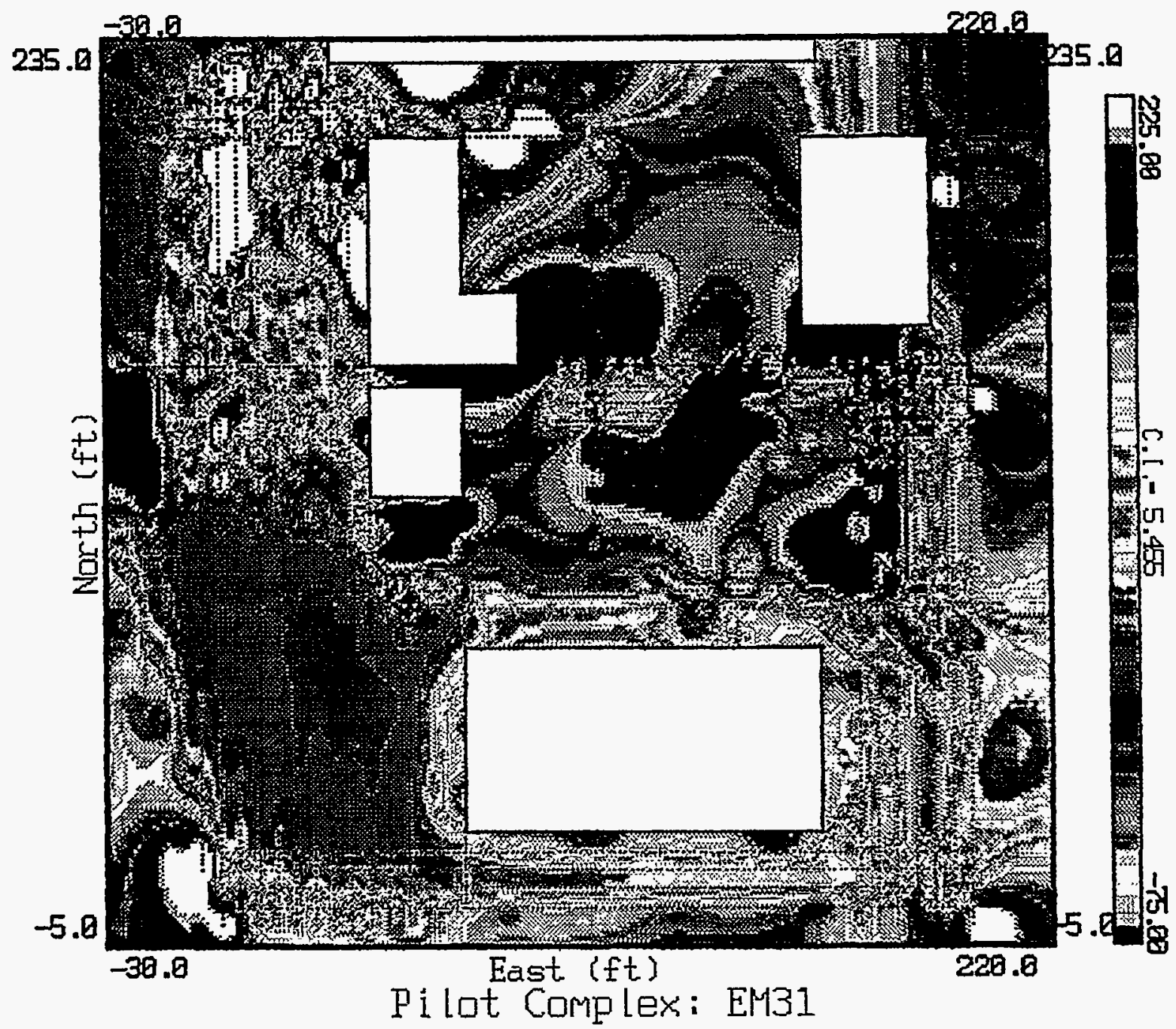

FIGURE 37 EM31 Anomalies Inside the Security Fence from $5 S$ to $235 \mathrm{~N}$

A north-south lineament in the northeast corner of the survey area extends northward without break from $430 \mathrm{~N}, 200 \mathrm{E}$ to $589 \mathrm{~N}, 200 \mathrm{E}$. This feature is also part of an apparent buried pipe complex that extends around the perimeter of the buildings in the northern third of the complex.

The area between $400 \mathrm{~N}$ to $445 \mathrm{~N}$ (which lies between Buildings E5627 and E5625) is dominated by a large metallic object under the apron north of Building E5625. The anomaly is probably concrete reinforcement. If there were tanks or other objects buried beneath this apron, they would not be seen because of the amplitude of the interference. Other large positive anomalies adjacent to buildings may also be caused by concrete reinforcement. An east-west anomaly centered at $440 \mathrm{~N}, 80 \mathrm{E}$ is separated from the main east-west band of anomalies. The source of this anomaly is unknown, but it may be related to reinforced surface concrete; nevertheless, it should be investigated further. 


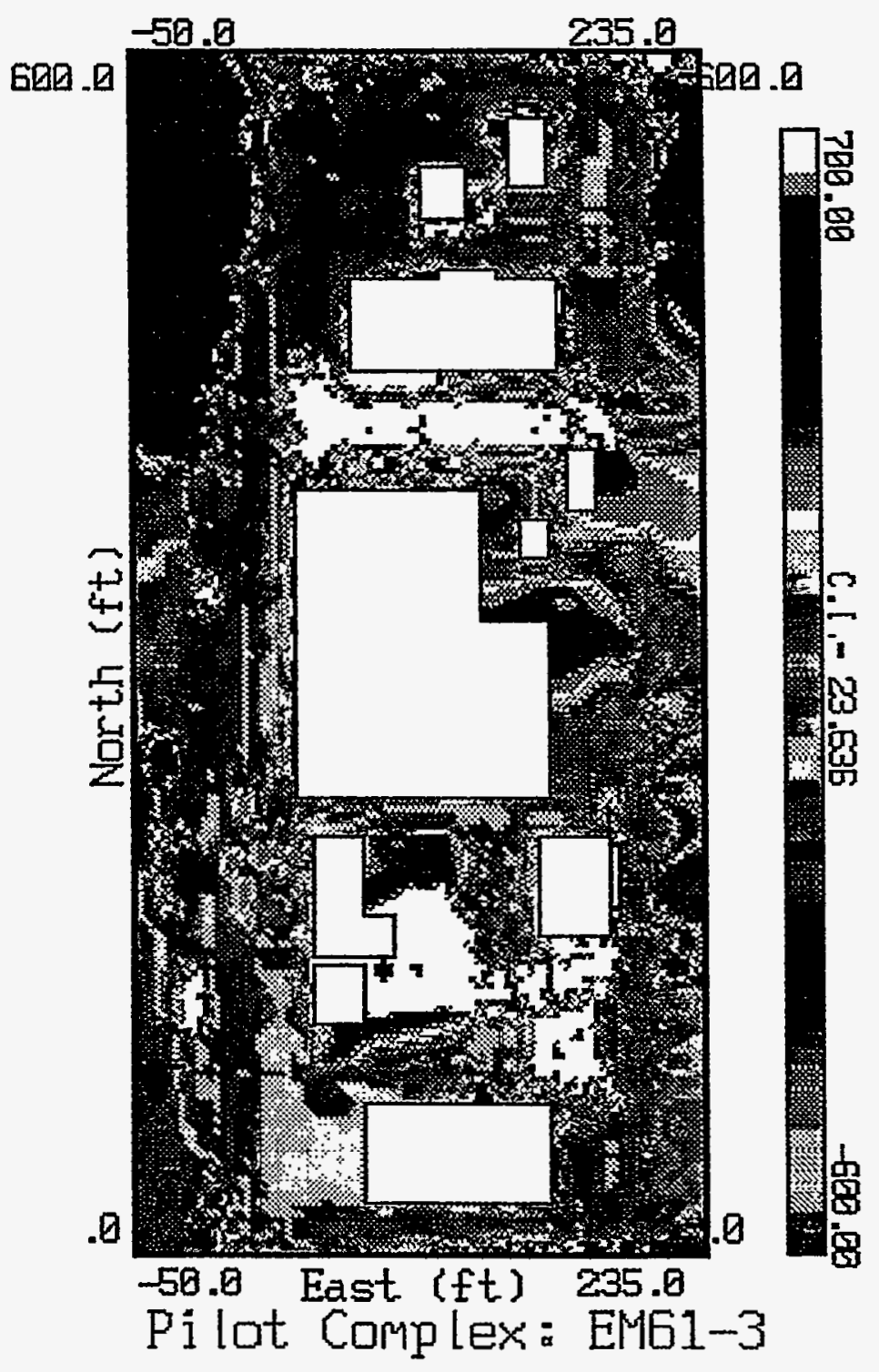

FIGURE 38 Regional EM61 Anomalies Inside the Security Fence

2. Figure 40-Millivolt Measurements from $200 \mathrm{~N}$ to $400 \mathrm{~N}$. Building E5625 occupies the interior of this area. Therefore, only north-south profiles on the west and east were run. Two metallic objects are observed in the northwest quadrant of this region, one centered at 10W, 395N and a second at $11 \mathrm{~W}, 335 \mathrm{~N}$. Both anomalies are observed on more than one profile and are unexplained.

The eastern edge of the area contains a large metallic object extending west from the east fence and centered at $214 \mathrm{~N}, 268 \mathrm{E}$. A second anomaly in the east is located at $201 \mathrm{~N}, 190 \mathrm{E}$. Without further field inspection, these anomalies are unexplained. 


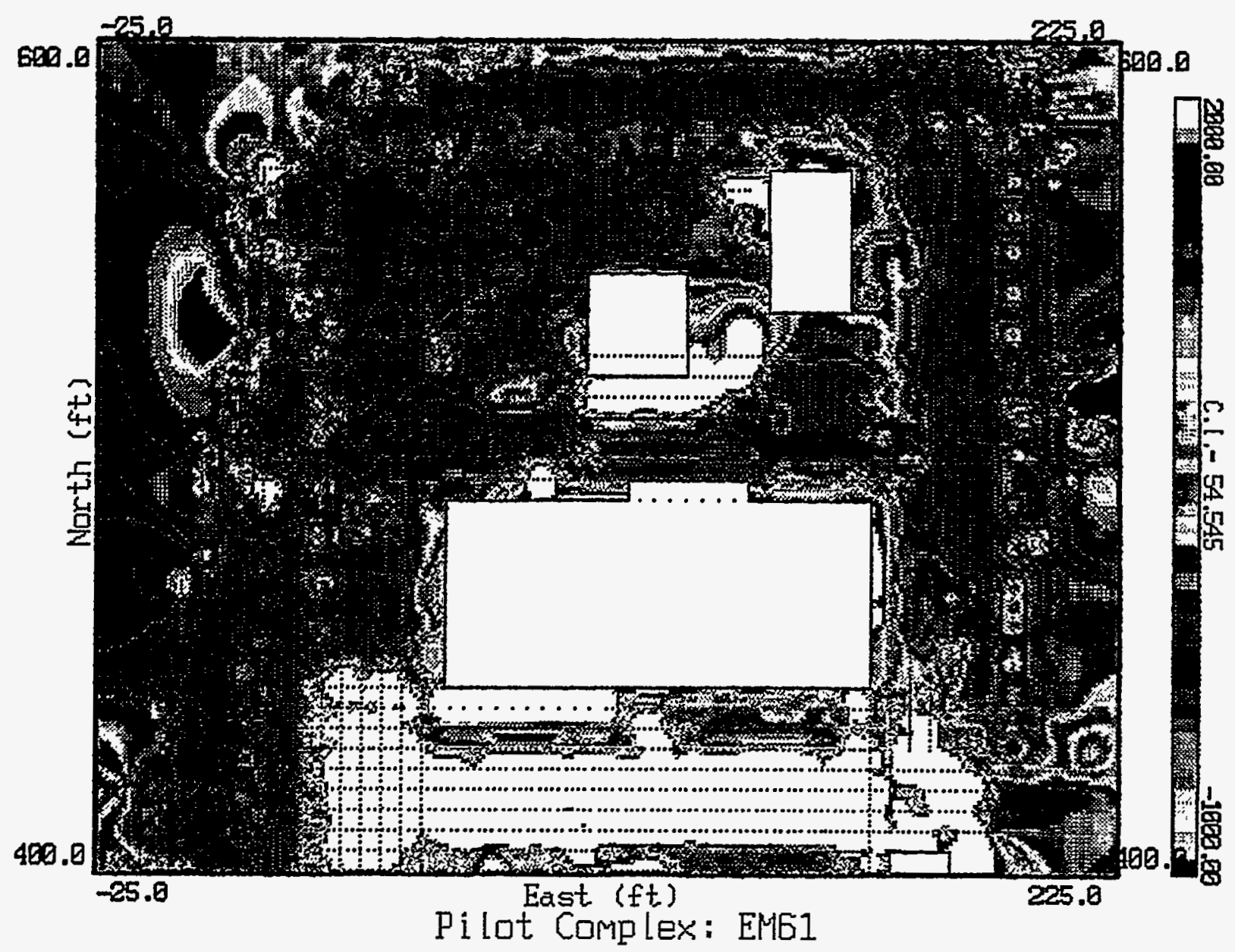

FIGURE 39 EM61 Anomalies Inside the Security Fence from $400 \mathrm{~N}$ to $600 \mathrm{~N}$

An anomaly located at $200 \mathrm{~N}, 23 \mathrm{E}$ in the southwest quadrant is produced by the same source described in Section 3.1.

3. Figure 41 - Millivolt Measurements from $0 N$ to $200 N$. Three well-defined anomalies caused by buried metals (centered at $201 \mathrm{~N}, 22 \mathrm{E} ; 197 \mathrm{~N}, 5 \mathrm{~W}$; and $167 \mathrm{~N}, 8 \mathrm{E}$ ) are clustered in the northwest corner of this area. This cluster has equivalent magnetic anomalies described in Section 3.1; however, the EM61 metal detector more clearly defined these anomalies. Closure of the EM61 anomalies provides better definition of subsurface sources.

The eastern half of the area is dominated by anomalies, which were observed in traverses crossing concrete slabs. The slabs are reinforced with rebar. Two north-south lineaments in the southeast comer are associated with steam conduits.

The west and southwestern section of the area contains a large, well-defined anomaly, centered at $126 \mathrm{~N}, 23 \mathrm{~W}$, with its long axis oriented north-south. The source of this anomaly will need to be checked in the field, although it is near a feature shown in Figure 4 that appears to mark 


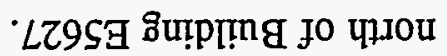

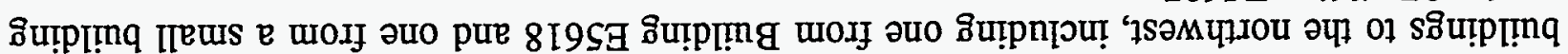

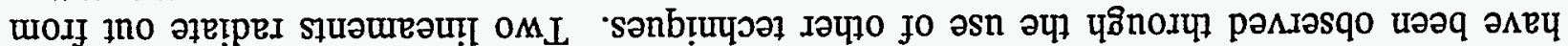

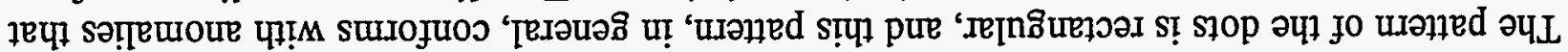

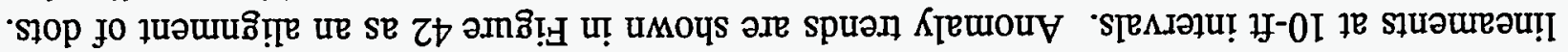

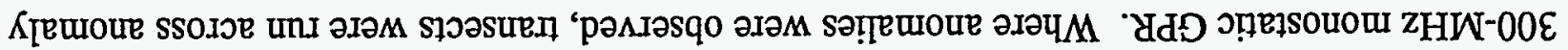

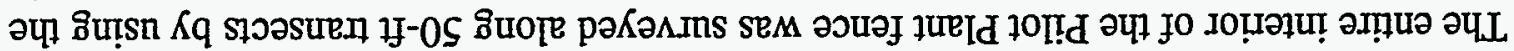

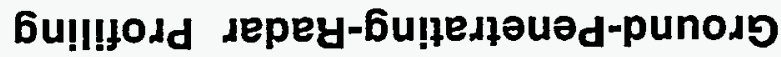

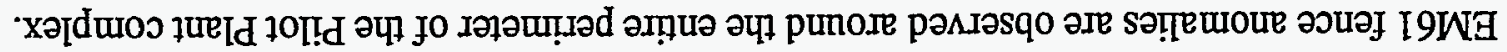

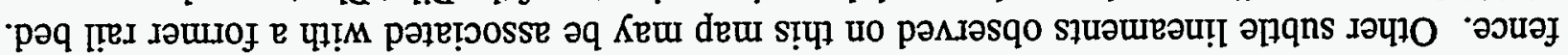

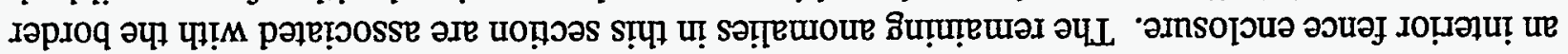

NOOt of NOOZ سodf әэuә

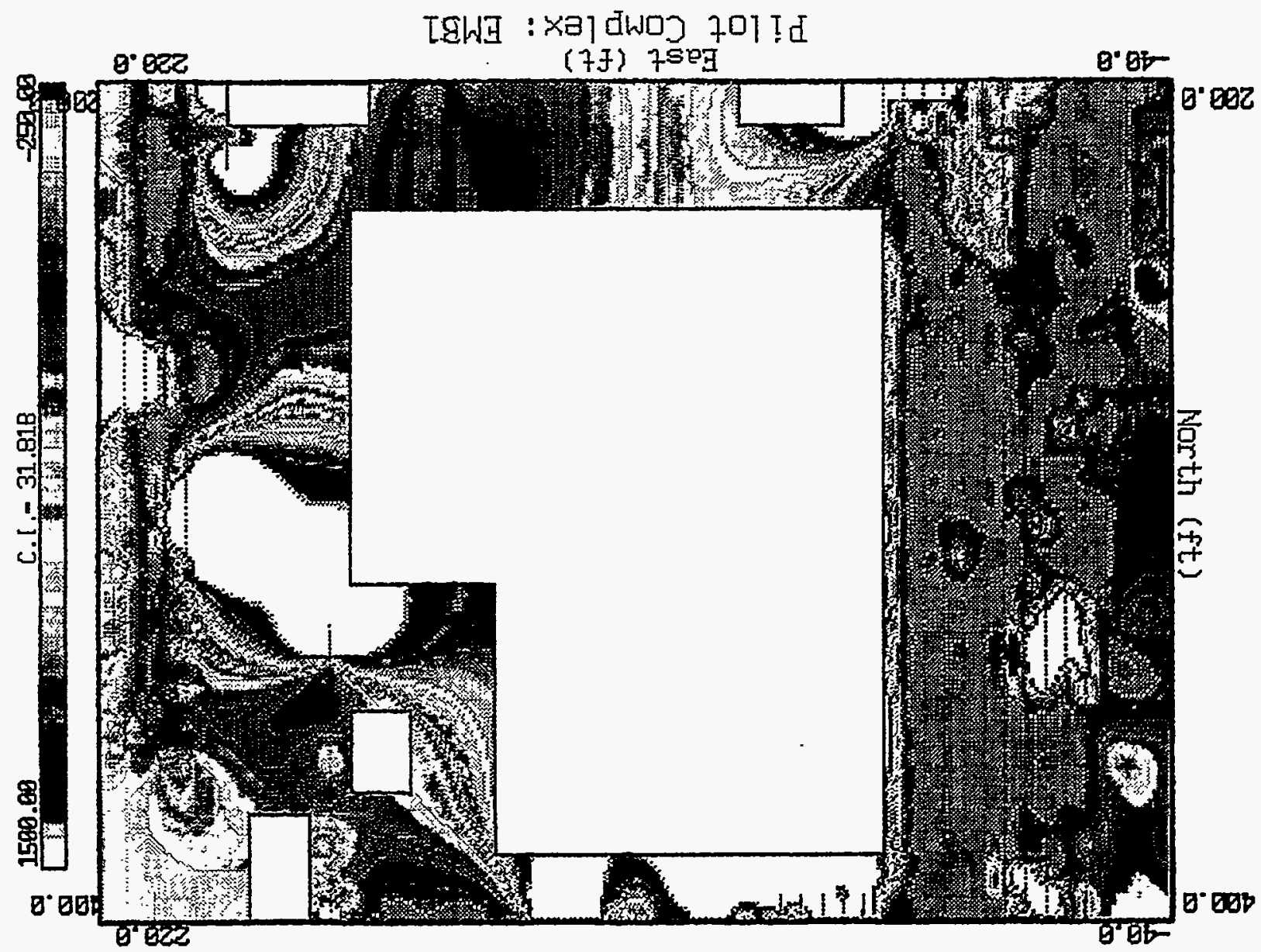




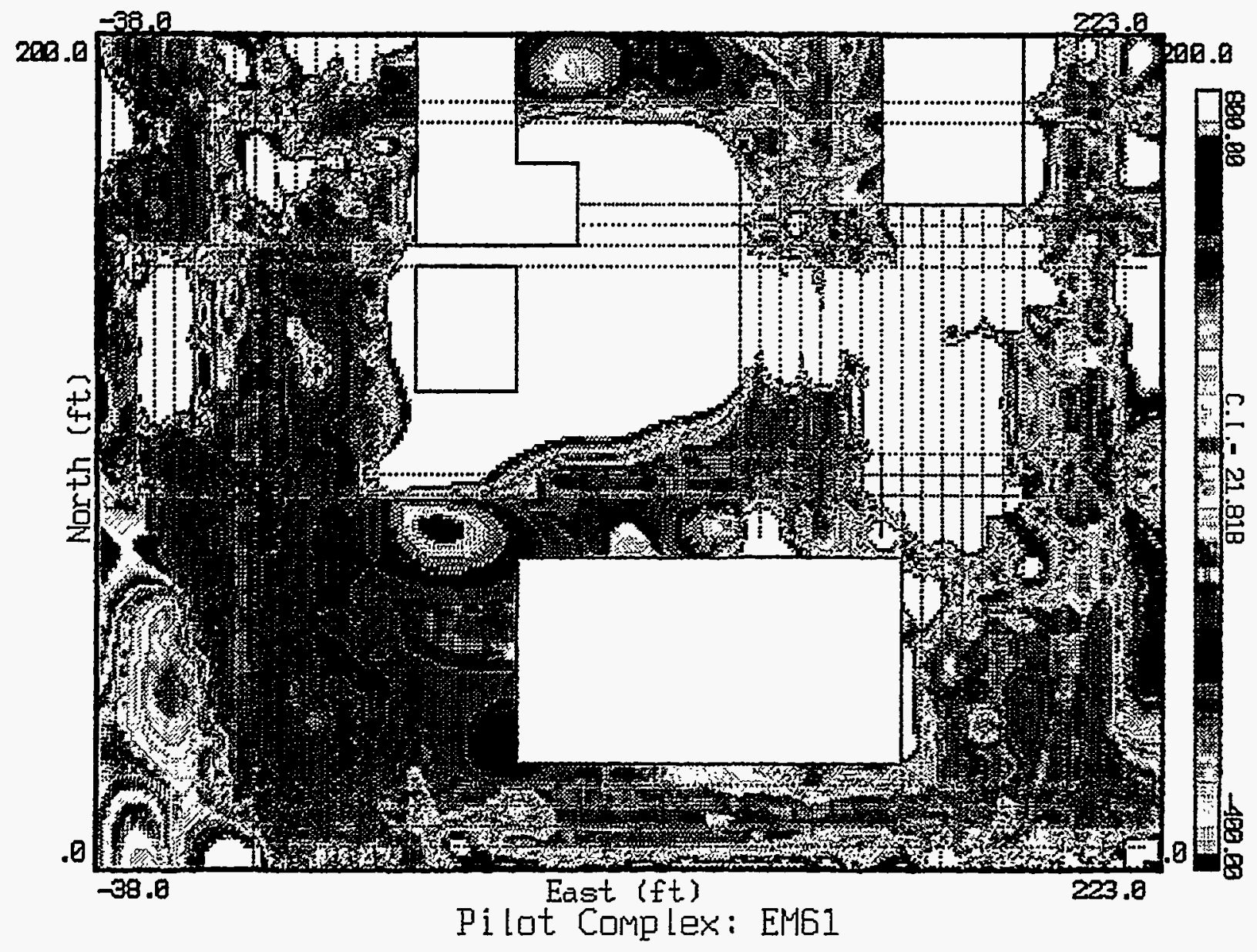

FIGURE 41 EM61 Anomalies Inside the Security Fence from oN to 200N 


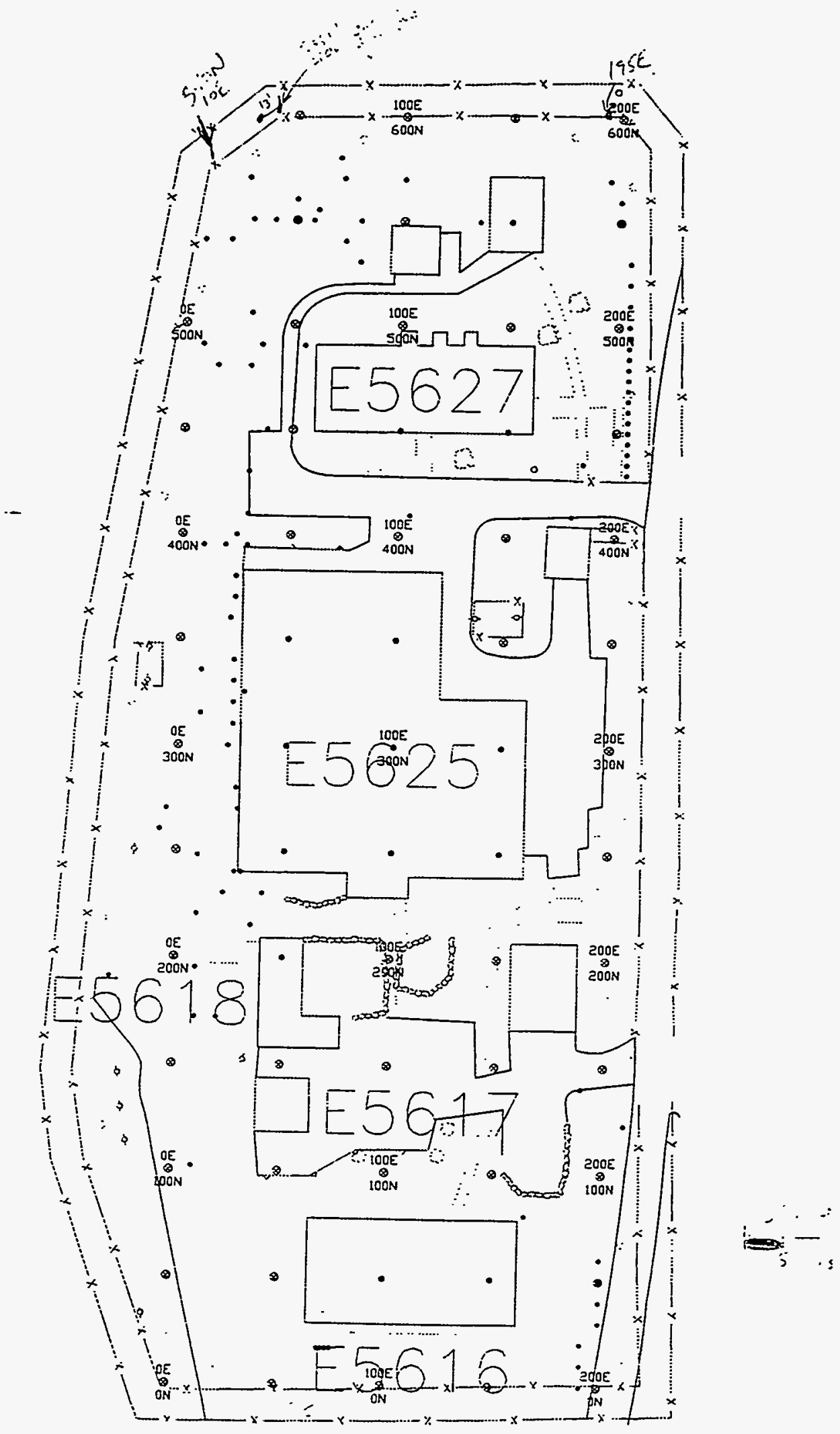

FIGURE 42 Locations of GPR Anomalies Caused by Buried Utilities and Unidentified Objects Inside the Security Fence 


\section{Discussion}

\subsection{Surveys Outside the Security Fence}

Four geophysical technologies, including magnetics detection, EM31 (electrical conductivity), EM61 (metallic induction, in $\mathrm{mV}$ ), and ground-penetrating radar, have been applied to study the Pilot Plant complex, exterior to the security fence, in an attempt to map subsurface utilities (such as sewer and pipelines) and the hydrogeologic framework. Areas of the drainage basin outside the fence were included so that potential contaminants introduced in the Pilot Plant could be discriminated from sources that might have occurred outside the fence.

\subsubsection{Hydrogeologic Framework}

The hydrogeologic framework has been defined best by GPR data (see Figures 25-28). The Pilot Plant complex rests on several feet of fill material, which was used to raise the grade of the site above the fine-grained alluvial sediments deposited by the west branch of Canal Creek. The GPR data have been correlated with well $\mathrm{CC} 17$ to indicate that near-surface, flat-lying sands and clays are contained in an east-west trending paleochannel that extends $25-30 \mathrm{ft}$ beneath the southern third of the Pilot Plant. The GPR reflector at the base of the paleochannel corresponds to a dipping sandy-clay bed, described in well $\mathrm{CC} 17$ at a depth of $16 \mathrm{ft}$ (Table 2).

Sediments above the reflector are all flat-lying, whereas sands below the reflector dip toward the center of the paleochannel. The section above the strongly dipping clay reflector consists primarily of fine sand, but below the reflector, the sands become more coarse-grained and gravely. We interpret the sands above the reflector to be surficial aquifer, whereas the sands and gravels below the reflector are probably Canal Creek aquifer. Well data indicate that the coarse-grained sands extend to depths of $40.6 \mathrm{ft}$.

The GPR profiles shown in Figures $25-28$ provide a detailed image of the 200 -ft-wide paleochannel striking east-west across the southern third of the site. The south bank of the buried valley serves, inadvertently, as the route of a storm-sewer line traversing the site. The paleochannel will play a major role in controlling the path of groundwater flow across the southern half of the site. The electromagnetic anomaly over the valley indicates that the conductivity of the fill material is low, and therefore it is probably sand.

\subsubsection{Subsurface Utilities from Geophysical Measurements Outside the Fence}

Three magnetic lineaments in the northwest corner of the survey area (Figure 9), west of the west bank of Canal Creek, do not have corresponding EM31 anomalies (Figure 18). Thus, all anomalies on the west bank of the west branch of Canal Creek north of Fleming Road are probably 
due to surficial objects. Therefore, all buried utilities observed in the geophysical study, except for lineaments observed along Fleming Road, occur on the east shore of the west branch of Canal Creek and are associated with operations in the Pilot Plant or in the Edgewood area east of the Pilot Plant.

To organize a description of the large number of underground facilities around the Pilot Plant, those appearing in Figure 3 have been numbered, starting with lines near the northeast corner of the exterior fence and continuing clockwise around the complex. Descriptive data appear in Table 3. If an anomaly is present and is believed to be associated with the facility, the technology space contains an "x."

Geophysical data also indicate that buried facilities are present in five areas where none are indicated on Figure 3. These areas are listed below.

1. Figure 10 - a magnetic and EM31 anomaly radiating out from the northwest corner of the fence.

2. Figure 11 - a magnetic and EM31 anomaly (110W, 590N), extending out to the northeast from the fence, may be caused by extensions of interior pipes shown in Figure 4.

TABLE 3 Status of Geophysical Anomalies at Buried Facilities Outside the Security Fence (taken from Figure 3)

\begin{tabular}{|c|c|c|c|}
\hline No. & Mag & EM31 & Comments \\
\hline 1 & $x^{a}$ & $\mathbf{x}$ & strong positive lineament \\
\hline 2 & $x$ & $\mathbf{x}$ & strong positive lineament \\
\hline 3 & $?$ & $?$ & scattered anomalies, no lineament \\
\hline 4 & $\mathbf{x}$ & $x$ & prominent $E-W$ lineament \\
\hline 5 & $x$ & $x$ & prominent E-W lineament \\
\hline 6 & $\mathbf{x}$ & $x$ & prominent lineament south of Bldg E5654 \\
\hline 7 & $x$ & $x$ & prominent SW lineament \\
\hline 8 & $x$ & $x$ & strong positive double lineaments \\
\hline 9 & $n d^{b}$ & nd & inaccessible \\
\hline 10 & nd & nd & inaccessible \\
\hline 11 & $x$ & nd & fence interference, possible anomaly \\
\hline 12 & $x$ & nd & fence interference, possible anomaly \\
\hline
\end{tabular}

a See text for explanation.

b No data. 
3. Figure 12 - complex east-west magnetic and EM31 lineaments extending out from fence immediately south of Building E5609.

4. Figure 13 - a prominent magnetic and EM31 lineament extending to the southeast, near the southeast corner of the fence.

5. Figure 14 - a strong magnetic and EM31 lineament trending eastwest as a result of a recently installed sewer line.

\subsection{Subsurface Utilities from Geophysical Surveys Inside the Security Fence}

Underground facilities contained within the Pilot Plant fence, as shown in Figure 4, have also been numbered, starting with lines near the northeast corner of the fence and continuing clockwise around the complex. If an anomaly is present, the technology space contains an "x."
TABLE 4 Status of Geophysical Anomalies at Buried Facilities Inside the Security Fence (taken from Figure 4)

\begin{tabular}{|c|c|c|c|c|}
\hline No. & Mag & EM31 & EM61 & GPR \\
\hline 1 & & & & $x^{a}$ \\
\hline \multicolumn{5}{|l|}{2} \\
\hline 3 & $x$ & $x$ & $x$ & \\
\hline 4 & $x$ & $x$ & $x$ & $x$ \\
\hline 5 & $?$ & $n d^{b}$ & nd & \\
\hline 6 & $?$ & $x$ & nd & \\
\hline 7 & $?$ & nd & nd & \\
\hline 8 & nd & nd & nd & \\
\hline 9 & nd & nd & nd & \\
\hline \multicolumn{5}{|l|}{10} \\
\hline 11 & $x$ & & $x$ & \\
\hline 12 & $x$ & $x$ & $x$ & $x$ \\
\hline 13 & $x$ & $x$ & & \\
\hline 14 & $x$ & & $x$ & \\
\hline 15 & $x$ & & & \\
\hline 16 & nd & & & \\
\hline 17 & nd & & $x$ & \\
\hline 18 & $x$ & $x$ & $x$ & $x$ \\
\hline 19 & $x$ & $x$ & $x$ & $x$ \\
\hline 20 & $x$ & $x$ & & $x$ \\
\hline 21 & $x$ & & & $x$ \\
\hline 22 & $x$ & & & $x$ \\
\hline 23 & $x$ & & & \\
\hline 24 & $x$ & & $x$ & $x$ \\
\hline 25 & & & $x$ & $x$ \\
\hline 26 & $x$ & $x$ & $x$ & $x$ \\
\hline \multicolumn{5}{|l|}{27} \\
\hline 28 & & & & \\
\hline
\end{tabular}

a See text for explanation.

b No data.

Identifying the anomalies listed in Table 4 is difficult because aboveground structures, fences, and piping are present. In addition, where facilities lie beneath reinforced concrete, they cannot be detected by using the geophysical methods reported here. 


\section{Summary and Conclusions}

A series of nonintrusive geophysical studies was initiated on the basis of plans to demolish and remediate of the Pilot Plant complex in the watershed of the west branch of Canal Creek in the Edgewood area of Aberdeen Proving Ground, Maryland. The studies were conducted within the security fence (as well as exterior to the fence) and down-gradient toward the west branch of Canal Creek. Accessible terrain on the west bank of the west branch of Canal Creek was also studied.

Surveys were conducted to assist a sampling and analysis team in locating potential contaminant sources and pathways, such as sewers, pipes, drainage tile, trenches, and natural paleochannels. The specific objectives of the geophysical surveys were as follows:

1. Define storm, sanitary, and chemical sewer lines and drainage pipes connecting the Pilot Plant to other facilities and wetlands;

2. Identify possible underground tanks, drums, and miscellaneous materials beneath the Pilot Plant;

3. Define the horizontal distribution of possible contaminant plumes or buried debris; and

4. Characterize the hydrogeologic framework of sediments beneath the Pilot Plant.

Geophysical surveys, supported by drilling, have defined the geologic framework; the former land surface beneath fill material; and the locations of sewer lines, pipes, tanks, and trenches beneath the Pilot Plant. Not all subsurface facilities have been identified, because some were too close to buildings or fences or were overlain by reinforced concrete. Some geophysical lineaments, particularly outside the security fence, indicate that buried lines are present, but they are not included on available maps. These lineaments include the following:

1. A magnetic and EM31 anomaly radiating out from the northwest corner of the fence (Figure 10);

2. A magnetic and EM31 anomaly observed in Figure 11 at $110 \mathrm{~W}, 590 \mathrm{~N}$, extending out to the northeast from the fence, may be caused by extensions of interior pipes shown in Figure 4;

3. A complex east-west magnetic and EM31 lineament observed in Figure 12, extending out from the fence immediately south of Building E5609;

4. A prominent magnetic and EM31 lineament observed in Figure 13, extending to the southeast, near the southeast corner of the fence; and 
5. A strong magnetic and EM31 lineament observed in Figure 14, trending east-west. The source of this lineament is a recently installed sewer line.

In conclusion, the authors reaffirm that multiple geophysical techniques are fundamental to properly diagnosing buried anthropogenic facilities and wastes. Proper spacing of stations and transect lines is critical to anomaly detection, as are carefully prescribed data-acquisition procedures. 


\section{References}

Bennett, R.B., and R.R. Meyer, 1952, Geology and Ground-Water Resources of the Baltimore Area, Maryland Department of Geology, Mines, and Water Resources, Bulletin 4.

Dingman, R.J., H.F. Ferguson, and R.O.R. Marten, 1956, The Water Resources of Baltimore and Harford Counties, Maryland Department of Geology, Mines, and Water Resources Bulletin 17.

EAI Corporation, 1989, Historical Records Search and Site Survey of Edgewood Area Buildings, EAI Corporation, Abingdon, Maryland, Prepared for U.S. Army Chemical Research, Development and Engineering Center, Contract No. DAAA15-87-D-0021, Task 021.

Lorah, M.M., and J.S. Clark, 1992, Contamination of Ground Water, Surface Water, and Soil and Evaluation of Selected Pumpage Scenarios in the Canal Creek Area of Aberdeen Proving Ground, Maryland, U.S. Geological Survey Open-File Report 92-1651.

Lorah, M.M., and D.A. Vroblesky, 1989, Inorganic and Organic Ground-Water Chemistry in the Canal Creek Area of Aberdeen Proving Ground, Maryland, U.S. Geological Survey WaterResources Investigations Report 89-4022.

McGinnis, L.D. et al., Environmental Geophysics at Beach Point, in press.

McGinnis, L.D., et al., 1992a, Interim Progress Report - Geophysics: Building E5440 Decommissioning, Aberdeen Proving Ground, Argonne National Laboratory report ANL/ESD/TM-42.

McGinnis, L.D., et al., 1992b, Geophysical Study of the Building 103 Dump, Aberdeen Proving Ground, Argonne National Laboratory report ANL/ESD/TM-51.

McGinnis, M.G., et al., 1992a, Interim Progress Report - Geophysics: Building E5375 Decommissioning, Aberdeen Proving Ground, Argonne National Laboratory report ANL/ESD/TM-37.

McGinnis, M.G., et al., 1992b, Interim Progress Report - Geophysics: Building E5974 and E5978 Decommissioning, Aberdeen Proving Ground, Argonne National Laboratory report ANL/ESD/TM-47.

Miller, S.F., et al., 1992, Interim Progress Report - Geophysics: Building E5476 Decommissioning, Aberdeen Proving Ground, Argonne National Laboratory report ANL/ESD/TM-43. 
Miller, S.F., et al., 1992, Interim Progress Report - Geophysics: Building E5190 Decommissioning, Aberdeen Proving Ground, Argonne National Laboratory report ANL/ESD/TM-33.

Munsell Soil Color Charts, 1975, Macbeth, a division of Kollmargen Corp., Baltimore, Md.

Nemeth, G., J.M. Murphy, and J.H. Zarzycki, 1983, Environmental Survey of the Edgewood Area of Aberdeen Proving Ground, Maryland, Report No. DRXTH-AS-FR-82185, U.S. Army Toxic and Hazardous Materials Agency, Aberdeen Proving Ground, Maryland.

Oliveros, J.P., and P. Gernhardt, 1989, Hydrogeologic Data for the Canal Creek Area, Aberdeen Proving Ground, Maryland, April 1986-March 1988, U.S. Geological Survey, Open-File Report 89-387.

Oliveros, J.P., and D.A. Vroblesky, 1989, Hydrogeology of the Canal Creek Area, Aberdeen Proving Ground, Maryland, U.S. Geological Survey Water Resources Investigations Report 89-4021.

Southwick, D.L., J.P. Owens, and J. Edwards, Fr., 1969, The Geology of Harford County, Maryland, Maryland Geological Survey.

Thompson, M.D., et al., 1992a, Interim Progress Report - Geophysics: Building E5282 Decommissioning, Aberdeen Proving Ground, Argonne National Laboratory report ANL/ESD/TM-36.

Thompson, M.D., et al., 1992b, Interim Progress Report - Geophysics: Building E5481 Decommissioning, Aberdeen Proving Ground, Argonne National Laboratory report ANL/ESD/TM-44. 
Appendix:

Location of GPR Profiles 
TABLE A.1 Ground-Penetrating-Radar Profiles: Outside the Pilot Plant

\begin{tabular}{|c|c|c|c|c|}
\hline \multirow[b]{2}{*}{ - Line No. } & \multicolumn{2}{|c|}{ Start Coordinates } & \multicolumn{2}{|c|}{ End Coordinates } \\
\hline & North & East & North & East \\
\hline 1 & -50 & 500 & 150 & 500 \\
\hline 2 & 250 & 450 & 000 & 450 \\
\hline 3 & 000 & 450 & -45 & 450 \\
\hline 4 & 00 & 400 & 250 & 400 \\
\hline 5 & 220 & 350 & 000 & 350 \\
\hline 6 & 000 & 300 & 150 & 300 \\
\hline 7 & 100 & 300 & 100 & 500 \\
\hline 8 & 250 & 400 & 400 & 400 \\
\hline 9 & 400 & 400 & 600 & 450 \\
\hline 10 & 550 & 450 & 700 & 450 \\
\hline 11 & $730 \mathrm{~N}$ & $460 N$ & \multicolumn{2}{|c|}{ edge of road } \\
\hline
\end{tabular}


TABLE A.2 Ground-Penetrating-Radar Profiles: Inside the Pilot Plant

\begin{tabular}{|c|c|c|c|c|}
\hline \multirow[b]{2}{*}{ Line No. } & \multicolumn{2}{|c|}{ Start Coordinates } & \multicolumn{2}{|c|}{ End Coordinates } \\
\hline & North & East & North & East \\
\hline 12 & 350 & -20 & 400 & -20 \\
\hline 13 & 350 & -10 & 450 & -10 \\
\hline 14 & 350 & 00 & 380 & 00 \\
\hline 15 & 400 & 00 & 500 & 00 \\
\hline 16 & 350 & 10 & 550 & 10 \\
\hline 17 & 350 & 20 & 570 & 20 \\
\hline 18 & 350 & 30 & 580 & 30 \\
\hline 19 & 400 & 40 & 590 & 40 \\
\hline 20 & 400 & 50 & 590 & 50 \\
\hline 21 & 400 & 55 & 500 & 55 \\
\hline 22 & 490 & 60 & 590 & 60 \\
\hline 23 & 590 & 70 & 500 & 70 \\
\hline 24 & 500 & 80 & 570 & 80 \\
\hline 25 & 500 & 90 & 570 & 90 \\
\hline 26 & 500 & 120 & 570 & 120 \\
\hline 27 & 500 & 130 & 570 & 130 \\
\hline 28 & 500 & 140 & 530 & 140 \\
\hline 29 & 500 & 150 & 530 & 150 \\
\hline 30 & 500 & 160 & 530 & 160 \\
\hline 31 & 500 & 170 & 570 & 170 \\
\hline 32 & 500 & 180 & 570 & 180 \\
\hline 33 & 500 & 190 & 590 & 190 \\
\hline 34 & 500 & 200 & 600 & 200 \\
\hline 35 & 500 & 210 & 590 & 210 \\
\hline 36 & 570 & 170 & 570 & 210 \\
\hline 37 & 560 & 170 & 560 & 210 \\
\hline 38 & 550 & 170 & 550 & 210 \\
\hline 39 & 540 & 170 & 540 & 210 \\
\hline 40 & 530 & 120 & 530 & 210 \\
\hline 41 & 520 & 000 & 520 & 210 \\
\hline 42 & 430 & 210 & 500 & 210 \\
\hline 43 & 430 & 205 & 500 & 205 \\
\hline 44 & 430 & 200 & 500 & 200 \\
\hline 45 & 430 & 195 & 500 & 195 \\
\hline 46 & 430 & 190 & 500 & 190 \\
\hline 47 & 430 & 185 & 500 & 185 \\
\hline 48 & 430 & 180 & 500 & 180 \\
\hline 49 & 410 & 170 & 490 & 170 \\
\hline 50 & 430 & 180 & 430 & 210 \\
\hline 51 & 435 & 180 & 435 & 210 \\
\hline 52 & 440 & 180 & 445 & 210 \\
\hline 53 & 445 & 180 & 445 & 210 \\
\hline 54 & 450 & 170 & 450 & 210 \\
\hline 55 & 455 & 170 & 455 & 210 \\
\hline 56 & 460 & 165 & 460 & 210 \\
\hline 57 & 465 & 165 & 465 & 210 \\
\hline
\end{tabular}


TABLE A.2 (Cont.)

\begin{tabular}{|c|c|c|c|c|}
\hline \multirow[b]{2}{*}{ Line No. } & \multicolumn{2}{|c|}{ Start Coordinates } & \multicolumn{2}{|c|}{ End Coordinates } \\
\hline & North & East & North & East \\
\hline 58 & 470 & 165 & 470 & 210 \\
\hline 59 & 475 & 165 & 475 & 210 \\
\hline 60 & 480 & 165 & 480 & 210 \\
\hline 61 & 485 & 165 & 485 & 210 \\
\hline 62 & 490 & 170 & 490 & 210 \\
\hline 63 & 495 & 180 & 495 & 210 \\
\hline 64 & 500 & 170 & 500 & 210 \\
\hline 65 & 510 & 210 & 510 & 000 \\
\hline 66 & 530 & 90 & 530 & 10 \\
\hline 67 & 540 & 90 & 540 & 10 \\
\hline 68 & 550 & 140 & 550 & 10 \\
\hline 69 & 560 & 140 & 560 & 20 \\
\hline 70 & 570 & 140 & 570 & 20 \\
\hline 71 & 500 & 60 & 500 & 00 \\
\hline 72 & 490 & 60 & 490 & 00 \\
\hline 73 & 480 & 60 & 480 & 00 \\
\hline 74 & 470 & 60 & 470 & 00 \\
\hline 75 & 460 & 60 & 460 & 00 \\
\hline 76 & 450 & 55 & 450 & -10 \\
\hline 77 & 445 & 175 & 445 & -10 \\
\hline 78 & 440 & 175 & 440 & -10 \\
\hline 79 & 430 & 175 & 430 & -10 \\
\hline 80 & 420 & 190 & 420 & -10 \\
\hline 81 & 410 & 175 & 410 & -10 \\
\hline 82 & 400 & 100 & 400 & -20 \\
\hline 83 & 390 & 30 & 390 & 10 \\
\hline 84 & 380 & 30 & 380 & -20 \\
\hline 85 & 370 & 30 & 370 & -20 \\
\hline 86 & 360 & 30 & 360 & -20 \\
\hline 87 & 350 & 30 & 350 & -20 \\
\hline 88 & 340 & 30 & 340 & -5 \\
\hline 89 & 340 & -10 & 340 & -25 \\
\hline 90 & 330 & 30 & 330 & -5 \\
\hline 91 & 330 & -10 & 330 & -25 \\
\hline 92 & 320 & 30 & 320 & -30 \\
\hline 93 & 310 & 30 & 310 & -30 \\
\hline 94 & 300 & 30 & 300 & -30 \\
\hline 95 & 290 & 30 & 290 & -30 \\
\hline 96 & 280 & 30 & 280 & -30 \\
\hline 97 & 270 & 30 & 290 & -30 \\
\hline 98 & 260 & 30 & 260 & -30 \\
\hline 99 & 250 & 30 & 250 & -30 \\
\hline 100 & 300 & -30 & 150 & -30 \\
\hline 101 & 300 & -20 & 150 & -20 \\
\hline 102 & 300 & -10 & 150 & -10 \\
\hline 103 & 350 & 00 & 150 & -10 \\
\hline
\end{tabular}


TABLE A.2 (Cont.)

\begin{tabular}{|c|c|c|c|c|}
\hline \multirow[b]{2}{*}{ Line No. } & \multicolumn{2}{|c|}{ Start Coordinates } & \multicolumn{2}{|c|}{ End Coordinates } \\
\hline & North & East & North & East \\
\hline 104 & 350 & 10 & 150 & 10 \\
\hline 105 & 350 & 20 & 150 & 20 \\
\hline 106 & 350 & 30 & 20 & 35 \\
\hline 107 & 230 & 35 & 100 & 35 \\
\hline 108 & 240 & 30 & 240 & -30 \\
\hline 109 & 230 & 50 & 230 & -30 \\
\hline 110 & 220 & 105 & 220 & -30 \\
\hline 111 & 210 & 105 & 210 & 80 \\
\hline 112 & 210 & 60 & 210 & -50 \\
\hline 113 & 200 & 40 & 200 & -50 \\
\hline 114 & 190 & 20 & 190 & -50 \\
\hline 115 & 180 & 40 & 180 & -40 \\
\hline 116 & 170 & 40 & 170 & -40 \\
\hline 117 & 160 & 40 & 160 & -40 \\
\hline 118 & 150 & 40 & 150 & -40 \\
\hline 119 & 140 & -40 & 140 & 40 \\
\hline 120 & 130 & -40 & 130 & 40 \\
\hline 121 & 120 & -40 & 120 & 40 \\
\hline 122 & 110 & -35 & 100 & 40 \\
\hline 123 & 100 & -30 & 100 & 40 \\
\hline 124 & 90 & -30 & 90 & 40 \\
\hline 125 & 80 & -30 & 80 & 40 \\
\hline 126 & 70 & -25 & 70 & 40 \\
\hline 127 & 60 & -20 & 60 & 40 \\
\hline 128 & 50 & -20 & 50 & 40 \\
\hline 129 & 40 & -10 & 40 & 40 \\
\hline 130 & 30 & -10 & 30 & 40 \\
\hline 131 & -20 & -5 & 20 & 40 \\
\hline 132 & 10 & 00 & 10 & 40 \\
\hline 133 & 00 & & 00 & \\
\hline 134 & 000 & 40 & 150 & 40 \\
\hline 135 & 150 & 30 & 000 & 30 \\
\hline 136 & 000 & 20 & 150 & 20 \\
\hline 137 & 150 & 10 & 000 & 10 \\
\hline 138 & 000 & 00 & 150 & 00 \\
\hline 139 & 150 & -10 & 30 & -10 \\
\hline 140 & 50 & -20 & 150 & -20 \\
\hline 141 & 150 & -30 & 80 & -30 \\
\hline 142 & 110 & -40 & 150 & -40 \\
\hline 143 & 25 & 160 & 00 & 160 \\
\hline 144 & 25 & 150 & 00 & 150 \\
\hline 145 & 25 & 140 & 00 & 140 \\
\hline 146 & 25 & 130 & 00 & 130 \\
\hline 147 & 25 & 120 & 00 & 120 \\
\hline 148 & 25 & 110 & 00 & 110 \\
\hline 149 & 25 & 100 & 00 & 100 \\
\hline
\end{tabular}


TABLE A.2 (Cont.)

\begin{tabular}{|c|c|c|c|c|}
\hline \multirow[b]{2}{*}{ Line No. } & \multicolumn{2}{|c|}{ Start Coordinates } & \multicolumn{2}{|c|}{ End Coordinates } \\
\hline & North & East & North & East \\
\hline 150 & 25 & 90 & 00 & 90 \\
\hline 151 & 25 & 80 & 00 & 80 \\
\hline 152 & 25 & 70 & 00 & 70 \\
\hline 153 & 25 & 76 & 10 & 76 \\
\hline 154 & 25 & 74 & 10 & 74 \\
\hline 155 & 25 & 72 & 10 & 72 \\
\hline 156 & 25 & 68 & 10 & 68 \\
\hline 157 & 00 & 62 & 80 & 62 \\
\hline 158 & 30 & 64 & 80 & 64 \\
\hline 159 & 00 & $60^{\circ}$ & 00 & 200 \\
\hline 160 & 10 & 60 & 10 & 200 \\
\hline 167 & 73 & 170 & 70 & 210 \\
\hline 168 & 80 & 160 & 80 & 210 \\
\hline 169 & 85 & 170 & 85 & 210 \\
\hline 170 & 00 & 210 & 150 & 210 \\
\hline 171 & 00 & 200 & 150 & 200 \\
\hline 172 & 00 & 215 & 70 & 215 \\
\hline 173 & 000 & 190 & 150 & 190 \\
\hline 174 & 000 & 180 & 80 & 180 \\
\hline 175 & 000 & 170 & 180 & 170 \\
\hline 176 & 000 & 165 & 65 & 165 \\
\hline 177 & 605 & 200 & 600 & 40 \\
\hline 178 & 600 & 40 & 570 & 10 \\
\hline 179 & 570 & 10 & 210 & -40 \\
\hline 180 & 620 & 210 & 620 & 36 \\
\hline 181 & 620 & 36 & 579 & -5 \\
\hline 182 & 579 & -5 & -20 & -16 \\
\hline 183 & 500 & 00 & 500 & 170 \\
\hline 184 & 495 & 50 & 495 & 160 \\
\hline 185 & 500 & 130 & 500 & 150 \\
\hline 186 & 498 & 130 & 498 & 150 \\
\hline 187 & 490 & 50 & 490 & 100 \\
\hline 188 & 490 & 140 & 490 & 160 \\
\hline 189 & 490 & 70 & 510 & 70 \\
\hline 190 & 490 & 80 & 510 & 80 \\
\hline 191 & 490 & 90 & 510 & 90 \\
\hline 192 & 490 & 100 & 510 & 100 \\
\hline 193 & 490 & 110 & 510 & 110 \\
\hline 194 & 490 & 120 & 510 & 120 \\
\hline 195 & 490 & 140 & 510 & 140 \\
\hline 196 & 490 & 150 & 510 & 150 \\
\hline 197 & 490 & 160 & 510 & 160 \\
\hline 198 & 580 & 30 & 580 & 210 \\
\hline 199 & 445 & 90 & 415 & 120 \\
\hline 200 & 77 & 50 & 77 & 120 \\
\hline 201 & 80 & 50 & 80 & 130 \\
\hline
\end{tabular}


TABLE A.2 (Cont.)

\begin{tabular}{|c|c|c|c|c|}
\hline \multirow[b]{2}{*}{ Line No. } & \multicolumn{2}{|c|}{ Start Coordinates } & \multicolumn{2}{|c|}{ End Coordinates } \\
\hline & North & East & North & East \\
\hline 202 & 90 & 50 & 90 & 150 \\
\hline 203 & 100 & 90 & 100 & 150 \\
\hline 204 & 90 & 70 & 80 & 70 \\
\hline 205 & 100 & 80 & 80 & 80 \\
\hline 206 & 100 & 90 & 80 & 90 \\
\hline 207 & 100 & .100 & 80 & 100 \\
\hline 208 & 100 & 110 & 80 & 110 \\
\hline 209 & 100 & 120 & 80 & 120 \\
\hline 210 & 100 & 130 & 80 & 130 \\
\hline 211 & 110 & 140 & 85 & 140 \\
\hline 212 & 125 & 150 & 80 & 150 \\
\hline 213 & 125 & 150 & 110 & 130 \\
\hline 214 & 120 & 150 & 120 & 130 \\
\hline
\end{tabular}

